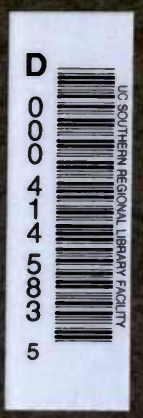

Spoehr, Herman Augustus

THE CARBOHYDRATE ECONOMY OF CACTI

$Q K$
$4: 5$
$C 1: 56$ 


\title{
THE CARBOHYDRATE ECONOMY OF CACTI
}

\author{
BY \\ HERMAN AUGUSTUS SPOEHR
}

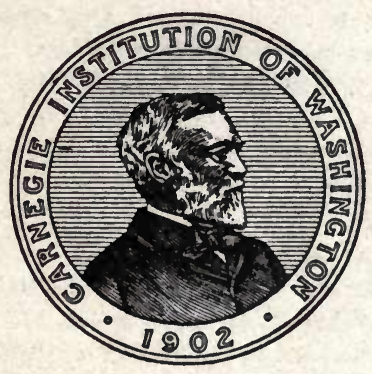

Publshed by the CARnegie Institution of Washington WASHINGTON, 1919 
CARNEGIE INSTITUTION OF WASHINGTON

Publication No. 287

EBe Eord Baftimore (pres:

BALTIMORE, MD., $v$. s. A. 


\section{PREFACE.}

The purpose of this work has been primarily to gather data and some necessary facts which could be brought to converge for an attack on the problems of photosynthesis. Experiments which have been in progress in the Desert Laboratory at Tucson for several years have indicated clearly that prerequisite to a rational discussion of the problems concerning the manner in which sugars are formed in the chlorophyllous leaf is a clearer understanding of the conditions governing the equilibria and mutual transformations of the various groups of carbohydrates in the leaf, as well as of the fate of these substances in the general metabolism. The complex and manifold character of the phenomenon of photosynthesis has, it would seem, not been very generally realized by workers in this field. The avenue of approach which appears most promising, at this stage at least, is that which employs chemical methods and conceptions. However, in following this line of attack, the dangers of reasoning from knowledge gained purely from in vitro investigations can hardly be overemphasized. Furthermore, consistent and valid results with living material can be gained only by the most careful control of conditions, such as temperature, water relations, light, and the previous history of the plant. While it is, of course, highly desirable to know the behavior of plants in the field and to develop methods for gaining such knowledge, it seems to the writer that a realization of this ideal can be hoped for only after the more fundamental principles of the phenomenon have been learned. In the study of photosynthesis it is impossible to segregate entirely the activity of sugar synthesis from that of the further metabolic transformations and from the catabolic processes which yield energy to the living organism, glycolysis. This latter phenomenon has received attention from many sides, and the application of the chemical point of view to the manner of sugar disintegration and rearrangement seems most promising as an aid to a clearer understanding of the nature and mode of the sugar break-down in the living cell.

This paper comprises the results of investigations carried out during 1916-1918. The work consisted largely of the analysis of plants which had been subjected to various experimental conditions. Of the large number of analyses made, only those are discussed here which are pertinent to the immediate subject. It is a pleasure to acknowledge here the assistance rendered in this work by Dr. J. M. McGee and Mr. R. A. Burt.

DEsert Laboratory,

Tucson, Arizona, December 1918. 


\section{CONTENTS.}

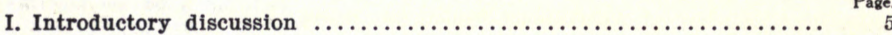

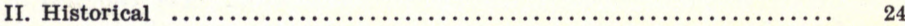

III. Experimental methods:

Preparation of material for estimation of sugars.............. 26

The determination of dry weight........................ 27

Preparation of material for analysis...................... 27

Calculation of analytical data........................... 30

The analysis of the sugar solutions........................ 31

The process of reduction............................. 33

The determination of copper........................... 34

The standardization of the solutions...................... 35

The estimation of the pentose sugars.................... 36

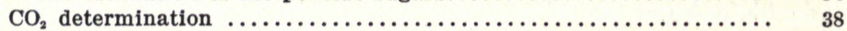

IV. The carbohydrates of the Cacti.............................. 39

V. Seasonal variations in the carbohydrate-content................. 48

VI. Effect of water on the carbohydrate-content.................... 57

VII. Effect of temperature on the carbohydrate-content................ 61

VIII. Aerobic and anaerobic respiration................................ 64

IX. Consumption of carbohydrates during starvation................. 70

X. Origin and rôle of pentose sugars........................... 75 


\title{
THE CARBOHYDRATE ECONOMY OF CACTI.
}

\author{
By HERMAN AUGUSTUS SPOEHR.
}

\section{INTRODUCTORY DISCUSSION.}

The best evidence gained since the time of Sachs points to the conclusion that sugars are the first products which accumulate in the process of the photosynthesis of carbon compounds in the chlorophyllous cell. Thus, sugars may be considered the starting-point for the synthesis of the tremendous number of substances found in living things, both vegetable and animal. What the sugar or mixture of sugars is which thus commands the center of attention in the metabolism of plants and of almost all living things is still a question of much dispute and uncertainty; nor does the solution of this problem seem possible until we have gained more knowledge of the transformations which the various sugars undergo in the cell, independent of photosynthesis. It has long been known that in the leaf, under circumstances, the polysaccharides are converted into the simpler sugars and vice versa, by what appears to be the shifting of an equilibrium by means of enzyme action. It is self-evident that a knowledge of these transformations must be obtained before the problem of the first sugar synthesized can be attacked.

Not only in relation to the question of the immediate products of photosynthesis is the study of the carbohydrate equilibrium important, but also to the question of metabolism. In a very large number of plants, especially the higher ones, both the living and the lifeless matter consists in the main of material of carbohydrate nature. The lifeless matter forms the walls, vessels, supporting frame-work, and often a considerable amount of the reserve food-material. Those portions of the plant in which the manifestations of life appear, as for instance the chromatin of the nucleus and the protoplasm itself, contain a considerable quantity of carbohydrates, the lifeless being formed from the living and the living drawing upon the lifeless for support. It is, however, a question whether the difference between the living and lifeless is essentially one of chemical constitution. The idea that the living substance or protoplasm is a complex compound of more or less definite chemical constitution no longer seems tenable. Protoplasm, a mixture of so many different substances, undoubtedly varies in composition in different organisms. It is in all probability the study of the physical and chemical properties of protoplasm as a colloidal mixture (such properties as imbibition of water, electrical charges, and surface phenomena) which will yield the most illuminating results. 
It seems highly improbable that the life processes consist of any one series of chemical changes or are dependent upon any particular molecule or chemical group. But rather the simpler life processes entailing energy changes may perhaps be regarded as a complex of interrelated chemical changes taking place in a certain medium or substratum. This medium, colloidal dispersion, mixture, or aggregate of various substances is the seat or substratum in which the various chemical reactions take place, the nature and course of which are determined by the complex of properties associated with water control, surface phenomena, and of course catalysts (such as inorganic salts and enzymes). These colloids do not enter into or support the chemical reactions or do so probably only in a rather indirect manner, serving primarily as a physical medium. Such a system would be of a heterogeneous nature and, of course, of the most complex type, and capable of various adsorption phenomena productive of localized action which would influence the function as well as the structure of the system. In fact, such a hypothesis would demand that the substratum be relatively stable, that the colloidal material once formed does not break down as readily as the other substances, or only after the supply of these has been exhausted. This does not mean actual or chemical stability, but rather relative to the other substances under the existing physiological conditions, as, for instance, relatively slightly dissociated by salts or other catalysts and resistant to the action of enzymes.

This colloidal material may also in part be composed of substances which do not undergo complete disintegration and thus are not excreted from the cell. The protein in most plants, due to the high synthetic power characteristic of plants, are rarely so drastically affected that they are not again reconstituted; these substances are thus relatively stable in the sense that under normal conditions they do not disappear in the course of metabolism: The cell substratum or protoplasm should then be regarded as a complex of substances of relative stability in which the more sensitive substances break down with the liberation of energy, the formation of products of catabolism, and the synthesis of other more complex substances in varying amounts. It is, then, the combination of the intricate chemical reactions taking place in this heterogeneous colloidal system that constitutes the principle of energy change of living processes. While the chemical reactions are influenced by the nature of the medium, the latter is also a product of the chemical processes.

The conception of protoplasm as a tremendously complex "living" protein molecule arose before any considerable chemical knowledge of this group of substances had been gained. Through the extensive researches of Fischer, Kossel, Abderhalden, and many others it has become apparent that the conception of such an enormous complexity and sensitiveness of the proteins was rather unwarranted. Furthermore, the theory that proteins, carbohydrates, and fats are synthesized into elaborate complex substances before they break down and yield energy was necessitated by the prevalent 
idea of the relative stability of these substances in simple solution. It is now becoming more evident that under conditions such as exist in an organism (i. e., in the presence of various catalysts such as inorganic salts, enzyme, acids, and alkalies), the molecules of proteins, fats, and especially carbohydrates break apart almost spontaneously. From a vast amount of physiological evidence now at hand, it appears that the energy of an organism is derived chiefly from the break-down of the material ingested as food. When the supply of nutritive material is insufficient the nature of the respiration changes and then, in all probability, the more stable substratum is drawn upon. This becomes evident in the cacti as well as in many other plants.

Kosinski ${ }^{1}$ has shown that when Aspergillus niger is grown on pure water, the carbon dioxid given off falls rapidly to a value about one-quarter of that when grown on sugar. During this time the organism is probably drawing on the more stable protoplasmic substances. When sugar is made available, the carbon dioxid rises immediately, indicating the direct utilization of that substance.

The colloidal materials found in plants are in general relatively chemically stable substances, although their exact chemical nature and mode of formation as yet have not been definitely established. It now seems probable that in a sense they represent by-products or end-products of the metabolic process. The nature of this material undoubtedly varies in different plants, especially in regard to the proportion of carbohydrate and proteinaceous substances. This is indicated in the study of the behavior of the colloids of various plants. Extensive comparative investigations with different vegetable tissues, prepared "biocolloids," and especially with the cacti, have indicated that these plants behave like masses of gels composed largely of colloidal carbohydrates. ${ }^{2}$

In the present investigation an effort has been made to determine the nature of the carbohydrates of the cacti and to study the transformations which these undergo under various conditions. In the conception of the colloidal nature of protoplasm briefly outlined, it has been stated that this is of necessity a relatively stable system and that the colloidal material is itself a product of metabolism. One of the most striking and interesting features of these plants is the presence of large quantities of pentosans and mucilaginous material. In the cacti it has been found that water imbibition, swelling, and growth are intimately related to the presence of pentose polysaccharides. The pentosans have been found as components in varying

${ }^{1}$ Kosinskr, I. Die Atmung bel Hungerzuständen und unter Einwirkung von mechanischen und chemischen Reitzmitteln bei Aspergillus niger. Jahrb. wiss. Bot., 37, 137-204, 1898.

MacDougal, D. T., and H. A. SPoenr. The behavior of certain gels useful in the interpretation of the action of plants. Science, n. s., 45, 484-488, 1917.

- - Growth and imbibition. Proc. Amer. Phil. Soc., 44, 289, 1917.

MacDougal, D. T. Imbibitional swelling of plants and colloidal mixtures. Science, $44,502-505,1916$.

McGee, J. M. The imbibitional swelling of marine algæ. The Plant World, 21, 13-15, 1918. 
amounts of almost all plants. In the cacti conditions are unusually favorable for the study of the formation and nature of these substances. It is not claimed that the pentosans in themselves represent the composition of protoplasm. The interest lies in the transformations which the carbohydrates undergo in the course of metabolism under varying external conditions and the nature of the chemical changes which are involved in the economy. Nor are these phenomena to be considered as a complete account, but at the most as a single chapter in a very extensive and involved story.

It would seem that the material used in respiration of most of the higher plants is essentially of carbohydrate nature. Whether plants use only carbohydrates in the course of normal respiration has not been established. Fats, of course, are used extensively by plants, especially in seeds; but whether the fat is converted into carbohydrate before it is used in the respiratory process is still unsettled. As to the rôle of proteins, especially in the higher plants, we are quite in the dark, but it can be assumed with safety that these substances do not play nearly so important a part in the economy of higher plants as they do in animals. As will be shown, of greatest importance to the mode of the breaking down of the simpler carbohydrates is the nature or condition of solution. In the investigations to be cited this condition refers more especially to the degree of alkalinity. There is considerable reason for believing that the proteins and their simpler derivatives, incorporated in this cell substratum or medium, produce therein the necessary conditions under which glycolysis may proceed, or through the production of acid and alkaline products regulate the enzymatic activities. These products are in turn again synthesized into the protoplasmic proteins, so that relatively small amounts of protein suffice for the conversion of large quantities of carbohydrate and (as actually seems to be the case) the major portion of the energy released is thus to be ascribed to the catabolism of the carbohydrates. Also, the remarkable property possessed by the proteins and their salts of neutralizing acids or bases by the opening up of successive N.H-O-C groups gives them the power of maintaining the $\mathrm{H}^{*}$ or $\mathrm{OH}^{-}$ion concentration of the medium within definite limits, usually close to neutral. In view of the fact that the products of carbohydrate catabolism are mostly acid, it might well be expected that this property is of prime physiological importance, and that herein lie some of the fundamental differences between cells of animals and those of plants with their vacuolar fluid. Some workers, in fact, have ascribed to the proteins themselves enzymatic properties which may be interpreted that the zymogen as well as the co-enzyme is a product of the protein. These conceptions evidently depend upon a clearer understanding of the nature of enzyme action and catalysis before any substantiation or further elucidation may be hoped for.

Deleano, ${ }^{1}$ working with mature leaves of Vitis vinifera at 18 to $22^{\circ}$ in the dark, found that these utilize only carbohydrates during the first

\footnotetext{
1 Demeano, Nicolas T. Studien ueber den Atmungsstoffwechsel abgeschnittener Laubbiätter. Jahr. f. wiss. Bot., 51, 541-592, 1912.

Boвodriv, J. Ueber die physiologische Rolie und die Verbreitung des Asparagins im Pflanzenreiche. Bot. Zeitg., 36, 801-832, 1878.
} 
100 hours. During this time the amount of protein and other nitrogen compounds in the leaves does not change; thereafter, and when all carbohydrate has disappeared, the nature of the respiratory process changes radically: the proteins are broken down, a variety of non-protein nitrogenous substances appears, and ammonium salts are formed. It is a matter of common knowledge that when a fungus is fed solely on proteinaceous material there is formed a large amount of ammonia, and that this is completely reduced or inhibited when sugar is made available to the organism. These phenomena indicate the widely different paths which the course of metabolism may follow under varying conditions and which, unfortunately for a clearer understanding of the subject, have been ascribed to obscure regulatory devices of the organism. They furthermore suggest the existence of a condition in the nature of a balance between or interdependence of carbohydrate and protein catabolism in the mature vegetable organism. In young and growing portions of a plant the state of affairs is of course quite different and more complex.

In spite of the enormous amount of work which has been done and its great economic importance, no definite conclusion has been reached even for the mammalian organism. Thus, to quote Lusk (Science of Nutrition, p. 277,1917$)$ :

" Thomas calculated that during the period of minimal 'wear-and-tear' protein metabolism, 0.4 calories were derived from the metabolism of 1.5 milligrams of protein per kilogram of body-weight every hour, while 0.96 calories were derived from the oxidation of 259 milligrams of glucose. In other words, protein furnished only 4 per cent of the energy required by a man at rest. Since mechanical work scarcely influences the 'wear-and-tear' quota of protein metabolism, although it largely increases the oxidation of carbohydrate, it is evident that protein may play a very small rôle as a producer of energy for the maintenance of the function of life. When carbohydrates are given in the diet, it is possible to establish nitrogen equilibrium at a much lower level than when protein alone or protein and fat are ingested."

Besides furnishing methods for the study of metabolic products, chemistry has been able to be of service to physiology largely because it has supplied many valuable analogies between chemical phenomena outside the cell and the processes in the living organism itself. These analogies are of closer relation than mere resemblance or likeness, and can with profit be reasoned from, so that it is safe to infer that other and often deeper relations exist. Such analogies have aided us greatly in our thinking and have influenced strongly the formulation of the theories of many vital processes. The method is, of course, open to some criticism, and its value depends upon the real identity in important aspects of the cases compared. Physiological experimentation is often associated with such great difficulties that its course can be opened only after the simpler, purely chemical relationships have been formulated. Then, as has often been the case, physiological investigation contributes to a clearer understanding of the chemical phenomena and the thread which binds the two is found to be the identity of a general principle. 
For the problems of carbohydrate metabolism, and especially for glycolysis, some recent investigations on the dissociation and molecular rearrangements of the sugars under various conditions have been most suggestive. No application of these newer conceptions has been made in the interpretation of the metabolic processes in the plant. The more important principles, therefore, are given here, as it seems to the writer that these ideas are among the most valuable which chemistry has given to physiology. For the more detailed exposition and proof, reference must be made naturally to the rather voluminous original works. A thorough knowledge of the chemistry of the substances concerned in these processes is, of course, essential to an understanding of the physiology. The attention can be confined to the reactions in aqueous solution, as it is in this state that the many transformations occur in the living organism. Pure solutions of the monosaccharides in vitro are comparatively stable. In living matter they are very unstable and capable of the most multifarious rearrangements and disintegrations. Some insight can be gained into the causes of this instability of sugars in living matter from a consideration of the manner in which these substances dissociate under the influence of various reagents and the products which result from such reactions.

Organic compounds containing one or more hydroxyl groups, such as alcohol, glycerine, or glucose, exhibit some of the properties of exceedingly weak acids. They form salts with metals and influence the electrical conductivity of weak electrolytes as other weak acids do. The electrolytic dissociation constants of several of these substances have been measured by electro-chemical methods. Thus Michaelis and Rona ${ }^{1}$ give the following constants at $18^{\circ}$ :

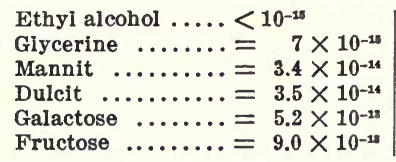

Mannose $\ldots \ldots \ldots \ldots=1.09 \times 10^{-18}$
Glucose $\ldots \ldots \ldots \ldots=6.6 \times 10^{-18}$
Maltose $\ldots \ldots \ldots \ldots=18.0 \times 10^{-18}$
Saccharose $\ldots \ldots \ldots=2.4 \times 10^{-18}$
Lactose $\ldots \ldots \ldots \ldots=6.0 \times 10^{-18}$
Raffinose $\ldots \ldots \ldots .=1.8 \times 10^{-11}$

That sugars are very weak acids can be seen by comparison with the dissociation constants of the following common organic acids:

$\mathrm{K}$ for $18^{\circ}$.

Acetic acld $\ldots \ldots \ldots \ldots \ldots \ldots . .8 \times 10^{-s}$

Butyric acid $\ldots \ldots \ldots \ldots \ldots \ldots . . .5 \times 10^{-5}$

Lactic acid $\ldots \ldots \ldots \ldots \ldots \ldots . . .1 .4 \times 10^{-4}$

Carbonic acid $\left(\mathrm{H}: \mathrm{HCO}_{3}{ }^{1}\right) \ldots 3.04 \times 10^{-7}$

Tartaric acid $\ldots \ldots \ldots \ldots \ldots .1 \times 10^{-5}$

Phenol $\ldots \ldots \ldots \ldots \ldots \ldots \ldots . . .6 .8 \times 10^{-11}$

Salts in which a metal replaces the hydrogen in the hydroxyl group of the alcohols and sugars have been known for some time. Thus sodium ethylate $\left(\mathrm{C}_{2} \mathrm{H}_{5} \mathrm{ONa}\right)$ can be readily obtained by the action of metallic sodium on absolute alcohol. Glycerine also forms similar compounds, the glycerates, with a large number of metals. Here there are three replaceable

${ }^{2}$ Michameis, L, and P. RoNa. Die Dissociationskonstanten einiger sehr schwacher saeuren, insbesondere der Kohlenhydrate gemessen auf elecktrometrischem wege. Blochem. Zeit., 49, 232-248, 1913. 
hydrogen atoms. In the same group fall the metallic derivatives of glucose and other sugars; these are already decomposed by such weak acids as carbonic acid. For the present purpose the most important property of these metallic compounds is the fact that they decompose very readily; far more easily than the original alcohol or sugar. Thus, $\mathrm{Nef}^{1}$ has shown that

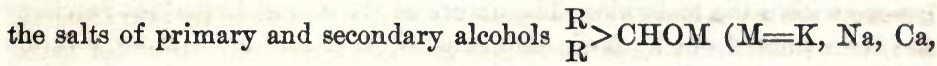
$\mathrm{Ba}$, or $\mathrm{Zn}$ ) dissociate at $180^{\circ}$ to $250^{\circ}$, while the corresponding free alcohols dissociate at much higher temperatures, $400^{\circ}$ to $600^{\circ}$. Hence the salts are much less stable and burn spontaneously in the air, while the free alcohols are quite stable.

A great deal of work has been done on the effect of alkalies and various salts on the sugars. ${ }^{2}$ One incentive to these investigations has been that the reactions thus produced simulate in some regard the action of various enzymes on sugars. The principle involved in these sugar reactions is the same or very closely related to the action of the alcohols just indicated. A few examples will suffice to illustrate. An aqueous solution of glucose is affected but very slowly by the oxygen of the air or by hydrogen peroxide. If, however, a trace of a salt of iron, for instance, is added to the mixture, the glucose is oxidized rapidly with the evolution of much heat and the formation of a large variety of compounds. An exceedingly small amount of iron suffices to oxidize large quantities of sugar.

In the presence of alkalies all the monosaccharides are unstable and spontaneously decompose into a large variety of substances." If the concentration of the alkali employed is very low, there takes place a series of

${ }^{1} \mathrm{NET}$, J. U. Dissociationsvorgaenge bei den einatomigen Alcoholen, Aethern, und Salzen. Llebig's Annalen der Chem., 318, 138, 1901.

${ }^{2}$ Fenton, H. J. H. The oxidation of tartaric acid in the presence of iron salts. Jour. Chem. Soc., 65, 899, 1894.

, and H. JACKSON. Oxidation of polyhydric alcohols in the presence of iron. Jour. Chem. Soc., 75, 1-11, 1899.

- The oxidation of organic acids in the presence of ferrous iron. Jour. Chem. Soc., 77, 69-76, 1900.

- - Degradation of glycolic aldehyde. Ibld., 77, 1294-1298, 1900.

MorreLL, R. S., and F. M. CrofTs. Action of hydrogen peroxide on carbohydrates in the presence of ferrous salts. Jour. Chem. Soc., 75, 786-792, 1899; Ibid., 77, 1219-1221, 1900; Ibid., 81, 666-675, 1902; Ibld., 83, 1284-1292, 1903; Ibld., 87, 280-293, 1905.

RUF, OTтo. Ueber die Verwandlung der D-glucose in D-Arabinose. Ber. chem. Ges., 31, 1573-1577, 1898.

D. D- und R-Arabinose. Ibid., 32, 550-560, 1899.

OLLeNDorF, D. G. Abbau von D-Galactose und von Michzucker (D- und Galactoarabinose). Ibid., 33, 1798-1810, 1900 .

Ueber die Oxidation der 1-Arabensaeure und l-xylonsaeure. Ibid., 34, 1362-1372, 1901.

Ueber den Abbau der Rhamnon und Isosaccharin Saeure. Ibid., 35, 2360 $2370,1902$.

SPOEHR, H. A. On the behavior of the ordinary hexoses towards hydrogen peroxide in the presence of alkaline hydroxides, as well as of various iron salts. Amer. Chem. Jour., 43, 248-254, 1910.

'NEF, J. U. Dissoclationvorgaenge in der Zuckergruppe: III. Liebig's Annalen der Chem., 403, 204, 1913. 
complex reciprocal transformations of the hexoses as discovered by Lobry de Bruyn and van Ekenstein." Here the sugar is not decomposed, but under the influence of the alkali the structural arrangement of the sugar molecule is affected in such a manner as to produce a number of substances which differ from each other only in respect to the position of certain chemical groups within the molecule. The nature of these most important reactions has been worked out by Nef. He demonstrated that an aqueous solution of either d-glucose, $d$-mannose, or d-levulose with $1 / 20$ equivalent of calcium hydroxide attains equilibrium when kept at $15^{\circ}$ to $20^{\circ}$. There is thus formed, when starting with any one of the above sugars, a mixture of-

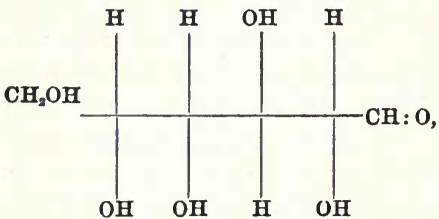

D-glucose.

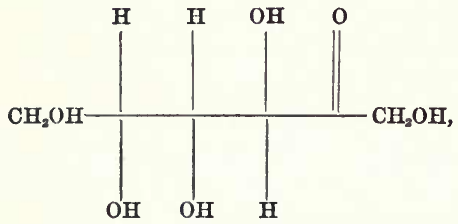

D-fructose.

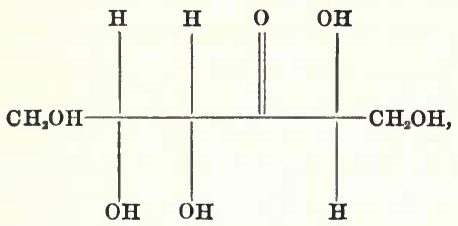

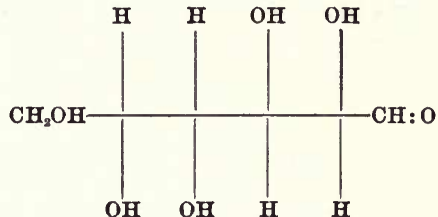

D-mannose.

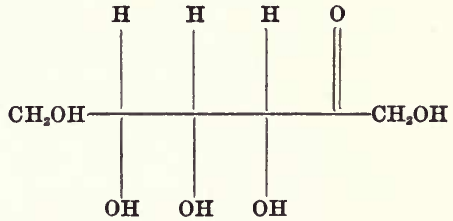

D-pseudo fructose.

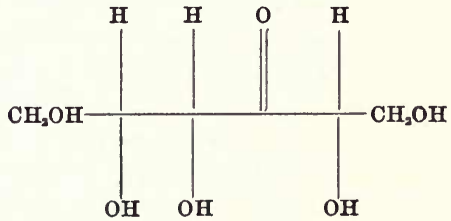

and $\alpha$ - and $\beta$ - d-glutose.

In a similar manner the d-galactose series yields $d$-galactose, $d$-talose, $d$-tagatose, $d$-sorbose, and $\alpha$ - and $\beta$ - d-galtose. It is noteworthy that a member of the d-glucose series is never converted into a member of the d-galactose

${ }^{2}$ Lobry DE BrUYN, C. A., and W. A. VAN Ekenstein. Action des alcalis sur les sucres. II: Transformation réciproque des uns dans les autres des sucres glucose, fructose et mannose. Rec. des trav. chim. des Pays-Bas., 14, 203-216, 1895 . - Action des alcalis sur les sucres. III: Transformations des sucres sous l'influence de l'hydroxide de plomb. Rec. des trav. chim. des Pays-Bas., 15, 92-96, 1896.

Action des alcalis sur les sucres. IV: Remarques génerales. Rec. des trav. chim. des Pays-Bas., 16, 257-273, 1897. 
series. The difference in structure of these two sugars lies especially in the space relation of the hydrogen and hydroxyl about the fourth and fifth carbon atom in the chain from the carbonyl group. It appears, therefore, that these reciprocal transformations involve only the first three carbon atoms of the chain, and that there exists a gradient of reaction in the sugar molecule, the highest being at the carbon atom adjacent to the carbonyl group and decreasing with each carbon atom removed therefrom. It is interesting to compare the proportion of the various sugars found in these mixtures with the conditions as they exist in nature. The majority of the 32 theoretically possible aldo-, 2-keto-, and 3-keto-hexoses are now known as synthetic products; it is, however, a striking fact (which has puzzled chemists for a long time) that but a very small number of all these substances is found in plants. D-glucose and d-fructose are by far the most common hexoses and are found in greatest abundance, and the only other hexoses at all common in plants are d-mannose, d-galactose, and l-sorbose. In these equilibrium sugar mixtures, Nef found aldoses and ketoses in about equal amounts, but in the glucose series, of the aldoses there were present only d-glucose and d-mannose and in the proportion of 5 parts of the former to 1 of the latter. In the galactose series over 90 per cent of the aldoses was d-galactose. Furthermore, no trace of d-allose nor d-latose on the one hand, nor of l-gulose or l-idose on the other was ever formed. It is most suggestive that the composition and proportion of the various sugars in equilibrium found in these experiments should so closely approach the conditions existing in nature. For the detailed chemical dynamics underlying these phenomena, reference must be made to the original elaborate discussion of Nef. However, the physiologist has herein for the first time the basis of a rational explanation of this most perplexing problem.

In the presence of higher concentrations of alkali the sugar molecule is affected in a more profound manner, and these reactions are of special interest in relation to glycolysis and carbohydrate metabolism in general. It should be stated that so far the study of plant juices and of body fluids by physico-chemical methods has not revealed concentrations of $\mathrm{OH}$ ions such as would be necessary to bring about reactions in simple solution like those under discussion here. At the same time our knowledge of the condition of plant protoplasm as to acidity or alkalinity must be considered as most unsatisfactory, such determinations as have been attempted being of a very crude nature. It is not implied that these sugar dissociations are accomplished necessarily by alkaline hydroxides or $\mathrm{OH}$ ions in the organism,

\footnotetext{
NotE.-Nef's investigations on the composition of formose are also of interest in this connection. The formation of formose (the mixture of sugars formed by the action of alkalles on formaldehyde) can be regarded as the keystone of the formaldehyde hypothesis of photosynthesis as first suggested by Baeyer. Nef found that formose consists of a mixture haif pentose and half hexose, and from the experiments of the action of weak alkalies on sugars he concluded that the hexoses in formose consist of 24 members, i. e., 8 aldohexoses, and 8 -ketohexoses and 83 -ketohexoses, and that the aldoses are primarily dl-glucose and dl-galactose.
} 
but rather by those substances (or catalysts) which under physico-chemical conditions existent in the cell exert on sugars an effect analogous or equivalent to that of metallic salts or hydroxides in aqueous solution. In fact, the importance and rôle of catalyzers in glycolysis has been established by the large amount of work which has been done with various tissue and pancreas extracts. Thus, for example, Walter Loeb ${ }^{2}$ has shown that substances obtained from the alcoholic pancreas extracts by treatment with iron salts effect a cleavage of glucose in which the products formed were formaldehyde and pentose. However, by the use of pure sugar solutions and alkalies, it has been possible to follow more clearly the many complex disintegrations and rearrangements which the sugar molecule undergoes. The principle of chemical action is most probably the same. The nature of the products formed under these conditions depends upon whether or not there is present an oxidizing agent, such as air. In the organism the same differentiation exists in regard to the catabolism of hexoses. Under anaerobic conditions one set of products is formed, while under aerobic conditions there is another set of products different from the first results. The similarity of the reactions obtained in vitro to those observed in the organism of anaerobiosis and aerobiosis are worthy of notice. In the succulent plants, such as the cacti, conditions exist which lie between these extremes, $i$. e., a low or insufficient oxygen supply. ${ }^{2}$ This is perhaps the most important single factor in the formation of acid in the plants. Under similar conditions there is formed in the plant, not d-lactic acid, but d-malic acid. The genesis of this latter substance in succulent plants has been a matter of much speculation, which, however, has in no case been founded on chemical experience. The relation between anaerobiosis and aerobiosis will become evident from the chemical discussion which is to follow.

If a solution of d-glucose is treated with alkali of higher concentration than that causing the reciprocal transformations, as $e . g ., 8 \times$ normal sodium hydroxide in the absence of oxygen or an oxidizing agent there are formed: large quantities of dl-lactic acid and dl 1-3 dioxybutyric acid, besides four isomeric $\mathrm{C}_{6}$ saccharinic acids. The importance of lactic acid in the metabolism of the mammalian organism and its formation under conditions of insufficient oxidation or restricted oxygen supply is well known." As will be shown later, the very large quantities of pentoses found in these plants arise from the hexoses under conditions of repressed metabolic activity; the further disintegration of the pentose sugars is therefore of special interest in relation to the present problem. That these plant acids are of great importance in many of the functions of the plant has been clearly established by Richards in regard to the gaseous exchange and

${ }^{2}$ voN FURRTH, OTTO, and A. J. SMITH. The problems of physiological and pathological chemistry of metabolism. Chapt. XIX, 1916.

${ }^{2}$ Richards, H. M. Acidity and gas interchange in cacti. Carnegie Inst. Wash. Pub. No. 209 , p. 32, 1915.

Dakin, H. D. Oxidations and reductions in the animal body. Pages 56-68, 85-87, 1912.

voN FUerth-SMrth. L. c., p. 452. 
recently has also been studied in relation to the absorption of water and growth.

From a study of the action of alkalies on the pentoses in the absence of oxygen or an oxidizing agent, some insight can be gained into the formation of malic acid in the succulents. When a solution of l-arabinose is thus treated with eight times normal sodium hydroxide there is formed a variety of acid products. Special interest is attached for present consideration to the dl-1, 3-dioxybutyric acid:

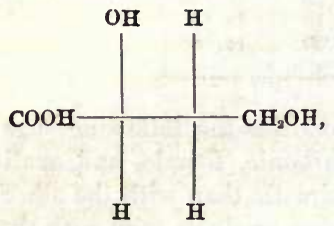
dl-2, 3-dioxybutyric acid:

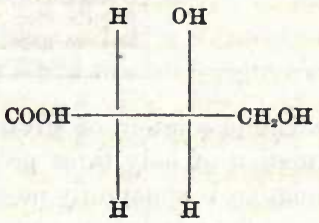

By oxidation these acids go over easily into d-l malic acid. ${ }^{2}$

Finally, to turn to the action of alkalies or metallic salts on sugars in the presence of oxygen or oxidizing agents: The relative stability of the sugars in aqueous solution toward oxidizing agents and the influence of small quantities of metallic salts has already been mentioned. Before entering upon the discussion of the way in which alkalies and salts affect the sugar molecule, it will be helpful to indicate the products which are formed in the oxidation of sugars. The nature of the products and the relative proportion of these varies tremendously with different conditions and depends upon a number of factors, more especially the concentration of the alkali or salt, the oxidation potential, $i$. e., whether the oxidizing agent is air, hydrogen peroxide, cupric hydroxide, silver oxide, etc., and the temperature. The different sugars also show wide variation in the proportion of the products formed. Thus, for example, certain sugars yielded as shown in table 1:

TABLE 1.

\begin{tabular}{|c|c|c|c|}
\hline & $\mathrm{CO}_{2}$. & Formic acid. & Oxalic acid. \\
\hline Hydrogen peroxide with & & & \\
\hline $\begin{array}{l}\text { ferric sulphate: } \\
\text { D-galactose....... }\end{array}$ & $\begin{array}{l}\text { p. et. } \\
69.28\end{array}$ & $\begin{array}{l}\text { p. et. } \\
3.00\end{array}$ & $\begin{array}{l}\text { p. ct. } \\
26.90\end{array}$ \\
\hline D-glucose............. & 70.98 & 3.00 & 16.66 \\
\hline D-fructose............ & 72.69 & 0.77 & 18.89 \\
\hline Hydrogen peroxide with & & & \\
\hline 0.5 normal KOH: & & & \\
\hline D-galactose........ & 4.65 & 80.2 & 0.0 \\
\hline $\begin{array}{l}\text { D-glucose........... } \\
\text { D-fructose. }\end{array}$ & 3.51 & 65.3 & $\cdots$ \\
\hline Air with normal sodium & 3.58 & 48.3 & $\cdots$ \\
\hline hydroxide: ${ }^{3}$ & & & \\
\hline D-glucose............... & .... & 14.80 & 1race \\
\hline
\end{tabular}

Ner, J. U. Llebig's Annalen, 376, 13-52, 1910.

SPOEHR, H. A. L. c., p. 234.

'NEF, J. U. Liebig's Annalen, 403, 244, 1913; Ibid., 357, 220, 1907; Ibid., 357, 289, 1907. 
An alkaline solution of cupric hydroxide (Fehling's solution) yielded from 100 grams of the following sugars:

TABLE 2.

\begin{tabular}{|c|c|c|}
\hline & $\mathrm{CO}_{2}$. & HCOOH. \\
\hline & grams. & grams. \\
\hline D-glucose ....... & 3.36 & 12.92 \\
\hline D-fructose ...... & 2.00 & 11.40 \\
\hline D-mannose...... & 4.40 & 12.00 \\
\hline D-galactose ..... & 2.19 & 13.30 \\
\hline D-arabinose..... & 3.40 & 14.66 \\
\hline
\end{tabular}

An alkaline solution of silver oxide oxidizes the following sugars with the formation of only three products, carbonic, formic, and oxalic acids. The oxidation is apparently much more drastic than with the other oxidizing agents; the relative amounts of the three products vary with the nature of the sugar and the concentration and temperature of the mixture:

TABLE 3.

\begin{tabular}{|c|c|c|c|}
\hline & $\mathrm{CO}_{2}$. & нсоОН. & $(\mathrm{COOH})_{2}$. \\
\hline & grams. & grams. & grams. \\
\hline D-glucose ....... & 22.56 & 38.45 & 85.34 \\
\hline D-fructose ...... & 26.00 & 35.30 & 82.70 \\
\hline D-galactose ..... & 29.95 & 43.63 & 64.47 \\
\hline D-arabinose...... & 29.34 & 37.29 & 80.20 \\
\hline
\end{tabular}

$\mathrm{D}$-glucose in alkaline solution when oxidized with air or with 3 per cent hydrogen peroxide yields besides carbonic and formic acids a large amount of non-volatile acids. The latter are a mixture composed of d-arabonic, d-erythronic, l-threonic, and dl-glyceric acids. The total amounts of these non-volatile acids, as well as the relative amounts of the individual acids, vary greatly, according to whether air or hydrogen peroxide is used as an oxidizing agent. Thus Glattfeld ${ }^{1}$ obtained for every 100 grams of glucose oxidized with $\mathrm{H}_{2} \mathrm{O}_{2}, 23.7$ grams of the mixed non-volatile acids, while with air 72 grams of the acid mixture were obtained.

These illustrations have been cited in order to show the variability of the process of glycolysis even in vitro. Among the important variable factors which influence enormously the course of glycolysis and the nature of the products are the rate of oxidation, concentration, the oxidation potential, temperature, and undoubtedly other less definite elements. It is therefore not in the least surprising that the living organism in which many of these factors are so closely interrelated and almost constantly changing should

${ }^{1}$ Grattreld, J. W. E. On the oxidation of d-glucose in alkaline solution by air as well as by hydrogen peroxide. Amer. Chem. Jour., 50, 135-157, 1913. 
display such a variety of metabolic products and reactions. As a possible explanation of this great instability and variability of reaction of the sugars, the theories and results of some of the recent chemical investigations give the most helpful suggestions yet offered. It has already been shown that sugars behave like very weak acids, that the hydrogen atoms of the hydroxyl groups ean be replaced by metals to form salts. A. P. Mathews ${ }^{1}$ has shown that the salts formed with sugars are easily ionized and thus lead to increased concentration of sugar anions. These, by virtue of partially unbalanced charges, are very unstable and highly reactive. The most reactive part of the sugar molecule is probably the first carbon atom, the carbonyl group; thereafter the reactivity decreases down the chain of carbon atoms, as these are removed from the carbonyl group. While the sugars are relatively stable substances, their salts decompose very readily.

The manner in which these salts decompose is of greatest importance to an understanding of glycolysis. In this decomposition or dissociation the sugar molecule is broken in fragments composed of carbon atoms in varying number. Thus a hexose may break into fragments containing 5 and 1 carbon atoms, into fragments of 2 and 4 , and into 2 pieces each containing 3 carbon atoms. The proportion in which any of these pieces are formed depends upon a number of factors, such as concentration of the sugar, temperature, etc. This dissociation or cleavage of the sugars results in mixtures of tremendous complexity. Of special importance is the fact that these pieces are unstable and of high reactivity, so that they react in a variety of ways; either the pieces undergo intramolecular rearrangements to form more stable compounds, or they may react with each other, oxidizing one and reducing the other; they may condense or polymerize, or finally unite with other substances present, such as oxygen, to form acids. It can readily be seen what an appalling complex of substances and tangle of reactions are involved in a system containing, for instance, dextrose and sodium hydroxide. Nef has found that in such a system there are finally in equilibrium no less than 93 different substances. Including the syntheses which always accompany these reactions, the number of products is considerably above 100 .

It is undoubtedly due to the ease and multifarious ways in which the sugars are dissociated and undergo chemical changes involving the liberation of energy that they can be used by the organism both under aerobic and anaerobic conditions. In this respect neither the fats nor the proteins can be compared with the sugars as to the possibilities of usefulness for the organism. It is impossible to give here the detailed chemical steps used in these considerations; reference must be made to the very extensive original literature. The arguments are based upon the following principles which are applicable alike to hexose, pentose, or tetrose sugars: There are formed

'MATHews, A. P. The spontaneous oxidation of sugars. Jour. Blol. Chem., 6, 3, 1909. 
(first) a series of compounds, the enols, in the following manner ( $M$ in the formulæ represents a metal or possibly enzyme), which replaces the ionized hydrogen:
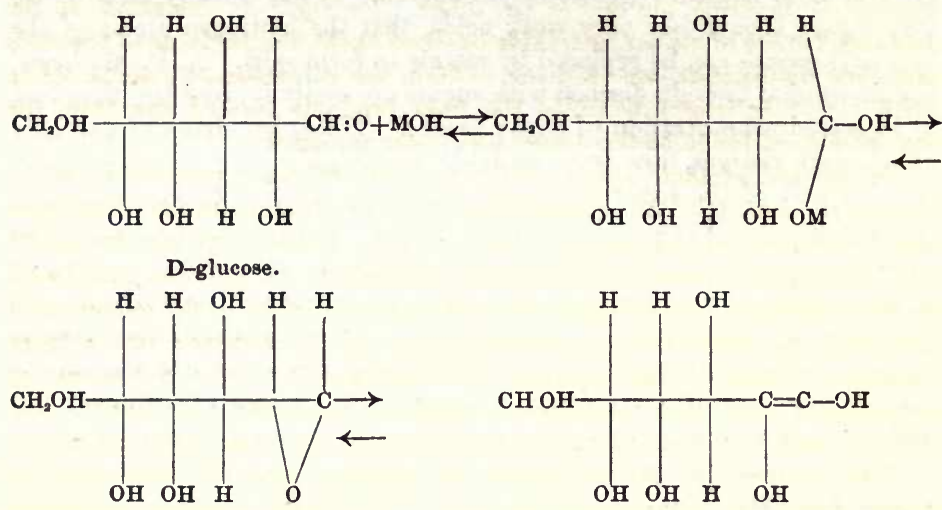

Common 1-2 dienol of D-glucose, D-mannose and D-fructose.

This 1, 2 dienol, by taking up one molecule of water at the double bond and rearrangement goes into either d-glucose, $d$-mannose, or into d-fructose, according as to whether the $\mathrm{OH}$ of the $\mathrm{HOH}$ attaches to carbon atom 1 or 2 . In this manner the interconversions of the hexoses above referred to are explained, the same principles holding for the other sugars as well as the d-glucose.

In a similar way there are formed:

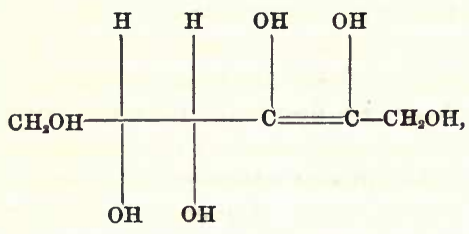

2.3 Dienol.

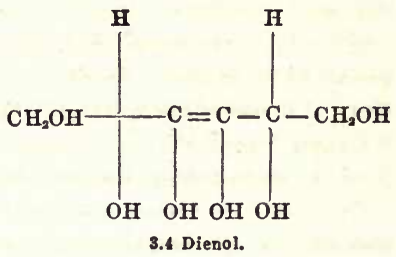

3.1 Dienol.

These dienols are also capable of rearrangement to form other monosaccharides and polysaccharides, as just indicated. However, the dienols are capable of another and more drastic change. As is almost general in carbon compounds, double carbon bonds break easily and are highly reactive. The enols break apart spontaneously at the double bonds; this results in the formation of substances of very great reactivity, capable of intramolecular rearrangement, action upon each other, and (if there is oxygen present), the formation of the large variety of acids briefly described above. Thus, e. g., 
the breaking of the 1,2 hexose dienol and subsequent immediate oxidation would result in the formation of formic and d-arabonic acids. All these actions proceed simultaneously, the final products depending upon the conditions favoring the one or the other. By vigorous oxidation, as for instance the use of copper hydroxide or silver oxide, the products of the more complete dissociation are oxidized to form the corresponding acids, while with air or hydrogen peroxide the final products formed are from the immediate oxidation of the dissociated sugar molecule.

On account of their great reactivity it has not been possible as yet to determine definitely the composition of all the fragments resulting from the dissociation of the sugars. The principle, however, of salt formation and subsequent dissociation seems well established. Of greatest importance to the problem of metabolism is the fact that precursory to the oxidation of sugars is the dissociation or rearrangement of the molecule into a large number of pieces of high reactivity and that these products of dissociation are capable of the most multifarious reactions depending upon various conditions, such as concentration, temperature, and the presence of oxygen.

From a survey of the phenomena of oxidation over the very extensive range of chemical substances, it becomes evident that a primary dissocation is conditio sine qua non before oxidation can take place. This conception in one form or another is of greatest importance to the physiologist in the interpretation of phenomena of catabolism, but has been considered very little by plant physiologists. That pure aqueous solutions of sugars are relatively stable has led to many misconceptions and the formulation of elaborate hypotheses as to the process and agents inducing glycolysis. It need hardly be mentioned that conditions in the cell are very different, that the reactions do not take place in pure water solution, but largely in a colloidal mixture in the presence of a large variety of inorganic salts, and that such conditions lead to a dissociation of the sugar molecule. The rôle and mode of function of enzymes is in all probability a special form of this group of reactions. In fact, it seems doubtful that for these reactions, at least, it is necessary to assume that the sugars are first organized into a large "biogen" molecule in the cell prior to the release of energy or oxidation. Such an assumption lies quite outside of the range of scientific investigation.

By means of the treatment with calcium salts of organic acids, the products of dissociation of the dextrose molecule are capable not only of rearrangement and oxidation, but also of union to form polysaccharides and more complex substances. ${ }^{2}$

The relatively simple dissociation of sugars by means of alkali must yield considerable energy, as Nef observed a decided rise in temperature on mixing the solutions. ${ }^{2}$ It would be exceedingly interesting to have accurate experimental data on this point.

The questions relative to the mechanism of the utilization of energy in the vegetable organism have as yet not been stated by plant physiologists

'NeF, J. U. Liebig's Annalen, 403, 226-234, 373, 1913.

'Ibid., 376, 12, 1910. 
in such terms as to permit of any well-defined experimental investigations. The form in which energy is utilized in the plant is still a matter of much conjecture. This is, of course, aside from the utilization of solar energy in photosynthesis.

Many animal physiologists have assumed for a long time that dextrose is not burned as such in the body, but that by the action of protoplasm it is first dissociated (in a very similar manner as has been described through the action of alkali) to form various dissociation products, which in turn are either oxidized or are reduced or condensed to form other metabolic products. ${ }^{2}$ These opinions were greatly influenced by the work of G. von Liebig, who showed that the legs of frogs continued to react and produce $\mathrm{CO}_{2}$ in an oxygen-free atmosphere, and by that of Pettenkofer and Voit, who demonstrated that the total protein dissociation is independent of oxygen. Voit showed that for proteins the metabolism was not proportional to the oxygen supply, that metabolism was a process of cleavage of sugar, fat, or protein molecules into simpler products which then united with oxygen; in brief, that absorption of oxygen is not the cause of metabolism but rather that metabolism, the process of dissociation, determines the amount of oxygen which is used. This whole conception has been tersely stated by Lusk: "Metabolism vivifies the energy potential in chemical compounds."

That the production of heat is roughly proportional to the oxygen-supply has been a familiar fact since the well-known researches of Garreau and of Erikksson. That many plants live and grow to some extent for a limited time in an atmosphere freed of oxygen is also a matter of common knowledge. Many animals exhibit the same phenomenon, although to a more limited extent. Under these conditions the organism obtains its energy through so-called intra-molecular respiration. In the higher plants and animals anoxybiosis usually produces substances which are toxic to the organism, and in most cases suffocation is the result of the accumulation of these substances to an extent causing death. The fact that in general plants are more resistant to these effects can probably be explained by their high synthetic power. Thus, for example, alcohol and many hydroxyl acids are converted into substances which can be drawn into the stream of anabolism, especially in the light.

From observations on the temperature rise in the fermentation of sugars by yeasts, Fitz comes to the conclusion that each gram molecule of dextrose fermented yields 57,500 calories. The heat of combustion of dextrose is 684,000 calories." These figures give some indication of the cause of the differences in the thermal relations of the two processes of oxybiosis and anoxybiosis. However, it is an open question whether the thermal properties alone express the true energy relations in so complex a process as

"Vorr, C. voN. Handbuch der Physiologie des gesammtstoffwechsels under der Fortpflanzung, 6, 279, 1881 . Leipzig.

2 Lusk, GrafaM. The elements of the science of nutrition, page 33, 1917.

-Euler, H. Grundlagen und Ergebnisse der Pflanzenchemie, II, page 161, 1909. Braunschweig. 
respiration. Undoubtedly the economic coefficient varies greatly in different plants, and in all probability heat is to a large measure only the unaroidable accompaniment of catabolism, and the plant must use other forms of energy for the synthesis of formative material. The results of the very extensive and thorough work which has been done in the field of mammalian physiology on this subject as yet find very little application to the problems in the plant. This, of course, is not surprising in view of the fundamental differences in the normal mode of life and functions between plants and animals.

There is as yet no definite way of determining the form in which energy is released and utilized in the processes in the living plant. Practically the only factors which so far have been within the range of experimental investigation have been the study of the end-results and outer manifestations of the energy transformations. For the majority of plants the liberation of heat is probably the most general. The very interesting experiments of Bonnier ${ }^{1}$ indicate that this varies greatly under various conditions and stages of development. By comparing the heat liberated with the theoretical amount possible by simple combustion calculated from the absorption of oxygen and liberation of carbon dioxid, Bonnier found that the former often greatly exceeds the latter, while in other cases, as in mature plants, the heat liberated was decidedly lower than the amount calculated from their respiration. While these results but indicate the transformations of the obscure chemical energy, it would be highly desirable to elaborate investigations of this nature, and to do so in collaboration with a study of the energy relations of the intricate chemical dissociations discussed above. Investigations thus far undertaken have not contributed greatly to a fuller understanding of the subject, as in the measurement of heat liberated little attention has been paid to the chemical changes and the nature of exothermic reactions involved.

Of interest in this connection are the old observations of Radzisezewski ${ }^{\text {* }}$ who studied the phosphorescence which is produced in plants and animals and which also accompanies the autoxidation of a very large number of organic compounds. He interpreted his findings on the basis of the old Schönbein theory of oxidation, and showed that all substances which by oxidation Schönbein had noticed formed hydrogen peroxide and active oxygen also produced light, and generally at ordinary temperatures. Radzisezewski was the first to observe that sodium hydroxide induces this phosphorescence in many organic compounds; $e . g .$, all aldehydes and their ammonia derivatives, the higher alcohols (it has since also been observed with sugars), fats, the higher fatty acids, the soaps, and a large variety of others. Knowledge of the liberation of other forms of energy besides heat in the dissociation and oxidative reactions induced by catalysts may be of

${ }^{1}$ Bonnier, G. Recherches sur la chaleur végétale, Ann. Sclence Nat. Serie, VII, $18,1,1893$.

'RAdzisezewskx, M. Ueber der Phosphoriscenz der organischen und der organ1sierten Koerper, Liebig's Ann. der Chem., 203, 305-336, 1881. 
the utmost importance in the study of the problem of metabolism in the plant.

The special attention which has been given here to results so far obtained from the investigations of the reactions of sugars in combination with salts and alkalies seem warranted in that they represent a system in dynamic equilibrium; the breaking down is always accompanied by the synthesis of more complex substances, and while such a complex system is still beyond the experimental control of physical chemical methods, it simulates the dynamic nature of living things, it emphasizes process rather than single substances, and brings these processes within the range of experimental science by centering energy changes on the fundamental properties of the carbon atom. Furthermore, these reactions give a clear indication of the nature of one form, at least, of enzyme action in a homogeneous system and argue strongly for the theory of the formation of intermediate compounds.

But before such a chemical system can be rationally applied to the functionings of a living plant, some further knowledge is essential of the nature of the carbohydrates and the transformations which these undergo in the plant under various conditions. Here again the aspect of a dynamic equilibrium is evident. It is a matter of common knowledge that most plants contain monosaccharides, disaccharides, and the condensation products of these (the polysaccharides) in various proportions. Each of these types of carbohydrates is what might be termed a "physiological group," and the proportion in which they are present in a plant leaf, for instance, is the result of certain factors, and in turn controls to a large measure the physiological activity of the organism. An effort has been made to determine some of the conditions affecting this equilibrium of monosaccharide $\longleftrightarrow$ disaccharide $\rightleftarrows$ polysaccharide and to study the effect of this on metabolism.

In general, chemical inversion, or the transformation of the condensed to the simpler molecules capable of oxidation, translocation, and the formation of other substances, takes place under conditions of ample water-supply. However, these reversible enzymatic reactions never run entirely in one direction; only differences between the two are observable. We are dealing with delicate compound dynamic equilibria involving probably dozens of steps and many more substances. The enormous importance of water in various functions of the organism, such as growth, has long been recognized. When it is realized that it is to a great extent only under conditions of sufficient water that the simpler and more reactive carbohydrates are present in sufficient amounts in the cell, this fact becomes understandable. It has been found that variations in the water-content of the cactus joints greatly influence the proportion of the various groups of sugars. As a consequence, the course of metabolism is also decidedly affected. This undoubtedly also is true for other plants. With high water-content the polysaccharides are converted into monosaccharides, and from all evidence available under normal conditions, the latter are the carbohydrates most 
readily dissociated and drawn into the stream of catabolism. It is only under conditions of stress that the plant uses the disaccharides or polysaccharides with the result of the formation of pentosans and pentoses. These actions will be discussed under the section on pentose sugars. With ample water-supply and oxygen the hexoses are burned in such a manner that there is not an accumulation of end-products which are deleterious to the plant. Another feature of such complete burning is the influence of the products on the water-absorbing capacity of the colloidal substratum of the cell, and hence on the growth of the organism. The influence of the various intermediate products of metabolism on imbibition and the manner in which this is correlated with growth is being extensively studied at the Desert Laboratory.

Early in the course of the investigations on the metabolism of succulent plants it was recognized that the organic acids found therein are the accumulating intermediate or end-products of a modified form of catabolism due to morphological peculiarities of the plant. The chemical principle which underlies the acidification is the formation of acids by the oxidation of sugars; the manner in which this occurs and the products formed have already been indicated. One of the principal agents of deacidification in plants is sunlight; organic acids, such as oxalic, malic, tartaric, etc., break down very readily in the light in that the carboxyl group, $\mathrm{COOH}$, splits off $\mathrm{CO}_{2}{ }^{3}$ It is a noteworthy fact, discussed by Richards, that cacti rich in acid exhale carbon dioxid abundantly in the sunlight, even at moderately low temperatures. This fact also finds application in the formation of pentose sugars, as will be discussed later.

The total carbohydrate content or of food-supply in general is of little significance or value in studying the various functions of a plant. It is rather the nature of the sugars, or the degree of general chemical inversion, that determines the supply of material available for respiration or growth. The relative amounts and proportion of the carbohydrates in a leaf, for example, are dependent upon several factors, primarily water-content and temperature. Also it is essential to realize that the transformation of the various groups of carbohydrates represents thus an equilibrium system subject to change by several factors. It is evident, therefore, that only after determining the influence of these factors and taking them into consideration can any safe conclusion be drawn as to the significance of the presence of any one of the various groups of sugars. This fact finds immediate application in the problem of photosynthesis. There has been a great deal of dispute over the first sugar formed in the process of photosynthesis. Various workers have arrived at conclusions which are still very contradictory. Unfortunately, in most of the work the factors already referred to were not determined, so that it is impossible to explain the variable results on this basis.

${ }^{2}$ RICHARDS, H. M. L. C., 83.

SPOEHR, H. A. Photochemische Vorgaenge bei der Diurnalen entsaeurung der Succulenten, Biochem. Zeitschr., 57, 95-111, 1913. 


\section{HISTORICAL.}

Beyond the proximate analyses incident to investigations of the food value of cacti for agricultural purposes, very little work has appeared on the carbohydrates of the cacti. ${ }^{2}$ Nor is there any extensive information on the subject available for other succulent plants. However, on account of the complex character of its respiratory processes, its structural peculiarities, and the rather extreme climatic conditions under which many of its members live, this group of plants has been subjected to extensive physiological investigations. Some of the earliest and now classical researches on respiration were carried out with this material.

The interest has centered primarily around the gas interchange and the periodic acidification and deacidification of the plants. De Saussure was the first to study thoroughly the respiratory relations of these plants. The question of acidity in succulents has been subjected to extensive investigations; most recent are the very thorough researches of Richards ${ }^{\circ}$ and those of Jenny Hempel." In the publication of Richards is given a clear discussion of the historical development of the subject, and the conditions inducing acidification and deacidification, together with the effect on the respiratory quotient, are there elaborately formulated, based upon wide observation and comprehensive experimentation.

The relation of the plant acids to the carbohydrates has been the subject of much speculation ever since the appearance of Liebig's theories of the origin of sugars from hydroxy acids in ripening fruits. Although the weight of evidence seems to be against the Liebig theory, and it is considered as untenable by most plant physiologists, the principle thereof has been frequently revived and has found expression in modified forms." The formation of organic acids as catabolic products of carbohydrate metabolism has received very little attention from plant physiologists. From the chemical evidence available, many of the intermediate products of sugar degradation are acids of the nature of those found in the plant, as has been discussed in the introduction. However, the manner in which the carbohydrates are first affected, the actual mode of acid formation in the plant, and the further transformations are all questions toward which very little physiological inquiry has been directed. As prerequisite knowledge for investigation of these problems, we must have some understanding of the interrelation and transformations of the carbohydrates from the simple to the complex, and vice versa, the conditions inducing such changes and also,

${ }^{2}$ GRIFFTth, D., and R. F. HARE. Prickly pear and other cactl as food for stock. Bull. 60, New Mexico College of Agriculture and Mechanic Arts, 1906. Ibid., 72.

Haraington, H. H. Analysis of cactacus. Tex. Expt. Station Report 1, 28, 1888.

DE Saussure, Theo. Recherche chemique sur la végétation. 1804.

'RICHarDs, H. M. Acidity and gas interchange in cacti. Carnegie Inst. Wash. Pub. No. 209, 1915.

- Hemper, JenNy. Buffer processes in the metabolism of succulent plants. Comptesrendus des travaux du Laboratoire de Carlsberg, 13, 1917.

- Baur, E. Ueber die Genesis der Kohlenhydrate. Naturwissenschaften 1, 474-477, 1913. Zeit. physik chem., 63, 683-710. 
of course, the chemical nature of the carbohydrates in the organism under investigation.

For the succulent plants especially very little data of this nature have been gathered. In 1902 Harlay $^{1}$ published some investigations on the mucilage of Opuntia vulgaris. The mucilaginous substances are located in special, large cells. These were made visible in material which was conserved in alcohol and examined with lead subacetate. By allowing the cactus joints to remain in an atmosphere of ether, Harlay found that the mucilages exuded as a clear, slightly colored, thick liquid. He obtained the mucilage by removing the exterior chlorophyllous portion, chopping, grinding with sharp sand, heating with water at $110^{\circ}$, filtering through cloth, and precipitating with 90 per cent alcohol; this precipitate was filtered off, washed with alcohol and dried. Thus he obtained a gray powder, which when dissolved in water did not reduce Fehling's solution, but always contained a small amount of inorganic material. The aqueous solution could not be filtered. His analysis indicated the presence of galactose and arabinose.

Recently Long ${ }^{2}$ made some analyses of the carbohydrate-content of Echinocactus in collaboration with the studies of MacDougal on the water balance and desiccation of this plant.

${ }^{1}$ Hartar, V. Sur le mucilage du cactus à raquettes, Opuntia vulgaris Mil. Jour. de Pharm. et de Chem. (6), 16, 193-198, 1902.

'MAcDougat, D. T., E. R. Long, and J. G. Brown. End results of desiccation and respiration in succulent plants. Physiol. Researches 1, 289-325, 1915.

LoNG, E. R. Further results in desiccation and respiration of Echinocactus. Bot. Gaz., 65, 334-358, 1918. 


\section{EXPERIMENTAL METHODS.}

\section{SELECTION AND PREPARATION OF MATERIAL.}

The greater part of the work here recorded was done with Opuntia phoeacantha, known locally as Opuntia blakeana. ' Other species were also used, but the results do not differ materially from those obtained with this plant. In working with the cacti considerable difficulty is encountered on account of the large amount of mucilaginous substances therein. However, this in itself is a subject of great interest, the nature, source, and function of these slimes being still unknown and to a greater or less extent forming a characteristic property of all succulent plants. Furthermore, the joints of Opuntia phocacantha are of a size that can be most easily handled for the various experimental procedures, and also grow in abundance on the laboratory domain. On account of the smaller amount of mucilaginous substances, Opuntia versicolor ${ }^{2}$ was used where it was necessary to press out the juice. Such a procedure is quite impossible with Opuntia phacacantha, especially during the dry seasons.

Each series of determinations or experiments was carried out with material from one plant. Although there are naturally differences among individual plants, the changes which these undergo with season and under experimental conditions are entirely parallel. Large, healthy plants have a sufficient number of joints of the same age, so that extended experiments can be conducted with material from the same plant and a number of joints can be used for each determination. For the work on sugar estimation the material was collected between 10 and 11 o'clock in the morning. The joints were removed by cutting at the base with a sharp knife. The cut surfaces were 2 to 3 square centimeters, and no loss of juice or other injury was ever observed therefrom. The joints were immediately taken to the laboratory, and the spines were removed with sharp pruning shears, care being taken not to cause any injury.

The cacti offer splendid material for investigations of this nature. All the year fresh and normal material can be obtained in abundance; it is notably resistant to lack of water, as well as to variations in temperature, and can be kept in the dark for months without fatal results. Nevertheless all these conditions effect decided changes in the plants. Furthermore, they can be easily grown, even in nutrient solutions, and if necessary a single joint offers ample material for complete analysis.

\section{PREPARATION OF MATERIAL FOR ESTIMATION OF SUGARS.}

All material, whether it had been subjected to experimental conditions or taken immediately from out of doors, was prepared alike for analysis. The joints, freed from the spines, were cut into three or four strips and

${ }^{3}$ Britton, N. L., and J. N. Rose. The Cactaceæ: Description and illustration of Ibid., p. 62.

plants of the cactus family. Carnegie Inst. Wash. Pub. No. 248, vol. r, p. 144. 
ground in a meat-chopper. By using a fairly coarse cutter, there was no loss of juice. The manipulation was carried out as rapidly as possible. The ground mass was thoroughly mixed and put into a dish, covered, and placed in a hot-air oven at $98^{\circ}$. In this manner the plant material is quickly killed and all danger from enzyme actions, which by the usual means of drying are first considerably accelerated, is thus avoided. On account of the danger of subsequent action of enzymes on the carbohydrates, expression of the juice of a plant is also impractical. After heating thus for about 30 minutes, the cover was removed and the material dried for 24 hours at $98^{\circ}$. It was then ground to a fine homogeneous powder and was ready for analysis.

\section{THE DETERMINATION OF DRY WEIGHT.}

As has been indicated, in order to gain a clear conception of the rarbohydrate transformations in a vegetable organism, it is essential to know the water relations. For this reason each sugar analysis was supplemented with a determination of the dry weight. A small amount (about 10 grams) of homogeneous freshly ground material was placed in a tared wide-mouth weighing bottle, weighed, first heated with the cover on as described above, and then dried at $98^{\circ}$ and cooled in a desiccator before weighing. This always was done in duplicate or triplicate and the results agreed well with each other. Further heating at $98^{\circ}$ or keeping in a desiccator for several days caused no further appreciable loss in weight. Separate experiments showed that in this drying process the disaccharides were not appreciably inverted.

\section{PREPARATION OF MATERIAL FOR ANALYSIS.}

A separation of the simpler sugars from the condensed polysaccharides was attained by extracting one portion of the dry material with 95 per cent alcohol and by hydrolyzing another portion with dilute acid. For the alcoholic extract 30 to 50 grams of the dry material was mixed with 2 to 5 grams of powdered calcium carbonate in order to neutralize the plant acids present and thus prevent inversion of the disaccharides. Although calcium carbonate gives a very slightly alkaline solution, this is not sufficient to cause enolization and consequent rearrangement of hexoses or formation of saccharinic acids. Stronger alkalies are to be avoided, as they cause the reactions mentioned. This is a very serious source of error in much of the work in the literature on the nature of hexoses in leaves, as apparently the ease of mutual rearrangement of, e. g., d-glucose, d-mannose, and d-levulose was entirely disregarded. These transformations have already been discussed in the introductory discussion.

For the present purpose no attempt was made to distinguish these sugars in the analyses, but they are regarded rather as belonging to one physiological group. The calcium salts of most of the plant acids are quite insoluble in alcohol. The mixture of the dry plant material and calcium carbonate was extracted twice, with 10 times its weight of 95 per cent 
alcohol, each time heating to boiling for 3 hours, filtered, and the residue washed with hot alcohol. This procedure removed all alcohol-soluble sugars. The alcohol was then distilled off at reduced pressure, a greenishbrown gum remaining. To this was added hot water to dissolve the sugars; a considerable amount of oil (largely chlorophyll) was insoluble. A small quantity, $0.2 \mathrm{gram}$, of blood charcoal greatly facilitated the filtration. Without the addition of the blood charcoal it was almost impossible to get a clear solution on account of the clogging of the filter-paper by the fine oil particles. In order to make negligible any loss of sugar by adsorption by the charcoal, the same lot of Merck's blood charcoal was used throughout. ${ }^{2}$

As the amount of protein and tannin in the cactus is very small, it was found inadvisable to clarify the sugar solutions with lead acetate. The water from the clear aqueous solution was distilled off at reduced pressure $\left(75^{\circ}\right.$ and $35 \mathrm{~mm}$.) in a tared flask, finally with the water-bath boiling. The residual light-brown gum was weighed, dissolved in water, and the solution made up to a definite volume. The sugars were then determined as described below. The reducing sugars present were monosaccharide hexoses and pentoses. The mixture was then hydrolyzed with hydrochloric acid, using 5 c. c. normal acid solution for every 100 c. c. of the sugar solution and heating for 3 hours at $80^{\circ}$. Repeated trials with longer heating showed that the inversion was complete. By the use of invertine, the same values of cupric reduction were obtained as with hydrochloric acid, indicating that there was no maltose present.

The mixture was neutralized carefully with sodium bicarbonate, made up to a definite volume, and the sugars determined. This determination represents monosaccharide hexoses and pentoses and invert sugar. The sugar solution was then fermented in order to remove all hexose sugars. For this a fresh preparation of carefully washed bakers' yeast was used. To the sterilized sugar solution was added the yeast, mixed with distilled water to a thin paste, 0.25 gram pressed yeast per gram of original gum. The vessel was stoppered with cotton and left at $30^{\circ}$ to $35^{\circ}$ for 30 to 40 hours. Separate experiments with various mixtures of invert sugar and l-arabinose and l-xylose showed that by this procedure all hexose sugars present in the plant were removed, while the pentoses remained unchanged. The mixture was then filtered and distilled at reduced pressure in order to remove the products of fermentation. The residual gum was dissolved in a definite volume of water and the sugars determined with the alkaline copper solution.

For the estimation of the polysaccharides, 5 to 15 grams of the dry material was hydrolyzed with 200 to 600 c. c. of 1 per cent hydrochloric acid in a flask, with reflux condenser, in the boiling-water bath for 3 hours. The mixture was filtered, washed thoroughly with hot water, the filtrate neutralized carefully with sodium bicarbonate, and made up to a definite

${ }^{2}$ WoodyatT, R. T., and H. F. Heumholtz. The use of blood charcoal as a clearing agent for urine containing glucose. Arch. Intern. Med., 7, 598-601, 1911. 
volume. The solution was then ready for analysis. These solutions were a light-brown color; they were not treated either with lead acetate or blood charcoal, as the amount of error produced by such treatment is equal to or even greater than that produced by the very small amount of protein or tannin substances in the original material. The amount of sugar here found was equal to the hydrolyzed alcoholic extract plus the amount of sugar in the residue from the alcoholic extraction when the former was hydrolyzed and treated in a similar manner. The residue from the alcoholic extraction contained a slight excess of calcium carbonate. It also had to be entirely freed from alcohol before it could be used for the estimation of polysaccharides. For these and several other minor reasons, it was found much more rapid to make these determinations with a fresh sample of the dry material than with the residue from the alcoholic extraction, and it was found that the polysaccharides could be determined accurately from the total sugars by calculation.

One per cent hydrochloric acid was decided upon for the hydrolysis after considerable experimentation. It was desired to hydrolyze to monosaccharides all those disaccharides and polysaccharides including starch, dextrine and the mucilaginous substances, which may be important to the plant as reserve food material, but without affecting the cellulose which goes to make up the walls and vessels of the plant. It was necessary, therefore, to utilize the lowest concentration of acid which still hydrolyzed completely the normal reserve materials. Hydrochloric acid affects cellulose less than do other mineral acids of the same ionic concentration. It was found that when the acid mixture was heated for 3 hours on the boiling-water bath a rather definite end-point had been reached; further prolonged heating and using fresh acid caused exceedingly slight increase in the reducing power of the hydrolyzed mixture. Higher concentrations of acid already seemed to affect the cellulose so that no such definite end-point was obtained; while still lower concentrations required considerably longer heating in order to completely hydrolyze the starch and other polysaccharides. There was always an odor of furfural in the hydrolyzed mixture, but this was very slight, so that the pentose values were probably affected but very little. With higher concentrations of hydrochloric acid, the furfural was much more noticeable.

Judging from the microchemical test with iodine, the platyopuntias contain an abundance of small starch-grains. When the dried material is mixed with water it takes on the same slimy consistence of the freshlyground cactus. It was, therefore, impossible to determine the starch chemically by the use of taka-diastase on account of the mucilaginous substances. These can not be filtered through filter-paper even after the addition of much water, and boiling the solution is without effect on them, nor can they be precipitated except by the use of large quantities of alcohol. The clear mucilage which can be obtained by the use of a filter-press always contains considerable starch. 
A quantity of the dried cactus material was mixed with water and boiled for 2 hours, cooled, a solution of taka-diastase added, and kept at $37^{\circ}$ for 22 hours. This procedure was repeated for 8 days, each time adding fresh taka-diastase, and at the end of this time the small pieces of cactus, after treatment with alcohol and iodine in the usual manner, still showed distinctly the presence of starch. The slime of the cactus was quite unaffected by this treatment. A quantity of corn starch treated in a similar manner was completely hydrolyzed after the first day. It appears, therefore, that the slime in some manner protects the starch against the action of the takadiastase. It is evident that plant material containing such mucilaginous substances offers some unusual difficulties and is not amenable to the ordinary methods of analysis. These slimes are very readily hydrolyzed by dilute acids; by such treatment they lose entirely their mucilaginous character and the solutions can be easily filtered.

Cellulose was determined by taking the residue from the acid hydrolysis, digesting it with 1.25 per cent $\mathrm{KOH}$, washing thoroughly, and filtering through a tared filter-paper and drying. The dried mass was then incinerated in a crucible and the ash subtracted from the total weight of the crude fiber. The first determinations were made by use of the chlorination method, ${ }^{1}$ but as the differences between this and the much simpler method just described were found to be very slight and within the experimental error of either method, the first procedure was followed, which yielded results that had at least a comparative value.

\section{CALCULATION OF ANALYTICAL DATA.}

The analyses were calculated in terms of cubic centimeters of standardized Fehling's solution reduced, per gram of dry sample. The following deductions represent the various sugars. In the solution of the acid hydrolysis the copper values are distributed as follows:

A. Total sugars of the hydrolyzed material, i. e., the monosaccharides as well as the hydrolyzed polysaccharides.

B. Fermented residue of $\mathbf{A}$, or total pentose sugars, including monosaccharide pentoses and pentosans.

In the alcoholic extraction:

C. Monosaccharide hexose and pentose sugars.

D. Hydrolyzed product of $\mathbf{C}$ or inverted disaccharides, original hexose, and pentose. There are no disaccharide pentoses present.

$\mathbf{E}$. The fermented residue of $\mathbf{D}$ or monosaccharide pentose.

Then the copper value of the various sugars are:
A. Total sugars.
C. Monosaccharides.

A-D. Total polysaccharides.

D-C. Disaccharides.

D-E. Disaccharides plus hexoses.

C-E. Hexoses.

A-B. Total hexose sugars.

(A-B)-(D-E). Hexose polysaccharides.

B. Total pentoses.

E. Monosaccharide pentoses.

B-E. Pentosan.

${ }^{1}$ Cross, C. F., and E. S. Bevan. Cellulose. Page 94, 1895. London. 
The reducing power of these sugars is not equal, but the reduced copper was apportioned as follows: $100 \mathrm{c}$. c. standarized Fehling's solution $=1.00$ gram d-glucose, 0.95 gram invert sugar, 0.90 gram l-xylose, 0.90 gram hexose polysaccharides, and $\mathbf{0 . 8 5}$ gram pentosan. With these figures the amount of the various sugars per gram of dry material and in some cases of original fresh material was calculated.

\section{THE ANALYSIS OF THE SUGAR SOLUTIONS.}

On account of the large number of estimations of sugar which had to be made, it was necessary to employ a method of sugar determination which was rapid as well as accurate. The application of the reduction of alkaline copper solutions by sugars-that is, some modification of the Fehling method-is best suited to this purpose. The examination of the various current processes showed that these are open to serious error.

In the following method an attempt has been made to modify the usual procedures of sugar determinations by means of copper in such a manner as to avoid most of the sources of error inherent to these, especially as applied to the sugar solutions under consideration. It will not be necessary to enter into a detailed discussion of the theory and practice of sugar determinations by means of alkaline copper solutions. Such critical and experimental studies have been carried out by several workers, especially by Pflueger ${ }^{1}$ and by Peters,' which have yielded valuable results, but unfortunately have not been as universally applied as they deserve.

The results of these studies indicate clearly that where rapidity is of importance only volumetric methods should be considered. Any doubt regarding the accuracy of the volumetric procedure can pertain only to the measurement of the amount of copper reduced by the sugar; the conditions under which the reduction is carried out must in any case be carefully standardized. The majority of the methods require a filtration of the cuprous oxide which is either weighed as such or dissolved, and then determined by some suitable method.

It will be necessary to consider but a few of the most important factors affecting the accuracy of the procedure. The filtration of the cuprous oxide formed by the reduction of the alkaline copper solution, through an asbestos filter or some similar device, is open to several sources of error. Thus, it has been found by several investigators that the weight of the asbestos filters is not constant because of solution of the asbestos and the self-reduction of the reagents, and requires a correction which can not always be applied safely. In determining the sugars in solutions obtained from plant material such as the cacti, the precipitated cuprous oxide contains contaminating substances which are undeterminable and liable to affect the subsequent

${ }^{2}$ Pruugarr, E. Untersuchungen ueber die quantitative Analyse des Traubenzuckers. Arch. Ges. Physiol., 69, 399-471, 1898.

Peters, A. W. A critical study of sugar analysis by copper reduction methods. Jour. Amer. Chem. Soc., 34, 928-954, 1912. 
steps if the cuprous oxide is dissolved. Furthermore, the filtration must proceed as rapidly as possible and not infrequently do these contaminating substances greatly delay this process. Thus there is always danger of resolution of the cuprous oxide in the alkaline liquid, especially in the presence of dissolved atmospheric oxygen. It was therefore desirable to employ a method which did not depend upon the determination of the cuprous oxide formed in the reduction and which also obviated the necessity of filtering the solution. The only alternative was to employ the residual method, which depends upon the estimation of the unreduced copper. The accuracy of such a procedure naturally depends upon a good method of determining copper. This has been worked out by Peters in the iodide method and yields most satisfactory results.

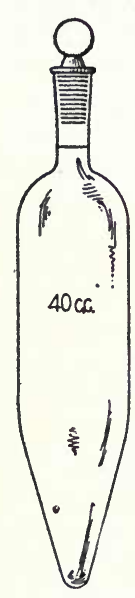

In the method used in this investigation, the reduction is carried out in specially designed tubes (fig. 1) of a capacity of 10 to $50 \mathrm{c} . \mathrm{c}$., depending upon the amount and concentration of the sugar solution to be determined. A very liberal excess of copper over that required to oxidize the sugar in solution is always provided. After heating a definite length of time, the tubes are rapidly cooled, made up to volume with distilled water, shaken in order to mix thoroughly, and then centrifuged until all the cuprous oxide (and other solid material) is in a compact mass at the bottom of the tube. The residual copper in the clear supernatant solution is then drawn off with a pipette and several determinations are made by the iodide-thiosulphate method. The difference between this result and the original strength of the copper solution represents the amount of copper reduced and is a quantitative index of the amount of sugar originally present.

Experience with this and various other methods of sugar determination by means of alkaline copper solutions has taught that reliable and quantitatively comparable results can be obtained FIG. 1. only by means of a most careful quantitative standardization of each step in the manipulation. Hence it is also necessary to adhere to the same procedure throughout an investigation. The sugar determinations were made by use of Fehling's solution (Soxhlet's modification: 69.28 $\mathrm{CuSO}_{4} \cdot 5 \mathrm{H}_{2} \mathrm{O}$ per liter), although it was later found that a solution containing sodium carbonate instead of caustic alkali possessed certain advantages, because the weaker alkali affects the sugar less profoundly. The Fehling's solution was used throughout in order to maintain the uniformity of procedure. Thus solution A was made up of 69.28 grams of pure $\mathrm{CuSO}_{4} \cdot 5 \mathrm{H}_{2} \mathrm{O}$ in 1,000 c. c. water, while solution $\mathrm{B}$ contained 346 grams of sodium potassium tartrate and 100 grams of sodium hydroxide in 1,000 c. c. of water. As will be seen later, a correction for the spontaneous reduction which takes place in this mixture was automatically adjusted in the blanks and standardization by means of pure d-glucose. 


\section{THE PROCESS OF REDUCTION.}

The solution containing the copper sulphate (solution A) was run out from a burette of $25 \mathrm{c}$. c. capacity graduated to $0.05 \mathrm{c}$. c. The alkaline tartrate solution, which need not be so accurately measured, was taken from a graduated pipette, and in the same amount as the copper solution. These solutions were placed directly into the specially designed tube. This consists essentially of any ordinary centrifuge or sedimentation tube with a narrow neck, the volume accurately graduated thereon, and fitted with a ground-glass stopper. ${ }^{2}$ The quantities are so arranged that there is always an ample excess of copper above that required to completely oxidize the sugar in the solution to be determined. As the method permits of such rapid work, a rough preliminary estimation can be made very quickly, if necessary, although after some experience this is rarely necessary. After the introduction of the copper and alkaline tartrate solutions, the sugar solution is run in. A burette of $25 \mathrm{c}$. c. graduated to $0.05 \mathrm{c}$. c. was used for most determinations. The contents of the tube were then thoroughly mixed by shaking. It was found that for work with very small quantities of sugar burettes of 3 c. c. capacity and graduated to 0.01 c. c. could be used with good results. However, in the work with the cacti there was always sufficient material, so that it was not necessary to resort to this apparatus.

The length of time prescribed by various methods and workers for heating the reduction mixture shows a great variation. The question has been carefully investigated by Peters. From this work it becomes clear that there is no advantage in protracted heating of the mixture; in fact, certain new errors are thus introduced which would quite counteract any advantage that might be gained from such a procedure. As the chemical reaction is actually probably quite complete only after long-continued heating," accurate termination of the process, characterized by constant values, can be attained only by very definite and exact standardization of the procedure. Thus, as Peters says:

"It matters but little whether the amount of the reduction is always 99 per cent or 97.5 per cent of $x$ if only the conditions are so sharply defined that the amount of reduction obtained at a selected point is characterized by great constancy."

This is a principle which is very generally overlooked in work with Fehling's solution. In the method here used the tube is immersed in a vigorously boiling water-bath and allowed to remain therein for $4 \frac{1}{2}$ minutes with the $40 \mathrm{c}$. c. tubes and 4 minutes with the $10 \mathrm{c}$. c. tubes. It was found experimentally that at the end of this time practically all of the easily oxidizable material in the sugar mixtures from the cactus had been exhausted. Almost all sugar solutions obtained from plant material, such as the ones under consideration, contain substances other than sugars which

2 These tubes were made by Mr. Paul Anders, glass-blower of the department of chemistry of the University of Illinois, Urbana, Illinois.

NEF, J. U. Llebig's Ann. d. Chem., 357, 218, 1907. 
on prolonged heating may thus introduce a not inconsiderable error. By aid of the curves of the rate of reduction of copper solutions elaborated by Peters, it can be established that the time decided upon for these determinations makes for greatest accuracy. As there is always an excess of copper in the solution, there is danger of effects inherent to the use of too dilute solutions; this can futhermore be easily regulated by properly preparing the sugar solution.

At the expiration of the requisite time the tube is at once removed from the boiling water-bath and rapidly cooled in cold water. In order to avoid cracking of the tubes it was found advisable, first, to wet the hot tube with a little cold tap-water with the hand for a moment, rather than plunge the tube into a bath of cold water. Thereafter the tube can be immersed safely. It is desirable that the cooling be done as rapidly as possible in order to avoid any resolution of cuprous oxide. The tube (the contents of which have been cooled to $15^{\circ}$ ) is then filled up to the graduation mark with distilled water which has been recently boiled in order to expel dissolved air, and the solution is thoroughly mixed, the tube being closed with a ground-glass stopper. The tubes are then placed in a centrifugal machine and revolved for 5 minutes. In the arrangement used the centrifugal head was fastened to the chuck of an electric motor of $1,700 \mathrm{r}$. p. m. After centrifuging for 5 minutes, the cuprous oxide, together with any other solid or suspended matter that may have been in the sugar solution, is thrown down in a compact mass in the bottom of the tube. Occasionally when a sugar solution was used containing considerable foreign matter, a small amount of cuprous oxide would settle on the sides of the tube. By shaking a little and centrifuging again this was readily clarified.

The obvious advantage of this procedure is that the cuprous oxide is in a small compact mass removed from access to the air, and the danger of resolution is thus avoided. A perfectly clear solution of the residual copper solution is obtained without the employment of any filter or transference to another vessel. The entire operation can be carried out in a very short time, and it remains then simply to determine the amount of unchanged copper left in solution. Sugar values derived from these data are based upon a standardization of the copper solutions by means of pure d-glucose, according to the data of Peters.

\section{THE DETERMINATION OF COPPER.}

Peters ${ }^{2}$ has worked out the conditions essential for obtaining accurate results of copper determination by means of the iodide method. The essential features of these findings have been applied to the present circumstances. Aliquot portions of the clear supernatant liquid in the tubes after centrifuging are removed, by means of a pipette, into $150 \mathrm{c}$. c. Erlenmeyer flasks. These are acidified with concentrated sulphuric acid. It is necessary

\footnotetext{
${ }^{1}$ Peters, A. W. The sources of error and the electrolytic standardization of the conditions of the fodide method of copper analyses. Jour. Amer. Chem. Soc., 34, 422-454, 1912.
} 
to have an excess of acid in order to obtain complete evolution of iodine, about 1 c. c. of the concentrated acid for each 10 c. c. of Fehling's solution. Where a copper solution other than Fehling's solution is used, the amount of acid added is naturally regulated to the concentration of the alkali. Too great an excess of acid is also to be avoided, as under such conditions iodine is liberated from potassium iodide in the presence of air. The flasks are then cooled to a temperature of not below $15^{\circ}$ nor above $20^{\circ}$. This is very important. After acidification and cooling, a solution of potassium iodide is added to each flask.

The reaction between copper sulphate and potassium iodide runs to completeness only when there is present a considerable excess of the iodide; hence it is essential that the iodide be high in comparison with the equivalent of copper present and also in relation to the final volume at the end of titration. A saturated solution is therefore used, and for each cubic centimeter of the original copper solution remaining, about 0.5 c. c. of the iodide solution is used. A solution of sodium iodide may also be used. The final volume of the titration mixture was usually 30 to $40 \mathrm{c}$. c.

The iodine which is evolved is titrated immediately with sodium thiosulphate, using a fresh solution of soluble starch (Merck) as indicator, which is added near the end of the titration. The concentration of the thiosulphate used can be adjusted according to the amount of copper to be determined, thus assuring the greatest accuracy under different conditions. The concentrations of the thiosulphate generally used were $\frac{\mathrm{N}}{20}$ and $\frac{\mathrm{N}}{50}$. It is, of course, essential that the thiosulphate produce a definite end-point in the titration.

The presence of the slightly yellowish cuprous iodide makes the recognition of the end-point a little more difficult than in a simple iodine titration. Toward the end of the titration the mixture assumes a very light brown or lavender color, which changes to a cream or very faint pink when the last drop is added. The end-point can be verified best by means of back titration with an iodine solution of the same concentration as the thiosulphate, which is a good precaution for very accurate work. Where there are a number of determinations to be made the various steps of measuring out the solutions, heating, centrifuging, cooling the copper solutions, and titrating can be so arranged that the operator is constantly busy and does not have to wait. An interval-timer with alarm attachment was found very helpful.

\section{THE STANDARDIZATION OF THE SOLUTIONS.}

The copper value of the thiosulphate solution is first determined by going through the entire procedure, heating, centrifuging, etc., without the addition of any sugar solution. In this way any self-reduction of the alkaline copper solution is also adjusted. The dilute solutions of sodium thiosulphate change in strength with time, but a stock solution of normal concentration changes only very slowly. The sugar value of the copper solution is determined by using a standard dextrose solution. The purest material was used 
for this, the dextrose supplied by the United States Bureau of Standards. The thiosulphate difference between the original standardized copper solution and the value found for the residual copper solution of a determination with sugar represents reduced copper from which can be calculated the

TABLE 4.

\begin{tabular}{|c|c|}
\hline $\begin{array}{c}\text { Sugar } \\
\text { present. }\end{array}$ & $\begin{array}{c}\text { Sugar } \\
\text { found. }\end{array}$ \\
\hline 0.0012 & 0.0012 \\
0.0009 & 0.0010 \\
0.0125 & 0.0125 \\
0.0120 & 0.0121 \\
0.0122 & 0.0122 \\
0.0299 & 0.0291 \\
0.0287 & 0.0290 \\
0.0481 & 0.0481 \\
0.0484 & 0.0486 \\
\hline
\end{tabular}
amount of sugar present. With some foresight, the sugar solutions to be determined can be so made up and the amount of copper solution as well as the concentration of the thiosulphate solution used can be so arranged as to fall within the range of the most accurate work. This can be determined by reference to the valuable table of Peters.

Experiments with a known sugar solution gave the results shown in table 4.

For very small quantities of sugar a more dilute copper solution can be used, though in this investigation the above copper solution was employed throughout. Thus a solution composed of 17.3 grams copper sulphate, 173 grams sodium citrate, 100 grams anhydrous sodium carbonate made up to 1,000 c. c. with water gave good results with small quantities of sugar. ${ }^{2}$

\section{THE ESTIMATION OF THE PENTOSE SUGARS.}

The accurate estimation of pentoses in mixtures with other sugars is associated with many difficulties. It may, therefore, not be amiss to give here briefly my experiences and conclusions regarding the methods of determination, as a great deal of time was spent in casting about for the proper means of estimation of this group of sugars. The method which has found most general application is that of Tollens, or one of the many slight modifications thereof. This method is based upon the property of the pentoses of their partial conversion into furfural by the action of mineral acids. The sugar mixture is distilled with hydrochloric acid (usually 12 per cent) and the furfural is collected in the distillate. After neutralization, the furfural can be determined in a number of ways; for instance, the gravimetric estimation of the phenylhydrazine or phloroglucine compounds; the titration with phenylhydrazine (aniline acetate as indicator) or with Fehling's solution; or the employment of an excess of phenylhydrazine and gasometric determination thereof; finally, the titrimetric method, in which an excess of sodium bisulphite is added to form the aldehyde addition compound and the unchanged bisulphite titrated with potassium permanganate." Careful examination has shown that all of these methods are

${ }^{3}$ Benedrct, S. R. A reagent for the detection of sugars. Jour. Biol. Chem., 5, 485487, 1909 .

'Joluss, A. Ueber ein neues Verfahren zu quantitativen Bestimmung der Pentosen. Zeit. f. Anal. Chem., 45, 196-204, 1906.

Maquenne, L. Les sucres et principaux dérives. Page 312, 1900. Paris.

Toluess, H. In Abderhalden's Biochemische Arbeitsmethoden, II, p. 99, 1910.

Dox, A. W., and G. P. Puarsance. A comparison of barbituric acld, thiobarbituric acid, and malonyguanidine as quantitative precipitants for furfural. Jour. Amer. Chem. Soc., 38, 2156-2164, 1916. 
open to serious error and are not reliable in a quantitative sense. Of special importance is the fact that 12 per cent hydrochloric acid is not without effect upon the furfural formed from the sugars. The amount of furfural also varies with the proportion of pentose in the original mixture; it is necessary to apply a special coefficient for all concentrations. In using the gravimetric method corrections, not altogether satisfactory, are to be applied for the solubility of the condensation product; on account of the instability of solutions of phenylhydrazine, this method is also associated with great inconvenience. Jolles's method of titration with sodium bisulphite has many advantages. However, as the proportion of pentose is sometimes very small and the furfural solution therefore exceedingly dilute, the method is by no means reliable. Other and perhaps better substances for the precipitation of furfural have been suggested; however, these do not solve the main difficulty.

It must also be borne in mind that pentoses are by no means the only substances that yield furfural on treatment with mineral acids. The hexoses, cane-sugar, and many other substances found in plants also form furfural under these conditions. Davis and Sawyer ${ }^{1}$ have shown that a mixture of 0.01 gram of arabinose plus 25 grams cane-sugar yielded 20 per cent more furfural than without the cane-sugar, while 0.02 gram arabinose plus 0.25 gram cane-sugar (the proportion usually present in plant extracts with which they were working) was 15 per cent high for pentose alone. Besides the hexose and disaccharides, furfural is also formed from starch, cellulose, and oxycellulose, as well as glucuronic acid. Furthermore, rhamnose and the methyl pentoses by the treatment with hydrochloric acid yield methyl-furfural, which by the usual methods can be easily mistaken for furfural.

In view of these facts it appears that the only reliable method of estimating pentoses must be based upon a separation of these sugars from other substances. At present the most practical way of doing this is by means of fermenting away the hexoses. A good culture of baker's yeast serves this purpose admirably, followed then by the procedure with alkaline copper solution already described. Experimental mixtures of l-arabinose or l-xylose with dextrose and cane-sugar showed that the latter were entirely removed, while the pentoses remained unaffected. The removal by distillation of the alcohol and other products formed in the fermentation is naturally essential. It is, of course, necessary to make certain that the non-fermentable residue is actually pentose and not some other non-fermentable sugar-for instance the interesting d-mannoketo-heptose described by La Forge, which is occasionally present in plants.

\footnotetext{
2 DAVIS, W. A., and G. C. SAWYER. The estimation of carbohydrates. The presence of free pentoses in plant extracts and the influence of other sugars on their estimation. Jour. Agr. Sci., 6, 406-412, 1915.
}

' LA Forge, F. B. D-mannoketoheptose, a new sugar from the avocado. Jour. Blol. Chem., 28, 511-522, 1917. 


\section{$\mathrm{CO}_{2}$ DETERMINATION.}

The method employed for determining the rate of $\mathrm{CO}_{2}$ emission was based upon the absorption of the carbon dioxid in a standard solution of barium hydroxide and titration of the unchanged base. The spines were first carefully removed from the cactus joints, weighed, and the cut ends were covered with a soft wax preparation to prevent a traumatic effect. The joints (usually 4 to 6 were employed) were placed in a desiccator provided with entrance and exit tubes. The desiccator was then hermetically sealed, and a light-proof cover placed thereover. This was immersed completely in a Freas electric water thermostat and the tubes were connected. The air was drawn through the apparatus by means of a specially devised electric pump and the pressure was regulated by a Palladin pressure regulator. The air passed first through a train of moist soda-lime, then through a 25-foot coil of glass tubing in the thermostat, into the respiration chamber; from there through a water-trap, and finally through the Meyer's tubes containing 125 c. c. of 0.1 normal barium hydroxide. A series of tubes was so arranged that the stream of air could be passed into a fresh tube without interrupting the experiment. A single tube collected the carbon dioxid for from 4 to 12 hours, and the experiment was allowed to run usually from 48 to 60 hours. The barium hydroxide together with the precipitated barium carbonate was poured into a narrow bottle, sealed, and the carbonate allowed to settle. After 24 hours aliquot portions of the clear solution were drawn off with a pipette and titrated with standard hydrochloric acid, using methyl orange as indicator. The amount of carbon dioxid per unit time can be easily calculated from the difference in strength of the barium hydroxide solution between the original and after the air from the plant had passed through. 


\section{THE CARBOHYDRATES OF THE CACTI.}

As has already been indicated, the cacti consist essentially of carbohydrate material. Compared to this the protein and fats are present in only small quantities, nor does the content in the plant of these latter substances

TABLE 5.

\begin{tabular}{|c|c|c|}
\hline & p. ct. & p. et. \\
\hline 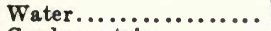 & 95.00 & 75.00 \\
\hline Crude protein........... & 0.50 & 1.00 \\
\hline $\begin{array}{l}\text { Carbohyrdrates hydroly. } \\
\text { zable with } 1 \text { per cent. }\end{array}$ & & \\
\hline 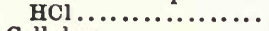 & 2.00 & 10.00 \\
\hline Cellulose ............. & 1.00 & 3.00 \\
\hline Crude fat............ & 0.25 & 0.50 \\
\hline 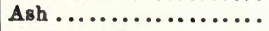 & 1.00 & 3.50 \\
\hline
\end{tabular}

vary appreciably by the change of conditions which so decidedly affect the carbohydrates. Roughly, the fresh material of the growing and mature joints is composed about as shown in table 5 .

Griffiths and Hare ${ }^{2}$ give the following analysis (table 6) of the ash of Opuntia phosacantha collected in the Santa Rita Mountains near Tucson, Arizona.

Individual plants show a considerable variation in all their components, depending upon their location and the general complex of environmental conditions.

The differences in carbohydrate-content and in the proportion of the various sugars between plants growing in the desert at Tueson and in the cool, humid climate of Carmel, California, is illustrated in the accompanying analyses of Opuntia phocacantha during September (table 8 ). The values are in per cent of the fresh weight. An analysis of the causes which induce these differences in composition will be taken up later.

TABLE 7.

\begin{tabular}{|c|c|c|}
\hline & Carmel. & 1. Tueson. \\
\hline Water..... & 91.15 & 80.34 \\
\hline Total sugars ........ & 2.61 & 4.30 \\
\hline Total polysaccharides..... & 1.94 & 3.50 \\
\hline Hexose polysaccharides... & 0.09 & 1.65 \\
\hline Disaccharides............. & 0.07 & 0.04 \\
\hline Hexoses................ & 0.52 & 0.06 \\
\hline Pentoses....$\ldots \ldots \ldots \ldots \ldots$ & 0.14 & 0.05 \\
\hline Pentosans................ & 1.70 & 1.74 \\
\hline
\end{tabular}

TABLE 6.

\begin{tabular}{|c|c|}
\hline 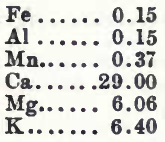 & 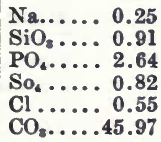 \\
\hline
\end{tabular}

For comparison analyses are given in table 8 of Opuntia phoacantha and of Opuntia versicolor, the latter being relatively free of the mucilaginous substances so profuse in the former.

It is evident that the major portion of the carbohydrates in these plants is in the form of polysaccharides and, as will be seen, the simpler sugars (monosaccharides and disaccharides) vary greatly with conditions, both in total content and in the proportion to the polysaccharides. A separation of the monosaccharides and disaccharides from the polysaccharides was obtained by means of thorough extraction with alcohol, the first two groups going completely into alcohol, while the latter are insoluble. The acid hydrolysis portion contained the hydrolyzed polysaccharides as well as the monosaccharides and disaccharides.

${ }^{1}$ Griffiths, D., and R. F. Hark. Prickly pear and other cactl as food for stock. Bull. New Mexico Agri. Expt. Station, 60, 15, 1906. 
The polysaccharides are present mainly in the form of starch and also as a mucilaginous substance of pentosan nature. As was explained in the section on methods of analysis, it was unfortunately impossible to determine the starch quantitatively. However, by means of the iodine reaction it became evident that the starch is present in the form of very numerous small starch grains. The Schimper chloral hydrate-iodine reagent proved the most satisfactory for the detection of these. From the variation in size and number of the starch grains a general idea could be gained as to the amount of this substance, though, of course, this is not an accurate measure and reveals only wide differences. It is, nevertheless, a reliable method for the detection of the presence of starch and can be used (to a measure) to indicate the fate of this material under the various experimental conditions hereinafter discussed.

TABLE 8.-Results of analyses of 0 . versicolor and 0 . phacacantha in percentages of the fresh and dry material.

\begin{tabular}{|c|c|c|c|c|}
\hline & \multicolumn{2}{|c|}{ Opuntia veraicolor. } & \multicolumn{2}{|c|}{ Opuntia phæacantha } \\
\hline & Fresh. & Dry. & Fresh. & Dry. \\
\hline 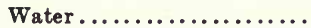 & 82.15 & & 78.70 & \\
\hline Total sugars............. & 1.97 & 11.05 & 3.53 & 16.60 \\
\hline Total polysaccharides...... & 1.50 & 8.40 & 3.22 & 15.15 \\
\hline Disaccharides and hexoses. & 0.33 & 1.87 & 0.24 & 1.10 \\
\hline Total hexose sugars........ & 1.59 & 8.92 & 1.81 & 8.50 \\
\hline Hexose polysaccharides..... & 1.29 & 7.20 & 1.59 & 7.44 \\
\hline Disaccharides............. & 0.15 & 0.86 & 0.08 & 0.36 \\
\hline 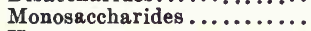 & 0.34 & 1.89 & 0.26 & 1.20 \\
\hline Hexose............... & 0.18 & 1.01 & 0.16 & 0.74 \\
\hline Total pentose ............ & 0.36 & 2.01 & 1.64 & 7.70 \\
\hline Pentose................. & 0.16 & 0.88 & 0.10 & 0.46 \\
\hline Pentosan ................ & 0.23 & 1.13 & 1.55 & 7.26 \\
\hline
\end{tabular}

The method adopted for the hydrolysis of the polysaccharides has already been described. In order to establish the nature of the carbohydrates in this hydrolyzed portion, the following procedure was carried out: The neutralized solution from the hydrolysis was evaporated down at reduced pressure. The residue, which contained a great deal of salt, was extracted with hot alcohol; this alcohol solution was evaporated at reduced pressure; the residue was dissolved in a very little water and a large quantity of alcohol added. Hereby more salt, as well as some gum, was thrown out of solution. This was repeated twice, after which the sugar residue from the evaporation of the alcohol showed but a trace of inorganic ash on ignition. This residue contained all the sugars present in the cactus, hydrolyzed to monosaccharides. It consisted of a clear brown gum. The aqueous solution was treated with a small quantity of lead acetate; the insoluble portion was filtered off; the lead in solution was precipitated with a slight excess of sulphuric acid, and the lead sulphate was filtered off. The sulphuric acid was then carefully removed by precipitation with barium hydroxide. After 
this treatment the sugar solution was somewhat lighter in color. It was subsequently treated with blood charcoal, which produced a light-yellow solution. From 200 grams of the dry cactus material 25.25 grams sugar gum were thus obtained. The solution was neutral towards litmus, reduced Fehling's solution strongly, and was dextro-rotatory, $[a]_{\mathrm{D}}^{20}=+25.60^{\circ}$.

The mixture was tested for the presence of galactose in the usual manner by treatment with nitric acid, sp. g. 1.15. No mucic acid, however, was obtained, which indicated the absence of galactose. The acid solution thus obtained from the oxidation with nitric acid was made alkaline with potassium carbonate and then treated with an excess of acetic acid. On standing, crystals of mono-potassium-saccharate separated out; this indicated the presence of glucose in the sugar mixture. The presence of fructose was established by means of the resorcin reaction.

A portion of the sugar mixture was fermented with pure baker's yeast, as has already been described. The residue from this process was a lightyellow gum. In solution this evolved furfural freely when heated with 12 per cent sulphuric acid, and gave an intense violet-red coloration with phlorogluzin. The reactions indicate the presence of a pentose sugar. The specific rotation in a $1 \mathrm{dm}$. tube was $[a]_{\mathrm{D}}^{25^{\circ}}=+22.1^{\circ}$ with $[a]=+2.05^{\circ}$ and 9.26 grams in 100 c. c. of water. ${ }^{2}$ The specific rotation of the solution did not change after standing 24 hours.

A portion of the sugar was treated with 2 parts of phenylhydrazine hydrochloride and 3 parts of crystalline sodium acetate and heated for an hour on the boiling water-bath. On cooling, a large quantity of bright yellow phenylosazon separated out. This was recrystallized from water and again from methyl alcohol. After drying in vacuum over sulphuric acid, this melted with gas evolution at $159^{\circ}$. $^{\text {. }}$

Another portion of the sugar mixture was treated in aqueous solution with an excess of bromine and powdered cadmium carbonate. After 24 hours the excess of bromine was driven off by heating on the water-bath, the mixture was filtered from unchanged $\mathrm{CdCO}_{3}$, and the filtrate was evaporated almost to dryness, and then 2 c. c. of alcohol was added thereto. After several days the characteristic crystals separated out of the double salt cadmium bromide xylonate,"

$$
\mathrm{Cd}\left(\mathrm{C}_{5} \mathrm{H}_{9} \mathrm{O}_{6}\right)_{2} \mathrm{CdBr}_{2} \cdot 2 \mathrm{H}_{2} \mathrm{O} \cdot[a]_{\mathrm{D}}^{20}=+6.9^{\circ} \text {. }
$$

From these results it is evident that the pentose sugar was l-xylose.

In the alcoholic extract of the dry plant material there would be present of the carbohydrates only the disaccharides and monosaccharides. The extract was prepared as has been previously described. The alcohol was distilled off at reduced pressure. The residue contained, besides the sugars, a large amount of chlorophyll and oil. To this was added water and some

${ }^{3}$ Maquenne, L. Les sucres et principaux dérives, p. $350 . \quad$ ' Ibid., p. 356.

"Bertrand, M. G. Recherches sur queiques dérives du xylose. Buil. Soc. Chim., III, $5,546,554,1891$.

NEF, J. U. Ann. d. Chem., 403, 253, 1913. 
blood charcoal and the mixture was heated on the water-bath. After such treatment the solution could be easily filtered and the filtrate was light brown in color. As has been described, the disaccharides in this mixture were determined by hydrolysis with hydrochloric acid and the determination of the cupric reducing value. The amount of maltose was exceedingly small, as was indicated by the fact that the difference was very little between solutions hydrolyzed with hydrochloric acid and with an invertase preparation. Equal amounts of the same sugar solution were treated, the one with hydrochloric acid in the manner already described, the other with a solution of invertase." Thus 100 c. c. of the solution hydrolyzed with acid required 22.20 c. c. copper solution, while the same amount treated with invertase took 23.30 c. c.

The presence of glucose and fructose in the alcoholic extract was also established, as in the case of the hydrolyzed portion. The mixture was fermented with baker's yeast in the usual manner in order to determine the nature of the pentose sugars. By treatment with phenylhydrazine-hydrochloride and sodium acetate, phenylxylosozone was obtained, which was purified by recrystallization from methyl alcohol. The specific rotation of the pure gum was found $[a]_{0}^{20}=+19.0^{\circ}$ to $+21.0^{\circ}$ from several preparations. Here, however, a difficulty was encountered. After the aqueous solution of the gum had stood for 24 hours it no longer showed the same specific rotation, but had dropped considerably, and in a few cases had even become levo-rotatory. In the cause of this phenomenon lay the substantiation of the theory of pentose formation which had been previously formulated and which is discussed in the section on the pentose sugars. This reduction of the specific rotation (as was finally established) was caused by glucuronic acid. The specific rotation of $l$-xylose is $[a]_{\mathrm{D}}^{20}=+20^{\circ}$, that of glucuronic lactone is given by Fischer as $[a]_{\mathrm{D}}^{20}=+19.1^{\circ}$.

A portion of the gum which showed this property of decreasing the specific rotation on standing in water solution was thoroughly dried by evaporating the water at reduced pressure from a boiling water-bath. The flask containing the gum was allowed to remain open for several months during the hot, dry summer. The gum was then dissolved in hot water and treated for 5 minutes with blood charcoal. After filtering, the water was again distilled off at reduced pressure. During this process small purewhite crystals separated out from the solution, and considerably more of the same substance crystallized out on cooling. This was filtered off and dried in vacuum over sulphuric acid. The substance showed the following properties: in water solution it reduced Fehling's solution strongly; when heated with 12 per cent sulphuric acid, furfural was liberated freely; it gave the red color with 2 per cent phloroglucine and hydrochloric acid;

${ }^{2}$ For this purpose the best invertase preparation was obtained by the process described by W. A. Davis, in The use of enzymes and special yeasts in carbohydrate analysis. Jour. Soc. Chem. Ind., 35, 201-240, 1916.

' Fischer, E., and O. Protr. Reduction der Zuckersaeure. Ber. d. deut. chem. Ges., 24, 523, 1891. 
10 c. c. of the solution with 1 to 2 drops of 15 per cent alphanaphthol and 3 c. c. concentrated sulphuric acid (Goldschmiedt reaction) gave the beautiful emerald green coloration characteristic of glucuronic acid. Special experiments with a large variety of substances apt to be found in plants showed that none of these except nitrates produce the green color. The absence of nitrates was established by the diphenylamine reaction. The hot aqueous solution was distinctly acid.

The substance under discussion melted sharply at $176^{\circ}$ and burned without leaving any ash. The specific rotation was $[a]_{\mathrm{D}}^{20}=+20.0^{\circ}$; that is, 1.25 grams in $100 \mathrm{co}$. c. in a $1 \mathrm{dm}$. tube gave [a] $=+0.25^{\circ}$. These properties establish the identity of this substance with glucuronic acid. After 28 hours the same solution showed a specific rotation of $[a]_{\mathrm{D}}^{20}=-3.2^{\circ}$.

It is a well-known property of the type of acid to which glucuronic acid belongs, that the lactones of the acids are usually strongly rotatory, but the free acids are only feebly so. Nef ${ }^{1}$ has worked out the conditions of equilibrium for $d$-mannonic acid. The normal $\beta$-lactone of $d$-mannonic acid in water solution has a specific rotation of $+111.1^{\circ}$. On standing at $20^{\circ}$ this solution changes, so that after 24 hours about 75 per cent of the lactone is converted into free d-mannonic acid and the rotation has dropped to $[a]_{\mathrm{D}}^{20}=+28^{\circ}$. The free $\mathrm{d}$-mannonic acid has a rotation of $[a]_{\mathrm{D}}^{20}=$ $-1.0^{\circ}$. From the data given it appears that glucuronic acid behaves in a similar manner and the reduction of the rotation is to be ascribed to the conversion of a portion of the dextro-rotatory lactone into the feebly levorotatory free acid.

This is the first time that glucuronio acid has been reported as a plant constituent. ${ }^{2}$ It is, however, probably a rather common component of plants, though its isolation is associated with considerable difficulty. Repeated attempts with the cacti have yielded only very small amounts. From 100 grams of the dry material, or about 500 grams of the fresh cactus, 0.1 gram of pure glucuronic lactone was obtained. The rôle of this substance in the carbohydrate metabolism will be discussed in the section on the origin and rôle of pentose sugars.

One of the most striking characteristics of the cacti is their high mucilage content. This property adds enormously to the difficulty of working with them and necessitates quite a different procedure of analytical and experimental technique from that commonly employed in work of this nature. Some of these peculiarities have already been discussed in the preceding chapter. The presence of mucilages or slimes has been very generally observed in succulent plants and many fleshy vegetable tissues, and is undoubtedly of great physiological importance. In fact, in one form or another, these colloidal substances are present in all plants to a greater or less extent. The exact nature of these substances has not been definitely

${ }^{1}$ NeF, J. U. Liebig's Ann. d. Chem., 403, 308, 1913.

2 Patuadr, W. Glucuronic acid, glucuronides and glyoxylic acid in plants. Chem. Abstracts, 11, 48, 351, 1917. 
established as yet, nor is there any satisfactory scheme of classification or identification, for different properties have been emphasized and varying results obtained from considering the morphological, functional, or chemical aspects. But from none of these aspects has a satisfactory or comprehensive view been gained of the nature or behavior of the mucilages. Hemicellulose, pectin, slime, and gum are names which have no definite or universal connotation either as to origin, structure, or chemical composition, although some efforts have been made for a system of classification." All of these substances are carbohydrates in which a number of simpler sugars are condensed to form highly complex compounds. It is very questionable whether any of these have ever been obtained in a pure state, and it seems very probable that in most cases mixtures of carbohydrates as well as of other substances have been dealt with. It has been known for some time that complex organic acids, such as gluconic acid and a number of gum acids, are also components, though their exact nature and the manner in which these are placed in the compounds are not definitely known. ${ }^{2}$ Furthermore, a small amount of proteins and other nitrogenous substances as well as inorganic salts usually are present as admixtures. All of these substances, hemicellulose, pectins, slimes, and gums, on hydroylsis with dilute acids, yield pentoses as well as hexoses, and they are therefore, in general, all pentosans.

It is indeed not surprising that such difficulty has been encountered in working out specific reactions for the detection of these substances, as they are so very much alike in general composition and undergo few characteristic reactions that could be utilized, for instance, for microchemical detection. Most of the work in this field has been carried out through microchemical means, and many of the tests employed for characterizing the various mucilages are based rather upon the presence of admixtures or of differences in the physical state than upon any definite chemical property. As a matter of tradition plant slimes and gums are differentiated in that under the former come all those polysaccharides which swell greatly in water, but show limited dispersion, and can not be drawn out in threads, while the gums are completely soluble in water." A much more rational system would be one based upon the nature of the products of hydrolysis and perhaps especially of the gum acids.

A very extensive literature has accumulated on the subject of these colloidal polysaccharides, dealing mostly, however, with the cytological aspect of their formation. The opinions run widely divergent, there is no uniformity of terms, and the subject in genéral is a most uncoordinated one. It is certain, however, that the various forms of mucilage are produced in a

1 Tunman,, O. Pflanzen microchemie. Pages 560-592, 1913. Berlin.

2 Czapek, F. Biochem. d. Pflanzen. 2d edition, p. 676 for literature, 1913.

Ruhland, W. Ueber Arabinbildung durch Bakterien und deren Beziehung zum gummi der Amygdaleen. Ber. d. deutsch. Bot. Ges., 24, 393-401, 1906.

Frank, A. B. Ueber die anatomische Bedeutung der vegetablischen Schleime. Jahr. 1. wiss. Bot., 5, 198, 1867. 
variety of ways, that this is not confined to the metamorphosis of the cell wall or middle lamella, and is often formed in the interior of the cell. The mucilages are undoubtedly used for a variety of purposes by the plant. The interest here is confined to their use as food material and their property of water imbibition.

In order to obtain the mucilage in as pure a condition as possible for further study, various procedures may be followed. A crude product can be obtained easily by first cutting up the plant material with a meat chopper and slowly pressing the mass through a muslin cloth. The portion which passes through is a thick, clear fluid. However, this latter material always contains reducing sugars and a little starch.

When the cactus joints are placed under a bell-jar in an atmosphere containing ether, chloroform, or acetone, after about 24 hours the heavy mucilage exudes from the cut surfaces of the joint. After several days a considerable quantity can thus be collected.

The most satisfactory results were obtained by cutting the cactus into pieces of about 1 c. c. These were placed in a quantity of distilled water equal to the volume of the pieces, and a few drops of formaldehyde were added. After 12 hours the mixture was poured onto a cheese-cloth filter and the liquid was allowed to drain off. The pieces of cactus were again placed in an equal quantity of fresh distilled water and after 12 hours the mass was again filtered. In order to free from small particles of tissue, the filtrate was passed through a very fine chiffon. The resulting filtrate was clear, colorless, and of about the consistency of fresh egg albumin. It had a decided acid reaction and, on heating, it browned and became thin, probably on account of hydrolysis. To the solution of the mucilage was added 3 times the volume of 95 per cent alcohol. This caused a white, gelatinous precipitate, which was rapidly filtered and washed. The amorphous, elastic mass was dried in vacuum over calcium chloride. Allowed to remain in the air, it became gray and finally dark brown. It dissolved in water to a mucilage with a small quantity of insoluble matter, probably coagulated proteins. The whole original precipitate was, therefore, again dissolved in water, filtered from the small amount of insoluble matter, precipitated again with alcohol, filtered, and dried in the same way. This material dissolved to a clear thick mucilage in water.

The solution exhibited still a slightly acid reaction. It showed a decided dextro-rotatory power, although the value was not constant in all preparations. It was impossible to salt out the mucilage from solution with ammonium sulphate or lead acetate. The free mucilage gave no definite coloration with iodine or with chlorzine iodine. The solution did not show the slightest reduction of Fehling's solution. It was, however, very easily hydrolyzed; after heating about 10 minutes with 0.5 per cent hydrochloric acid, the mixture reduced Fehling's solution very rapidly. A preparation of invertase (made as described above) was, however, absolutely without any effect after 48 hours, nor was the solution affected by pure baker's yeast. 
The hydrolysis of the mucilage with 1 per cent hydrochloric acid, and the quantitative determination of the sugars in the usual way, showed, that 34.1 per cent was d-glucose and 65.9 per cent was l-xylose.

The mucilage prepared as described above always contained a small amount of inorganic ash, from which it was impossible to free it by means of resolution and precipitation with alcohol. It is highly probable that this indicates the presence of a salt of an organic acid of the nature of glucuronic acid or some body akin to the gum acids.

As to the localization of the mucilage in the cactus and the visible changes associated with its formation, just a few observations were made. Under the microscope in fresh sections of the plant, the mucilage is most clearly visible in special, large cells, distributed throughout the tissue. These cells are two or three times the size of the rest of the cells and are filled with mucilage. When the fresh sections or larger pieces of the cactus are placed in distilled water the mucilage cells swell greatly and finally burst, allowing the mucilage to pass out. By cutting sections from material which had been previously well dehydrated in alcohol and then allowing water or 30 per cent alcohol to flow onto the sections on the microscopic slide, the process of swelling and eventual bursting of the cell can be closely followed. It is

TABLE 9.

\begin{tabular}{|c|c|c|}
\hline Substance. & Temp. & $\mathrm{D} \times \frac{\mathrm{cm}^{2}}{\text { sec. }} \cdot 10^{5}$ \\
\hline 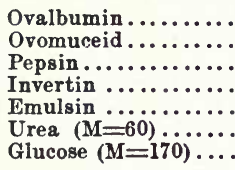 & $\begin{array}{r}15.5^{\circ} \\
7.5 \\
12.0 \\
16.6 \\
15.3 \\
18.0 \\
18.0\end{array}$ & $\begin{array}{l}0.063 \\
0.039 \\
0.073 \\
0.041 \\
0.042 \\
1.01 \\
0.57\end{array}$ \\
\hline
\end{tabular}

still an open question whether all the mucilage obtained comes from the bursting of the mucilage cells, as separate experiments have shown that the mucilage is capable of slowly passing through a parchment membrane. The behavior of these carbohydrates in colloidal solution has not been definitely established. The fact is very generally disregarded that

many emulsion colloids exhibit a decided diffusion, though this is, of course, much lower than most crystalloids. Thus, for example, Herzog ${ }^{2}$ obtained the accompanying constants (table 9), using a modification of Graham's method.

A case of the passage of gum arabic through living membranes exists where this substance is used to keep up the blood volume in animals and is found to be excreted in the urine." In the case of the flowing of the mucilage from the anesthetized plant it would seem that here the ether, chloroform, or acetone affect the membranes and cell walls so that there is a relatively rapid diffusion. Very recently Lloyd ${ }^{2}$ has devised methods of staining the mucilage cells in situ, showing in a beautiful way the distribution and behavior of these cells and their contents.

\footnotetext{
* Freunduch, H. Kapillarchemie. Page 402, 1909. Leipzig.

${ }^{2}$ Hogan, J. J., and Martin H. Frscher. Zur Theorie und Praxis der Transfusion. Kolloidchem. Beihefte, 3, 385-416, 1912.

HURwirz, P. H. Intravenous injections of colloidal solutions of Acacia in hemor rhage. Jour. Amer. Med. Assn., 68, 699-701, 1917.

'LioYd, F. E. Year Book, Carnegie Inst. Wash. 1918, p. 72.
} 
Of importance for the present consideration is the fact that the cells of the cactus under normal conditions contain many minute starch grains. However, in these mucilage cells the starch grains are either very few in number or absent entirely. When the microscopic sections or pieces of cactus $1 \mathrm{c}$. c. in size are washed, and then placed in water, the starch in the mucilage cells disappears within 18 hours. The starch in the other cells also disappears, though more slowly, 2 to 6 days, according to the material. During the process there is no loss of cane-sugar or reducing sugar from the plant into the water. In similar material, kept so that the water-content of the plant does not change greatly, the starch remains for several weeks, while, on the other hand, in the pieces of plant which are dehydrated, as, for instance, partially drying in the air or over calcium chloride, there is an increase in the starch in all cells. These facts are of importance in consideration of the carbohydrate equilibrium to be discussed later. The immediate source of formation of this mucilage has not been absolutely established, though from Lloyd's observations it would appear that the mucilage in some cases is a product of the cell wall. This is important in connection with the observations of MacDougal, Long, and Brown on the formation of lacunæ in the starved Bisnaga already referred to. The theory of the chemistry of mucilage and pentosan formation will be taken up under the chapter on respiration.

Finally, it may be of interest to note some experiments on the water-holding power of the mucilage, as this has often been considered the chief function of these substances

\begin{tabular}{|c|c|c|}
\hline Time. & Mucilage. & Water. \\
\hline $\begin{array}{l}1 \text { hour..... } \\
2 \text { hours.... } \\
3 \text { hours.... } \\
4 \text { hours.... }\end{array}$ & $\begin{array}{l}\left\{\begin{array}{l}2.4402 \\
2.4157 \\
3.1068 \\
3.0895\end{array}\right. \\
\left\{\begin{array}{l}4.6807 \\
4.6653\end{array}\right. \\
\left\{\begin{array}{l}5.2185 \\
5.3573\end{array}\right.\end{array}$ & $\begin{array}{l}2.4601 \\
2.4187 \\
3.1900 \\
3.2112 \\
5.2711 \\
4.5691 \\
5.5291 \\
5.5844\end{array}$ \\
\hline
\end{tabular}
in the succulent xerophytes. The mucilage had a specific gravity of 1.017 and was placed in wide-mouth weighing-bottles, of as nearly the same size as could be obtained. Comparisons were made with tap-water. The bottles were placed on a table 1 meter in diameter, which revolved once every 2 minutes. Weighings were made every hour. The difference, it will be noticed, is very slight until, of course, the evaporation is retarded through the formation of a slight film on the mucilage. 


\section{SEASONAL VARIATIONS IN THE CARBO- HYDRATE-CONTENT.}

The vegetation of the desert is exposed to extreme climatic variations. It is not any single factor that determines the features commonly ascribed to the desert, but rather a great complex of conditions. Thus, while scanty water-supply may be of greatest importance, it is not only the low average rainfall which makes for aridity, but the distribution of this precipitation throughout the year, as well as the nature of the soil and its drainage. To these must be added other conditions, such as the low relative humidity of the air and the high winds, all favorable conditions for water-loss, great diurnal variation in temperature, and intense sunlight.

TABLE 11 .

\begin{tabular}{|c|c|c||c|c|c|}
\hline Month. & 1916. & 1917. & Month. & 1916. & 1917. \\
\cline { 1 - 2 } & $\begin{array}{c}\text { Jan..... } \\
\text { 3.94 }\end{array}$ & $\mathbf{1 . 6 4}$ & July.... & $\mathbf{3 . 3 7}$ & $\mathbf{3 . 3 3}$ \\
Feb..... & $\mathbf{1 . 0 4}$ & $\mathbf{0 . 4 3}$ & Aug.... & $\mathbf{2 . 6 0}$ & $\mathbf{1 . 8 4}$ \\
Mar.... & $\mathbf{0 . 4 3}$ & $\mathbf{0 . 1 4}$ & Sept... & $\mathbf{1 . 1 8}$ & $\mathbf{1 . 1 9}$ \\
Apr.... & $\mathbf{0 . 6 8}$ & $\mathbf{0 . 0 1}$ & Oct.... & $\mathbf{1 . 4 8}$ & $\mathbf{0 . 0 0}$ \\
May.... & $\mathbf{0 . 0 0}$ & $\mathbf{0 . 7 3}$ & Nov.... & $\mathbf{0 . 0 0}$ & $\mathbf{0 . 0 0}$ \\
June... & trace & $\mathbf{0 . 0 5}$ & Dec.... & $\mathbf{0 . 7 8}$ & $\mathbf{0 . 0 0}$ \\
\hline
\end{tabular}

In table 11 is given the monthly precipitation during 1916 and 1917, the years in which these investigations were carried out.

In this consideration rainfall is, of course, of importance only as it replenishes the moisture of the soil as a supply for the plant.

Cannon ${ }^{2}$ has shown that the absorbing roots of these cacti lie at a depth of 10 to $20 \mathrm{~cm}$. It is, therefore, rather a consideration of soil moisture at this depth which is of immediate importance. Shreve ${ }^{3}$ has analyzed the relation between rainfall and soil moisture in the region from which the plants used in the present investigation were taken. There are two welldefined periods of rainfall during the year-the winter rains, December to March, and the summer rains, July to September. For the 34 years' rainfall record of Tucson, Shreve calculated the distribution of rainfall during the two rainy seasons and the intervening time. The percentages of the annual total are: winter 31.7 per cent; arid fore-summer 5.9 per cent; humid mid-summer 50.7 per cent; arid autumn 11.7 per cent. The seasonal variation of soil moisture during the year runs closely parallel to the significant periods of precipitation. The same conclusion may be arrived at from a study of the graphs prepared by Livingston ${ }^{3}$ of the relation of soil moisture to desert vegetation. This well-defined seasonal distribution of precipitation gives to the vegetation a very marked periodicity of activity.' Many of the reactions which have been observed as characteristic of these seasons have their origin in the more deep-seated metabolic activities in-

${ }^{2}$ Cannon, W. A. The root habits of desert plants. Carnegie Inst. Wash. Pub. No. $131,43-52,1911$.

2 Shreve, F. Rainfall as a determinant of soll moisture. The Plant Worid, 17, 9-26, 1914.

' Livingston, B. E. Relation of soll moisture to desert vegetation. Bot. Gaz., 50, 241-256, 1910.

- MacDougar, D. T. The course of the vegetative seasons in southern Arizona. The Plant World, 11, 189-201, 217-231, 237-249, 261-270, 1908. 
duced by changes in the external conditions. The driest portion of the year is the arid fore-summer (April to July) with no significant rainfall, high evaporation, and increasing temperature. The arid autumn (October and November) is as dry as the fore-summer, but, as will be seen, the effects of this season on the carbohydrate economy are somewhat moderated by the lower temperatures of the nights.

In table 12 are given the maximum and minimum temperatures of the locality in which the plants investigated grew.

TABLE 12.

\begin{tabular}{|c|c|c|c|c|c|c|c|c|c|}
\hline \multirow{2}{*}{ Month. } & \multicolumn{2}{|c|}{1916.} & \multicolumn{2}{|c|}{1917.} & \multirow{2}{*}{ Month. } & \multicolumn{2}{|c|}{1916.} & \multicolumn{2}{|c|}{1917.} \\
\hline & Max. & Min. & Max. & Min & & Max. & Min. & Max. & Min. \\
\hline & ${ }^{\circ} c$ & ${ }^{\circ} \mathrm{c}$. & ${ }^{\circ} \mathrm{c}$. & ${ }^{\circ} c$ & & ${ }^{\circ} \mathrm{c}$. & $\bullet$ & $\cdot c$. & ${ }^{\circ} c$. \\
\hline Jan............ & 24.1 & -3.2 & 22.8 & 0.2 & July........... & 43.8 & 17.7 & 32.2 & 15.6 \\
\hline Feb........... & 27.2 & -3.2 & 26.6 & 2.0 & Aug.... & 38.8 & 15.4 & 39.4 & 15.4 \\
\hline Mar........... & 33.2 & 0.3 & 28.1 & -0.9 & Sept..... & 38.7 & 16.4 & 39.7 & 16.4 \\
\hline Apr.......... & 32.5 & 3.6 & 34.2 & 2.1 & Oct.......... & 35.0 & 10.4 & 38.5 & 11.1 \\
\hline May.......... & 38.3 & 10.0 & 36.4 & 6.6 & Nov......... & 34.2 & 0.2 & 30.5 & 6.9 \\
\hline June ......... & 43.2 & 15.5 & 43.3 & 13.0 & Dec........... & 28.3 & -2.1 & 27.1 & 2.0 \\
\hline
\end{tabular}

More instructive than the air temperatures are the temperatures of the cactus joints themselves. Some results on this point have been obtained by McGee, and while these are not complete throughout the year, an idea can be obtained therefrom of the relation of air temperatures to that prevailing within the isolated plant. McGee summarizes his results as follows:

“(1) Joints of Opuntia blakeana in any position show temperatures above the air-temperature while exposed to solar radiation.

" (a) The temperatures of joints in an equatorial position rise steadily till $12 \mathrm{~m}$., then more slowly till $2 \mathrm{p}$. m., when the maximum is reached. After $2 \mathrm{p} . \mathrm{m}$. the temperatures steadily decline, becoming the same as that of the air soon after sunset and then falling slightly below the air-temperature and remaining so during the night.

" $(b)$ The temperatures of the joints in a meridional position rise sharply after sunrise, reaching a maximum about $11 \mathrm{a} . \mathrm{m}$. They then slowly drop until $12^{\mathrm{h}} 30^{\mathrm{m}} \mathrm{p}$. m., when they begin to rise again, reaching the second and highest maximum point about $4 \mathrm{p}$. m., after which they fall, at first slowly and then more abruptly, till sunset. After sunset the temperatures slowly fall below the air-temperature, as in the case of the other joints.

" (c) Computation of the area inclosed by each curve, using the 10-degree line as a base, shows that on March 9, 1916, the number of hour-degree units inclosed by the air-temperature curve was 134.6 ; by the curve of the joints in an equatorial position 211.5 hour-degree units; and by the curve of the joints in a meridional position 230.8 hour-degree units. Hence it will be seen that the temperature of the joints in a north-and-south position exceeds that in an east-and-west position by 19.3 hour-degree units and the air-temperature by 96.2 hour-degree units, and that in these joints the temperature effects would be accentuated. Similar computations show that on June 2, 1916, the number

${ }^{2}$ MCGEE, J. M. The effect of position upon temperature and dry weight of joints of Opuntia. Carnegie Inst. Wash. Year Book, 15, 73, 1916. 
of hour-degree units inclosed by the air-temperature curve was 273.0 ; by the curve of the equatorial joints 328.8 hour-degree units; and by the curve of the meridional joints 376.9 hour-degree units. The meridional joints exceed the equatorial joints by 48.1 hour-degree units of exposure, and the air-temperature by 103.9 hour-degree units.

" $(d)$ From the data just given, it will be seen that from sunrise to sunset the number of hour-degree units inclosed by the temperature curve for a June day is very much greater than the number for a March day, and that the increase is greater in the case of the meridional joints than in that of the equatorial joints. The numbers of hour-degree units inclosed by the curves of the meridional joints for March 9 and for June 2, 1916, differ by 146.1 hourdegree units; the numbers inclosed by the curves of the equatorial joints differ by $11 \% .3$ hour-degree units; and the numbers inclosed by the curves of the airtemperatures differ by 138.4 hour-degree units.

"(e) The loss of weight from February 28, 1916, to April 5, 1916, of joints m a meridional position was 18.59 per cent, the loss of weight of joints in an equatorial position was 16.30 per cent, and that of shaded joints was 5.79 per cent, whereas the loss of weight from May 15 to June 28, 1916, of joints in a meridional position was 24.70 per cent, that of joints in an equatorial position was 26.23 per cent, and that of shaded joints was 23.32 per cent. The dry weight of joints similar to those used in these observations was 16.15 per cent on March 8, 1916, and had increased to 17.70 per cent on April 5, an increase of 1.55 per cent; whereas the dry weight of joints on May 17 was 29.37 per cent and had increased 36.38 per cent on July 10, 1916, an increase of 5.01 per cent.

" $(f)$ The maximum temperatures reached by joints growing under natural conditions were found to be $53.0^{\circ} \mathrm{C}$. on July 24 , and $55.0^{\circ} \mathrm{C}$. on July $25,1916$. These temperatures are higher by several degrees than those reported by Askenasy or Ursprung for succulent plants such as Opuntia, and it is interesting to note that Pfeffer states that ' Prolonged exposure to a temperature of from $45^{\circ}$ C. to $46^{\circ}$ C. kills most Phanerogams' (Pfeffer's Plant Physiology, vol 11, p. 226)."

It is evident from these results that the conditions of temperature are accentuated within the plant during the arid fore-summer with its clear days of intensive insolation. During the seasons of rain, there is, of course, relatively much less direct insolation on account of cloudy and overcast weather and this would result in correspondingly lower temperatures of the plant.

To summarize, then, the period December to March is characterized by the winter rains and low temperatures; the period April through June by great desiccation and high temperatures; in July and August, the humid mid-summer, there occur heavy rains and slightly lower temperatures, while in part of September, October, and November, the arid autumn, there is little significant rainfall and the temperature, while still high in the beginning of the period, moderates in October and November. The limits of these periods may, of course, extend in either direction and vary somewhat in different years.

In this section are given the results of a study of the seasonal variation in carbohydrate-content of Opuntia phoeacantha with a view to establishing the nature and rate of its metabolic rearrangements and disintegration as affected by the climatic conditions just discussed. For each series of analyses the joints of the same age were taken from a single large, healthy 
plant. It was found that individual plants vary considerably in their sugarcontent, although the general course of the economy runs parallel. The methods of the preparation of the material and analysis have already been described. In table 13 are given the results of analyses of Opuntia phoracantha during the months indicated in 1916.

TABLE 13.-Seasonal variation in carbohydrate-content. Analyses expressed in per cent of the dry material.

\begin{tabular}{|c|c|c|c|c|c|c|c|}
\hline & June 10. & July 5. & July 81. & Sept. 20. & Oct. 27. & Nor. 15. & Dec. 20. \\
\hline Water........ & 76.59 & 63.62 & 83.55 & 80.34 & 79.70 & 76.95 & 69.90 \\
\hline Total sugars............ & 32.62 & 20.03 & 13.24 & 18.44 & 20.90 & 18.75 & 18.95 \\
\hline Total polysaccharides... & 31.71 & 19.35 & 12.30 & 17.80 & 19.05 & 16.82 & 16.73 \\
\hline Hexose polysaccharides...... & 16.05 & 9.72 & 8.16 & 8.40 & 8.86 & 13.45 & 6.04 \\
\hline Total hexose sugars........... & 17.67 & 10.45 & 8.60 & 8.83 & 9.32 & 5.50 & 7.90 \\
\hline Hexoses plus disaccharides... & 0.81 & 0.80 & 0.80 & 0.49 & 0.48 & 1.15 & 2.02 \\
\hline Disaccharides............... & 0.36 & 0.18 & 0.14 & 0.20 & 0.10 & 0.39 & 1.04 \\
\hline Hexoses................... & 0.45 & 0.62 & 0.66 & 0.29 & 0.38 & 0.76 & 0.98 \\
\hline Total pentose sugars.............. & 14.95 & 9.26 & 4.39 & 9.08 & 10.95 & 12.50 & 10.45 \\
\hline Pentosans $. . \ldots \ldots \ldots, \ldots, \ldots$ & 14.81 & 0.04 & 4.14 & 8.86 & 10.47 & 11.35 & 10.10 \\
\hline Pentoses................. & 0.14 & 0.20 & 0.25 & 0.24 & 0.48 & 0.82 & 0.35 \\
\hline Monosaccharides.............. & 0.59 & 0.82 & 0.91 & 0.53 & 0.86 & 1.58 & 1.33 \\
\hline
\end{tabular}

Although the values given in table 13 indicate the nature of the changes in the various sugars under different external conditions, the facts are more clearly expressed as proportional values. The factor of the synthesis of the carbohydrates is an exceedingly complex one and can not be dealt with here, so that variations in total sugar-content are of little significance for the present purpose. The influence of the external conditions on the proportional values will be brought out more clearly in the section dealing with the special influence of water-content and temperature where the factor of synthesis plays no rôle, as the plants were left in the dark and at constant temperature.

In table 14 the results of table 13 are given, calculated as proportional values.

TABLE 14.-Proportional values of the carbohydrate-content of Opuntia phaacantha on the basis of the analysis of the dry material.

\begin{tabular}{|c|c|c|c|c|c|c|c|}
\hline & June 10. & July 5. & July 31. & Sept.20. & Oct. 27. & Nov. 15. & Dec. 20. \\
\hline$\frac{\text { Total polysaccharides }}{\text { Total sugars }}$. & 0.973 & 0.960 & 0.930 & 0.965 & 0.955 & 0.897 & 0.888 \\
\hline$\frac{\text { Monosaccharides }}{\text { Total polysaccharides }} \ldots \ldots \ldots \ldots \ldots$ & .019 & .042 & .074 & .039 & .043 & .084 & .070 \\
\hline$\frac{\text { Hexoses plus disaccharides }}{\text { Hexose polysaccharides }} \ldots \ldots$ & .051 & .082 & .098 & .058 & .054 & .085 & .335 \\
\hline$\frac{\text { Hexoses }}{\text { Hexose polysaccharides }} \ldots \ldots \ldots \ldots$ & .025 & .064 & .081 & .035 & .043 & .056 & .162 \\
\hline$\frac{\text { Total pentose }}{\text { Total sugars }} \ldots \ldots \ldots \ldots \ldots \ldots \ldots \ldots$ & .459 & .462 & .332 & .492 & .524 & .667 & .551 \\
\hline
\end{tabular}


This series runs from the arid fore-summer through the humid midsummer, the arid autumn, and into the beginning of winter with its higher rainfall and lower temperatures. What, then, are the changes which occur in the carbohydrate-content of these cacti when exposed to these decided changes in the environment? The values in tables 13 and 14 for June represent the effect of extreme desiccation and high temperatures; there fell only 0.68 inch of rain in the preceding April, none in May, and but a trace in June. It is evident that here the polysaccharides, both in actual amount and in the proportion to the other sugar groups, are high. The monosaccharides, on the other hand, by the same criteria, are low, while the pentosans and total pentoses are relatively high. In the analysis of July 5 the desiccation has proceeded, though this was taken immediately after the first rain and the effect on the carbohydrates is hardly perceptible. By July 31, the next analysis, 3.37 inches of rain have fallen: the water-con-

TABLX 15.-Seasonal variation in carbohydrate-content. Analyses expressed in percentage of the dry material.

\begin{tabular}{|c|c|c|c|c|c|c|c|c|}
\hline & Jan. 11. & Feb. 16 & 3. Mar.17 & Apr. 25. & 5. May 22. & Oct. $\mathbf{3 1}$ & Dec. 19. & Jan. 24 \\
\hline 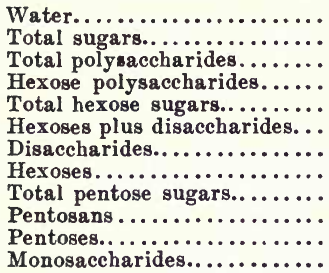 & \begin{tabular}{|r|}
77.80 \\
19.10 \\
15.10 \\
10.45 \\
14.95 \\
3.86 \\
1.27 \\
2.59 \\
4.73 \\
4.40 \\
0.43 \\
3.02
\end{tabular} & $\begin{array}{r}77.90 \\
21.32 \\
15.80 \\
9.98 \\
14.90 \\
5.30 \\
1.74 \\
3.56 \\
6.07 \\
5.51 \\
0.55 \\
4.11\end{array}$ & $\begin{array}{l}80.50 \\
28.05 \\
20.10 \\
15.00 \\
22.16 \\
7.80 \\
0.93 \\
6.87 \\
5.55 \\
4.75 \\
0.82 \\
7.69\end{array}$ & \begin{tabular}{|r|}
75.70 \\
32.40 \\
29.84 \\
20.65 \\
22.70 \\
2.27 \\
0.41 \\
1.86 \\
9.15 \\
8.68 \\
0.48 \\
2.34
\end{tabular} & \begin{tabular}{|r|}
74.75 \\
30.15 \\
28.38 \\
15.47 \\
17.08 \\
0.76 \\
0.48 \\
0.28 \\
12.34 \\
12.17 \\
0.16 \\
0.44
\end{tabular} & \begin{tabular}{|l}
72.75 \\
26.40 \\
24.95 \\
15.30 \\
16.61 \\
1.31 \\
0.48 \\
0.83 \\
9.79 \\
9.65 \\
0.14 \\
0.97
\end{tabular} & $\begin{array}{r}66.75 \\
26.88 \\
21.14 \\
20.76 \\
25.12 \\
4.36 \\
1.88 \\
2.48 \\
1.76 \\
1.38 \\
0.38 \\
2.86\end{array}$ & $\begin{array}{r}66.10 \\
25.90 \\
21.35 \\
16.92 \\
21.40 \\
4.48 \\
2.18 \\
2.30 \\
4.50 \\
4.23 \\
0.27 \\
2.45\end{array}$ \\
\hline
\end{tabular}

tent is decidedly higher, though the temperatures continue high. The polysaccharides, both in actual amount and in proportion to the other sugar groups, have fallen. The monosaccharides and the hexoses are higher than during the dry periods. The pentosans show a marked decrease with the increased water-content. The September analysis represents the beginning of the arid autumn, there has been little rain, and the water-content has dropped. The total polysaccharides have again risen, also in proportion to the other sugars; the monosaccharides show a corresponding drop, and the pentosans have also risen. During the following months, October, November, and December, the drought continues, with corresponding low watercontent. The amount of the polysaccharides again rises during October. In November and December, however, in spite of the continued dryness, the relative values again decrease. So also the monosaccharides, while very low in October, increase in November and December. The pentosans show a constant increase until they drop slightly in December. It appears, therefore, that the effects of the drought are first moderated and then counteracted by the lower temperatures prevailing during November and December. 
The proportional values calculated from the results in table 15 are given in table 16.

Further light on these phenomena can be gained from a study of tables 15 and 16, giving the results of analyses of joints from the same plant during 1917. These cover the periods beginning with the humid winter, then the arid fore-summer, the arid autumn, and finally again the humid winter. The humid summer is not included, as this period is covered in the preceding series. The water-content increases during January, February, and March, though the rainfall was relatively light for this season. Although the total amount of sugar present increases, the relative amounts of the polysaccharides decrease with increasing water-content. The simpler sugars, hexoses or monosaccharides, show again a corresponding increase with increased water-content, both in actual amount and in proportion to

TABLE 16.-Proportional values of the carbohydrate-content of Opuntia phaacantha on the basis of the analysis of dry material.

\begin{tabular}{|c|c|c|c|c|c|c|c|c|}
\hline & Jan. 11. & F Feb. 16. & Mar. 17. & Apr. 25. & May 22. & Oet. 31. & Dee. 19. & Jan. 24. \\
\hline$\frac{\text { Total polysaccharides }}{\text { Total sugars }}$. & 0.791 & 0.741 & 0.716 & 0.907 & 0.942 & 0.945 & 0.787 & 0.821 \\
\hline$\frac{\text { Monosaccharides }}{\text { Total polysaccharides }} \cdots \cdots$ & .200 & .260 & .380 & .078 & .016 & .039 & .135 & .115 \\
\hline$\frac{\text { Hexoses plus disaccharides }}{\text { Hexose polysaccharides }}$. & .202 & .249 & .278 & .070 & .025 & .049 & .162 & .173 \\
\hline$\frac{\text { Hexoses }}{\text { Hexose polysaccharides }} \cdots .$. & .248 & .357 & .457 & .090 & .018 & .054 & .195 & .136 \\
\hline$\frac{\text { Total pentose }}{\text { Total sugars }} \ldots \ldots \ldots \ldots \ldots$ & .248 & .283 & .198 & .283 & .409 & .371 & .066 & .174 \\
\hline
\end{tabular}

the other sugar groups. The monosaccharides thus reach their maximum in March at a time when the growth activity of the plant commences. The pentose sugars show a relative decrease with the higher water-content. The period from March 17 to April 25 was an exceedingly dry one, the water-content has dropped, and although the total sugar-content has increased, the proportion of these sugars is very different from what it was at the end of the winter rainy season. The polysaccharides have again increased in every respect, the monosaccharides have decreased very decidedly, and the pentosans have increased markedly. During May the arid fore-summer conditions persist, with increased temperatures, and the condition of the carbohydrates as described for April are accentuated; very marked is the increase in pentosans. The conditions from June to September are a repetition of what has already been described for these seasons. The arid autumn brings again the high polysaccharide and low monosaccharide content with abundance of pentosans. With the falling temperatures and rain of winter, the reverse conditions again set in. (The total pentose sugar and pentosan value for December is not reliable, as it 
was discovered that an impure culture of yeast had been used for the fermentation.)

To summarize, then, the observations of the seasonal variations in carbohydrate-content:

Low water-content and high temperatures are associated with: (1) increase of polysaccharides; (2) decrease of monosaccharides; (3) increase of pentosans.

High water-content and lower temperatures are associated with: decrease of polysaccharides; (2) increase of monosaccharides; (3) decrease of pentosans.

It remains, then, to determine experimentally whether under controlled conditions such a shifting of the relative amounts of the various sugars actually takes place, and to what extent the two factors, water-content and temperature, contribute to such an action. Before turning to these experiments, it may be of some value to consider briefly some other observations pertinent to the general problem.

During March the new joints develop; these grow quite rapidly, so that within about one month they have attained their full size of 100 to $125 \mathrm{~cm}$. Apparently the young joints become autonomous very early in their development; when cut from the plant with but a very small portion of the parent joint, and placed with the base in tap-water, the young joints grow to full size and develop normally. Comparative analyses of young and parent joints are given in table 17. The first young joints (March 27, 1916) were 2 to $4 \mathrm{~cm}$., about 12 days old.

The young joints are very high in total sugars compared with the parent joints. Although the young joints have attained almost their full size by April 16, the percentage of cellulose has not increased and the joints are very tender, while in the old joints the cellulose is considerably higher, due to the development of walls and vessels. The inorganic constituents increase rapidly in the young joints. It is a striking fact that although the young joints have a higher total sugar-content than the parent joints, both the actual percentages and the proportional values of the monosaccharides are lower in the former. This is probably due to the high respiratory activity of the young joints. It is evident that the amount of pentose sugar is considerable, even in the very early stages of development, although the proportion to the total sugars is somewhat higher in the old joints.

It has commonly been affirmed that the pentosans accumulate in the older portions of a plant. This contention is based upon results obtained from the older methods of analyses, in which the plant material was treated with hydrochloric acid of such concentrations as to affect also the cellulose. As by this treatment cellulose also yields furfural, the formation of which is taken as a measure of the pentosan content, it is not surprising that the older portions of a plant, which are very generally richer in cellulose, should give results indicating large quantities of pentosans. That the older parts of plants are not always richer in pentosans than the portions more recently formed is shown by results of analyses of the following two sets of joints. 
TABLE 17.-Carbohydrate-content of young and parent joints of Opuntia phaacantha. Values given in percentages of the dry material.

\begin{tabular}{|c|c|c|c|c|c|c|}
\hline & Mar. 27 & 1916. & Apr & & Apr & 16. \\
\hline & Young. & Parent. & Young. & Parent. & Young. & Parent. \\
\hline Water..... & 88.65 & 81.38 & 87.30 & 81.10 & 88.40 & 81.78 \\
\hline Total sugars... & 31.22 & 22.44 & 33.60 & 20.18 & 36.68 & 28.40 \\
\hline Monosaccharides ................ & 2.74 & 3.22 & 3.37 & 5.32 & 4.43 & 5.00 \\
\hline Total pentose................... & 6.23 & 5.21 & 9.57 & 10.04 & 7.48 & 5.23 \\
\hline Cellulose..................... & 7.24 & 11.35 & 6.96 & 11.86 & 7.22 & 12.08 \\
\hline 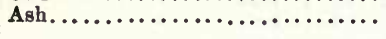 & 6.88 & 12.60 & 7.51 & 14.40 & 10.71 & 13.95 \\
\hline Monosaccharides & 0.088 & 0.144 & 0.100 & 0.264 & 0.121 & 0.176 \\
\hline Total sugars & & & & & & \\
\hline$\frac{\text { Total pentoses }}{\text { Total sugars }} \ldots \ldots \ldots \ldots \ldots \ldots \ldots$ & 0.199 & 0.232 & 0.285 & 0.495 & 0.204 & 0.185 \\
\hline
\end{tabular}

The analyses were made in October. From the same plant were taken a number of joints formed in the spring of the year 1916, as well as a number of joints which had been formed three years or more previous, as was indicated by their position on the plant; $i$. e., the old joints were fourth in a row counting from the youngest joints. The results are given in table 18.

TABLE 18.-Carbohydrate-content of young and old joints of Opuntia phoacantha, expressed in percentages of dry material.

\begin{tabular}{|c|c|c|c|c|c|}
\hline & \multicolumn{2}{|c|}{ Joint formed in } & & \multicolumn{2}{|c|}{ Joint formed in } \\
\hline & 1916. & 1913. & & 1916. & 1913. \\
\hline Water....... & 82.15 & 79.89 & Hexoses......... & 1.27 & 1.22 \\
\hline Total sugars ............... & 20.45 & 16.60 & Total pentose...... & 9.78 & 7.10 \\
\hline Total polysaccharides..... & 17.94 & 14.45 & 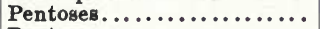 & 0.23 & 0.40 \\
\hline Total hexose sugars........ & 10.10 & 9.10 & Pentosans................. & 9.55 & 6.70 \\
\hline Disaccharides............. & 1.18 & 0.51 & Cellulose... & 9.10 & 10.26 \\
\hline
\end{tabular}

Although the cellulose is higher, it is noticeable that the pentosan content is lower in the old joints. This was found in a number of other analyses as well. In general, the carbohydrate content of the younger joints is higher than in older ones, though the proportion of the various groups of sugars to the total sugars is about the same in the two sets of joints.

As yet it has not been possible to obtain entirely satisfactory results on the photosynthetic activity of the mature cacti. The complexity of the gas interchange and the influence thereon of the high acidity as described by Richards, has already been alluded to. The diurnal variation in carbohydrate content is slight in these plants. In table 19 are given the results of analyses made before and after insolation.

The loss of water during the night, resulting in an increase of the total dry weight, is evident. This is a phenomenon commonly observed in these plants. The increase of the disaccharides and monosaccharides, both in actual amount and in the proportion to the polysaccharides, is considerable. 
How much of this increase is due directly to the photosynthetic activity it is difficult to establish, as the independent influence of the changed watercontent on the proportion of simple sugars to polysaccharides in all probability comes into play. This will be discussed in the following section.

TABLE 19.-Variation in carbohydrate-content of Opuntia phoacantha during 24 hours. Results in percentages of the dry material.

\begin{tabular}{|c|c|c|c|}
\hline & 5 p. m. & $7{ }^{7} 30^{m}$ a. m. & 5 p. m. \\
\hline 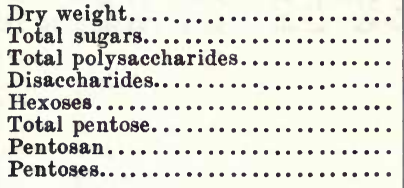 & $\begin{array}{r}17.58 \\
16.18 \\
14.40 \\
0.58 \\
1.06 \\
8.60 \\
8.34 \\
0.26\end{array}$ & $\begin{array}{r}18.80 \\
19.40 \\
18.15 \\
0.34 \\
0.83 \\
8.33 \\
8.22 \\
0.20\end{array}$ & $\begin{array}{r}17.85 \\
20.45 \\
17.94 \\
1.18 \\
1.27 \\
9.78 \\
8.55 \\
0.23\end{array}$ \\
\hline$\frac{\text { Monosaccharides }}{\text { Total polysaccharides }} \cdots \ldots \ldots \ldots \ldots$ & 0.092 & 0.057 & 0.084 \\
\hline
\end{tabular}

In perusing the results of the seasonal variation in carbohydrate-content, of significance is the fact that the greatest activity of the plant comes at the time when the content of monosaccharides and disaccharides is highest. The vegetative shoots and flowers are developed in March, and it is at this time that the general process of inversion has reached its maximum. This process of carbohydrate inversion, taking place in the plant as a consequence of low temperature and ample water-supply, can be prevented by artificially keeping the plant either at a higher temperature or with a low water-supply. In neither case does the plant then develop vegetative or flower buds at the regular season. Thus, a number of plants of Opuntia phoeacantha were put in soil, and so placed out of doors that they obtained only a minimum amount of rainfall during the winter rainy season. These plants produced no flowers or vegetative shoots. Other plants similarly treated, but allowed to receive the normal rainfall, developed normally in the spring. Again, a number of plants were kept at higher temperatures than normal by covering them with glass cages. Through the "trapping " of the solar radiation thus effected, the temperatures within the cages were decidedly higher than the surrounding air. The cages were not large enough to prevent the rain from reaching the extensive root system. None of the plants thus treated produced either flowers or new joints in the spring. Similarly, plants which had been kept in glass cages artificially heated during the winter showed the same behavior. It can not be maintained, of course, that the accumulation of relatively large quantities of the simpler sugars is the only prerequisite to growth. It is not possible to indicate any single factor or substance to which can be ascribed such properties, nor is such a state of affairs likely to exist. Physiological activity in all probability represents the "resultant of forces " and a supply of simple sugars above that required for the normal respiratory activity seems to be one of the factors necessary for growth. 


\section{EFFECT OF WATER ON THE CARBOHYDRATE- CONTENT.}

It has already been pointed out that the platyopuntias respond quickly to available water, and that although the rate of water-loss is low, the plant is capable of undergoing relatively great fluctuations in its water-content. Under natural conditions these plants are exposed alternately to conditions of extreme drought and to abundant water-supply. The changes in the carbohydrate-content occur especially at the times of the well-defined periods of rainfall. Low temperatures influence the carbohydrates in the same manner as high water-content does; both result in a condition of general inversion. It was necessary, therefore, to determine independently the influence of changes in water-content on the carbohydrate equilibrium. For

TABLE 20.-Loss of weight of joints of Opuntia phoacantha in a humid atmosphere.

\begin{tabular}{|c|c|c|c|c|}
\hline Date. & Days. & Weight. & $\begin{array}{l}\text { Loss in } \\
\text { grams. }\end{array}$ & $\begin{array}{l}\text { Percentage } \\
\text { of loss. }\end{array}$ \\
\hline $\begin{array}{l}\text { Feb. } 21 \ldots \ldots \ldots \\
\text { Mar. } 1 \ldots \ldots \ldots \\
\text { Mar. } 12 \ldots \ldots \ldots \\
\text { Apr. } 3 \ldots \ldots \ldots \\
\text { Apr. } 6 \ldots \ldots \ldots\end{array}$ & $\begin{array}{r}\cdots 8 \\
19 \\
41 \\
44\end{array}$ & $\begin{array}{l}397 \\
396 \\
393 \\
391 \\
391\end{array}$ & $\begin{array}{r}\cdots \\
i \\
4 \\
6 \\
6\end{array}$ & $\begin{array}{l}0.4 \\
1.0 \\
1.5 \\
1.5\end{array}$ \\
\hline
\end{tabular}

TABLE 21.-Loss of weight of joints of Opuntia phaacantha in a dry atmosphere.

\begin{tabular}{|c|c|c|c|c|}
\hline Date. & Days. & Weight. & $\begin{array}{l}\text { Loss in } \\
\text { grams. }\end{array}$ & $\begin{array}{l}\text { Percentage } \\
\text { of loss. }\end{array}$ \\
\hline Feb. 21 . & & 365 & & \\
\hline Mar. $1 . .$. & 8 & 340 & 25 & 6.8 \\
\hline Mar. 5... & 12 & 330 & 35 & 9.6 \\
\hline Mar. $12 .$. & 19 & 320 & 45 & 12.3 \\
\hline Apr. $3 .$. & 41 & 297 & 68 & 18.6 \\
\hline Apr. $6 \ldots$ & 44 & 294 & 71 & 19.5 \\
\hline
\end{tabular}

this purpose a number of healthy joints of the same age were cut from the same plant. These were divided into three sets of seven joints each; one set was analyzed immediately, another set was placed under a large bell-jar over a dish of water, and the third set was placed under a similar bell-jar over a dish containing anhydrous calcium chloride. A slow stream of moist and dry air respectively was passed through the bell-jars. These were kept in the dark in a constant-temperature chamber at $20^{\circ} \mathrm{C}$. The experiment ran for 44 days; at intervals the plants were weighed to follow the loss of weight. In table 20 the results of these weighings are given.

Thus the joints which were left in a humid atmosphere lost in 44 days only 6 grams or 1.5 per cent of their total weight. At the end of this time the water-content had fallen from 81.5 to 81.2 per cent. The joints kept over calcium chloride lost much more water, as is shown in table 21. 
After 44 days of desiccation these plants lost 71 grams or 19.5 per cent of their original weight. At the end of the experiment the water-content was 77.0 per cent, which, of course, does not equal the extreme desiccation the

TABLE 22.-Carbohydrate-content of Opuntia phacacantha before and after 44 days in the dark at $20^{\circ} \mathrm{C}$. in percentages of the dry material.

\begin{tabular}{|c|c|c|c|c|c|c|c|}
\hline & $\begin{array}{c}\text { Origi- } \\
\text { nal } \\
\text { condi- } \\
\text { tion. }\end{array}$ & $\begin{array}{l}\text { Kept } \\
\text { dry. }\end{array}$ & $\begin{array}{c}\text { Kept } \\
\text { moist. }\end{array}$ & & $\begin{array}{c}\text { Origi- } \\
\text { nal } \\
\text { condi. } \\
\text { tion. }\end{array}$ & $\begin{array}{c}\text { Kept } \\
\text { dry. }\end{array}$ & $\begin{array}{c}\text { Kept } \\
\text { moist. }\end{array}$ \\
\hline 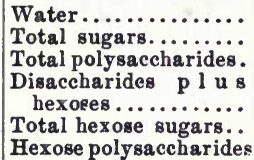 & $\begin{array}{r}81.50 \\
26.83 \\
19.02 \\
7.21 \\
25.13 \\
17.92\end{array}$ & $\begin{array}{r}77.00 \\
22.08 \\
19.40 \\
\\
2.44 \\
20.23 \\
17.79\end{array}$ & $\begin{array}{r}81.20 \\
23.76 \\
20.47 \\
\\
2.88 \\
22.39 \\
19.52\end{array}$ & $\begin{array}{l}\text { Disaccharides....... } \\
\text { Hexoses............. } \\
\text { Monosaccharides..... } \\
\text { Total pentoses ....... } \\
\text { Pentoses............. } \\
\text { Pentosans......... }\end{array}$ & $\begin{array}{l}3.47 \\
3.47 \\
4.34 \\
1.70 \\
1.60 \\
1.10\end{array}$ & $\begin{array}{l}0.60 \\
1.84 \\
2.08 \\
1.85 \\
0.24 \\
1.61\end{array}$ & $\begin{array}{l}0.58 \\
2.30 \\
2.71 \\
1.37 \\
0.41 \\
0.96\end{array}$ \\
\hline
\end{tabular}

plants attain under natural conditions. The processes which take place during such a period of desiccation are, of course, by no means simple, and it can not be considered as a simple loss of water. In the first place, the factor of respiration or the consumption of carbohydrates is to be taken into consideration. If it is assumed that the reaction is of the empirical nature $\mathrm{C}_{6} \mathrm{H}_{12} \mathrm{O}_{6}+6 \mathrm{O}_{2} \rightarrow 6 \mathrm{H}_{2} \mathrm{O}+6 \mathrm{CO}_{2}$, there is formed for each gram of sugar burned 0.6 gram of water, which can be considered as remaining within the plant. For each gram of total loss in weight of the plant due to carbohydrate burning, 2.5 grams of sugar must be consumed, resulting in the formation of 1.5 grams of water. Thus the respiration of the plant tends not only to reduce the dry mass but as well to increase the water-content. A second complicating factor is introduced when it is considered that the

TABLE 23.-Proportional values of carbohydrate-content of Opuntia phaacantha before and after 44 days in the dark at $20^{\circ} \mathrm{C}$.

\begin{tabular}{|c|c|c|c|}
\hline & $\begin{array}{l}\text { Original } \\
\text { condition. }\end{array}$ & Kept dry. & Kept moist. \\
\hline$\frac{\text { Total polysaccharides }}{\text { Total sugars }} \ldots$ & 0.709 & 0.879 & 0.860 \\
\hline$\frac{\text { Hexose }}{\text { Hexose polysaccharides }} \cdots$ & 0.209 & 0.104 & 0.118 \\
\hline$\frac{\text { Monosaccharides }}{\text { Total polysaccharides }}$ & 0.228 & 0.107 & 0.133 \\
\hline$\frac{\text { Hexoses plus disaccharides }}{\text { Hexose polysaccharides }}$ & 0.405 & 0.137 & 0.148 \\
\hline$\frac{\text { Pentosans }}{\text { Total sugars }} \cdots \ldots$ & 0.041 & 0.073 & 0.041 \\
\hline
\end{tabular}

hydrolysis of polysaccharides takes place accompanied by the absorption of water. This water is incorporated in the chemical composition of the sugars. The withdrawal of water by this process tends to increase the dry 
mass as well as to decrease the water-content. These factors are unquestionably of great importance to the plant, especially under conditions of restricted water-supply and during starvation. Discussion hereof will be taken up again in a following section.

Table 22 gives the results of analyses of the three sets of cactus joints.

The proportional values calculated from table 22 are given in table 23 .

The water-content of the plants kept over calcium chloride was reduced from 81.5 per cent to 77.0 per cent; those kept over water were reduced to a water-content of 81.2 per cent. In both cases there was a decided reduction in total sugars. From the available data it is impossible to tell whether all of this reduction is due to respiration or whether in part it is due to the formation of carbohydrates of the nature of cellulose which are not hydrolyzed with 1 per cent by hydrochloric acid and hence do not appear in the mass of total sugars. It is a noteworthy fact, however, that the actual percentage of total polysaccharides shows an increase in both cases. There is very little difference in the rates of respiration between the two sets of plants, as is shown in table 24.

TABLE 24.-Rate of respiration in milligrams $\mathrm{CO}_{2}$ of joints of opuntia phaacantha after being kept in the dark for 44 days.

\begin{tabular}{|c|c|c|c|}
\hline & $\begin{array}{l}\text { Original } \\
\text { condition. }\end{array}$ & Kept dry. & Kept moist. \\
\hline $\mathrm{CO}_{2}$ per gram fresh weight per & 0.0047 & 0.0038 & 0.0033 \\
\hline $\mathrm{CO}_{2}$ per gram dry weight per hour & 0.0252 & 0.0165 & 0.0176 \\
\hline $\mathrm{CO}_{2}$ per gram hexose per hour.... & 0.6730 & 0.8970 & 0.7650 \\
\hline
\end{tabular}

From results given in tables 22 and 23 it is clear that under controlled conditions the comparative values of the carbohydrate-content show that with decreased water-content the monosaccharides exhibit a decrease while the polysaccharides show an increase. Also the pentosans increase with decreasing water-supply.

TABLE 25.-Carbohydrate-content of Opuntia phaacantha as affected by increase and decrease in water-content. Values given in percentages of the dry material.

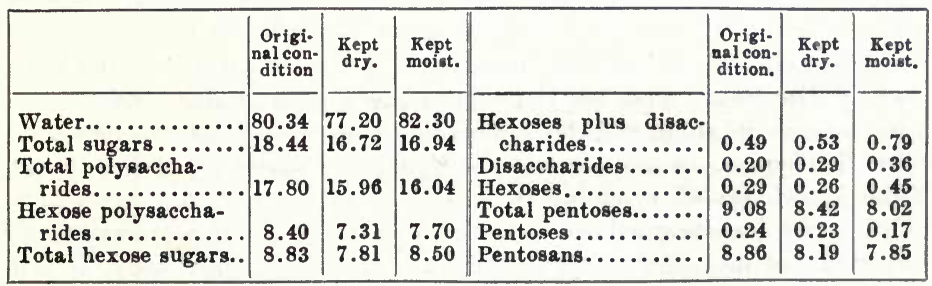

Similar results are obtained when instead of allowing only one set of the cactus joints to lose water, the experiment is so arranged that one set loses water while another exactly similar increases in water-content. This was done by placing one set of seven joints in glass battery jars in such a manner 
that the cut end of the joint extended into tap-water. It was found necessary to allow these cut surfaces to dry out well before placing in water; in this way any diffusion of sugar from the plant into the water was avoided. Another similar set of joints was placed in the same kind of vessel without water. Within a week the joints in water formed thin roots, which grew 15 to $20 \mathrm{~cm}$. in length within the month, but no trace of sugar was found in the water at the end of this time. The experiment was carried out in the dark at constant temperature of $20^{\circ} \mathrm{C}$. The analyses are given in table 25 .

From the experimental results just presented it appears that the conclusions in regard to the effect of water on the carbohydrate-content given in the preceding section are justified.

The agents effecting these changes of inversion and reversion of the carbohydrates according to the varying conditions of water-supply are not definitely known. The present state of our knowledge of reversible enzyme action offers little enlightenment on the phenomena under discussion. An explanation may be ventured, however, based on the known properties of the plasmic colloids. One of the most striking properties of hydrophile colloids is the avidity with which they take up water and the great pressure developed in the process. Conversely, also, it requires enormous pressures to express imbibed water, the colloids holding the water with tremendous tenacity. ${ }^{1}$ Contrary to the water in solutions of crystalloidal salts, the water in these colloidal dispersions is firmly held and has been designated as " hydratation water." Evidence of the avidity with which these colloids take up water can be gained from the fact that they absorb water and swell from concentrated solutions of salts such as calcium nitrate and ammonium sulphate. Now, the inversion of polysaccharides involves the taking up of water into the chemical composition of the resulting simpler carbohydrate. For each molecule of polysaccharide inverted or hydrolyzed, at least one molecule of water is taken up. As the water-content of the plant diminishes, the available water for this process is reduced. If finally the water is so firmly held that it can not enter into the chemical process of inversion, the hydrolysis of the polysaccharides can not take place, or, what is more probable, the inversion takes place at a greatly reduced rate. It must soon be realized that existing chemical knowledge is not sufficient to interpret the reactions taking place in living organism. As was emphasized in the introductory discussion, these reactions do not take place under conditions of pure aqueous solution, and deductions based upon such assumptions must prove inadequate in considering the chemical changes in living things. Some knowledge of reactions in colloidal media must supplement the existing physical-chemical conceptions. The formation of pentosans under conditions of decreased water-content, as pointed out previously, is intimately associated with the reduced supply of monosaccharides. These phenomena will be discussed under the section on pentose sugars.

${ }^{2}$ Rerrke, J. Untersuchungen ueber die Quellung einiger vegetablischer Substanzen. Haustein's Bot. Abt., 4, Heft 1. 


\section{EFFECT OF TEMPERATURE ON THE CARBOHYDRATE-CONTENT.}

The influence of temperature on the carbohydrate-content of plants such as the platyopuntias is, of course, the summation of the effect of this factor on a variety of activities. In order to eliminate photosynthetic activity in the tests, the plants were kept in the dark. In general the experiments were carried out in the same manner as those described in the preceding section. For each test a number of joints of the same age were taken from a single healthy plant; one set, usually seven joints, was immediately analyzed, while other sets were subjected to experimental conditions. Whether the increase of disaccharides and monosaccharides is the result of the effect of lower temperatures on certain enzyme actions, or whether this merely represents an accumulation of these sugars due to the reduced respiratory activity, it is difficult to establish quantitatively. In considering the effect of temperature on the seasonal variations of the carbohydrates in the cacti, it must be borne in mind that during the warm seasons the high temperatures are maintained for a long duration. It is this factor which must be of special importance in applying the thermolabile properties of the enzymes to the present problem. Relatively high temperatures may be borne by many enzymes for short periods, but when such temperatures are maintained for longer periods rapid inactivation ensues. Davis ${ }^{1}$ has shown that maltase in plants is greatly reduced in activity and finally destroyed at temperatures above $50^{\circ}$. From the records of McGee on the temperatures in cacti, already referred to, it is evident that these plants during the summer attain $35^{\circ}$ and higher, and that these temperatures are maintained during the day for 8 to 10 hours. A temperature of $50^{\circ}$ within the plant is not at all uncommon. Such conditions may persist daily for 5 months.

An indication of the effect of temperature on the rate of respiration may be gained from the following experiment. A number of similar joints were taken from the same plant in July and divided into three lots.

TABLE 26.

\begin{tabular}{|c|c|}
\hline Conditions. & $\begin{array}{c}\mathrm{CO}_{2} \text { in mg. } \\
\text { per grem } \\
\text { fresh weight } \\
\text { per hour. }\end{array}$ \\
\hline 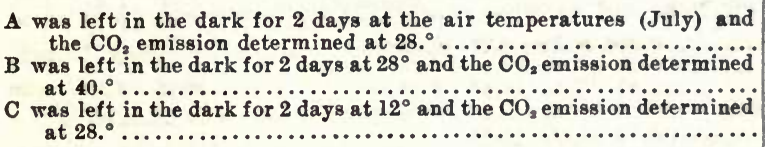 & $\begin{array}{l}0.075 \\
0.034 \\
0.160\end{array}$ \\
\hline
\end{tabular}

It is evident that $\mathrm{B}$, which, as the following analysis shows, had increased in both hexose and disaccharide contert even at $28^{\circ}$, evolved considerably

${ }^{2}$ Davis, W. A. The distribution of maltase in plants. Exp. Sta. Record, 35, 413, 1916. 
less $\mathrm{CO}_{2}$ at $40^{\circ}$ than did $\mathrm{A}$ at $28^{\circ}$, which had been exposed to air-temperatures. C, on the other hand, evolved a relatively large amount of $\mathrm{CO}_{2}$ at $28^{\circ}$ after having been kept at $12^{\circ}$. Richards ${ }^{1}$ found that the maximum carbon dioxid production for Opuntia versicolor was quite definitely at $45^{\circ}$. The analyses are given in table 27 .

TABLE 27.-Analysis of joints of Opuntia phoacantha which had been exposed to different temperatures. Values in percentages of the dry material.

\begin{tabular}{|c|c|c|c|c|c|c|c|}
\hline & $\begin{array}{l}\text { A, out- } \\
\text { of-door } \\
\text { temper- } \\
\text { ature } \\
\text { in July. }\end{array}$ & B, $28 \cdot \bullet$ & C, 12. & & $\begin{array}{l}\text { A, out- } \\
\text { of-d oor } \\
\text { temper- } \\
\text { ature } \\
\text { in July. }\end{array}$ & B, 28. & C, $120^{\circ}$ \\
\hline $\begin{array}{l}\text { Water................ } \\
\text { Total sugars ........ } \\
\text { Total polysaccha- } \\
\text { rides............... } \\
\text { Total hexose sugars. } \\
\text { Hexose polysac- } \\
\text { charides............ }\end{array}$ & $\begin{array}{r}19.35 \\
10.45 \\
9.72\end{array}$ & $\begin{array}{l}60.98 \\
24.50 \\
23.30 \\
11.47 \\
10.45\end{array}$ & $\begin{array}{r}60.00 \\
20.19 \\
18.89 \\
8.46 \\
7.28\end{array}$ & 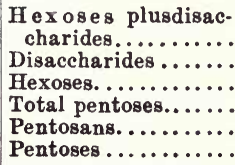 & \begin{tabular}{|l}
0.80 \\
0.18 \\
0.62 \\
9.26 \\
9.04 \\
0.82
\end{tabular} & $\begin{array}{r}1.12 \\
0.37 \\
0.75 \\
12.32 \\
12.16 \\
0.91\end{array}$ & $\begin{array}{r}1.28 \\
0.59 \\
0.69 \\
11.07 \\
10.96 \\
0.80\end{array}$ \\
\hline
\end{tabular}

The results from another series are given in table 28.

Here the plants contained a relatively large amount of monosaccharides and disaccharides to begin with. There were three sets of Opuntia joints: One was analyzed immediately and represents the condition of the joints at the end of the arid autumn, when the low temperatures had already affected the carbohydrate content, but before the winter rains caused a further decided increase in the simpler sugars. Of the two other sets of joints one was kept for 35 days at $28^{\circ}$ in the dark and the other for the same length of time at $12^{\circ}$. The analyses are given in table 28 .

TABLE 28.-Analysis of joints of Opuntia phaacantha, original conditon and after being kept for 35 days at $28^{\circ}$ and $12^{\circ}$, in percentages of the dry material.

\begin{tabular}{|c|c|c|c|c|c|c|c|}
\hline & $\begin{array}{l}\text { Origi- } \\
\text { nal } \\
\text { condi- } \\
\text { tion. }\end{array}$ & $\begin{array}{c}\text { Kept at } \\
28{ }^{\circ} .\end{array}$ & $\begin{array}{c}\text { Kept at } \\
12^{\circ}\end{array}$ & & $\begin{array}{c}\text { Origi- } \\
\text { nal } \\
\text { condi- } \\
\text { tion. }\end{array}$ & $\begin{array}{c}\text { Kept at } \\
28^{\circ}\end{array}$ & $\begin{array}{c}\text { Kept at } \\
12\end{array}$ \\
\hline 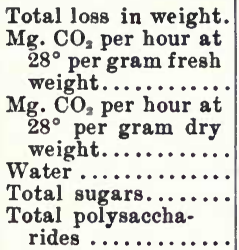 & $\begin{array}{c}\cdots \cdots \\
0.091 \\
0.308 \\
69.90 \\
18.95 \\
16.73\end{array}$ & $\begin{array}{c}0.156 \\
67.00 \\
17.34 \\
16.00\end{array}$ & $\begin{array}{c}18.40 \\
0.098 \\
0.294 \\
66.40 \\
18.46 \\
16.63\end{array}$ & 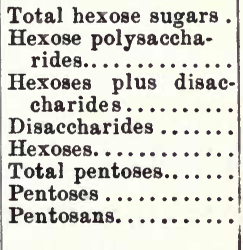 & $\begin{array}{r}7.90 \\
6.04 \\
2.02 \\
1.04 \\
0.98 \\
10.45 \\
0.35 \\
10.10\end{array}$ & $\begin{array}{r}6.62 \\
5.49 \\
1.21 \\
0.73 \\
0.48 \\
10.13 \\
0.22 \\
9.91\end{array}$ & $\begin{array}{r}7.11 \\
5.47 \\
1.77 \\
0.96 \\
0.81 \\
10.74 \\
0.20 \\
10.54\end{array}$ \\
\hline
\end{tabular}

The proportional values of the various groups of carbohydrates are given in table 29.

${ }^{3}$ Rrchards, H. M. Acldity and gas interchange in cacti. Carnegie Inst. Wash. Pub. No. 209 , p. 49, 1915. 
From these results it becomes evident that at higher temperatures the plant tends to the formation of polysaccharides, while at lower temperatures a condition of general inversion seems to prevail.

TABLE 29.

\begin{tabular}{|c|c|c|c|}
\hline & $\begin{array}{c}\text { Original } \\
\text { condition. }\end{array}$ & Kept at $28^{\circ}$ & Kept at $12^{\circ}$ \\
\hline$\frac{\text { Total polysaccharides }}{\text { Total sugars }}$. & 0.883 & 0.913 & 0.900 \\
\hline$\frac{\text { Hexoses }}{\text { Hexose polysaccharides }}$ & 0.162 & 0.088 & 0.147 \\
\hline$\frac{\text { Monosaccharides }}{\text { Total polysaccharides }} \cdots$ & 0.080 & 0.044 & 0.061 \\
\hline$\frac{\text { Hexoses plus disaccharides }}{\text { Total sugars }}$ & 0.107 & 0.069 & 0.096 \\
\hline
\end{tabular}

A similar modification of the carbohydrates concomitant with changes in temperature has been observed in a variety of other plants. Lidforss ${ }^{2}$ showed that all evergreen leaves in temperate latitudes are quite starch-free from the beginning of December and throughout the winter. With the advent of higher temperatures in spring starch again appears in the chloroplasts. Similar observations have been made by Mer, Haberlandt," and Schultz. That temperature is here actually the determining factor is demonstrated by the fact that when the leaves during any time in the winter are brought to a higher temperature, starch formation takes place very readily. Maximow "has made similar observations and has called attention to the high content of glucose in evergreen leaves during the winter. The low eutectic point of glucose solutions is regarded as a protection against freezing. Miyake reports similar conditions existing in Japan. In the winter many evergreen leaves in the middle and southern parts of Japan contain more or less starch, while in the colder parts the leaves are found to be starch-free. The very interesting experiments of Czapek " bear directly upon the question under discussion. He showed that at low temperatures the sugar concentration in the cell must be very much higher in order that starch formation may take place than at higher temperatures.

${ }^{1}$ Lmrorss, B. Zur Physiologie und Blologie der wintergruenen Flora. Bot. Centralblatt, 68, 33-44, 1896.

'Mer, F. De la constitution et des fonctions des feullles hivernales. Bull. Soc. Bot. France, 23, 231, 1876.

- Haberland, G. Vergleichende Anatomie des assimilatorischen gewebesytems der Pflanzen. Jahrb. f. wiss. Bot., 13, 74, 1882.

- Schultz, E. Ueber die Reservestoffe in immergruenen Blaettern. Flora, 71, 223, 1888.

saximow, N. A. Chemische Schutzmittel der Pflanzen gegen Erfrieren. Ber. d. deut. bot. Ges., 30, 52-65, 293-305, 504-516, 1912.

- Mryake, K. On the starch of evergreen leaves and its relation to photosynthesis during the winter. Bot. Gaz., 33, 321-340, 1902.

'CzApEK, F. Der Kohlenhydrat-Stoffwechsell der Laubblaetter im Winter. Ber. d. deut. bot. Ges., 19, 120-127, 1911. 
In none of the leaves employed by Czapek did starch formation occur at low temperatures with sugar concentrations under 7 per cent, while at ordinary temperatures a 1 per cent saccharose solution produced starch in abundance.

All of these results indicate that the enzymatic equilibria are so adjusted that at high temperatures there takes place a general reversion of the carbohydrates to the polysaccharides, while at lower temperatures there is general inversion to the simpler sugars.

\section{AEROBIC AND ANAEROBIC RESPIRATION.}

Richards ${ }^{2}$ made a number of determinations of the $\mathrm{CO}_{2}$ emission and the $\mathrm{CO}_{2} / \mathrm{O}_{2}$ ratio of Opuntia versicolor in atmospheres of hydrogen and of nitrogen. The most noteworthy result of these experiments is the relatively high rate of carbon-dioxid emission despite the absence of oxygen. The amount of carbon dioxid produced in normal air at $21^{\circ}$ was about twice that emitted in the absence of oxygen, while at $30^{\circ}$ the amounts were almost equal. Thus the $\mathrm{CO}_{2}$ per gram-hour at $21^{\circ}$ was in air 0.24 and $0.25 \mathrm{mg}$., in nitrogen 0.17 and $0.15 \mathrm{mg}$., while at $35^{\circ}$ it was in air 0.30 and $0.33 \mathrm{mg}$., and in nitrogen $0.38 \mathrm{mg}$. The acidity as determined by titration does not diminish at the rate at which it does in the presence of oxygen. It appears, therefore, that the carbon dioxid which is produced does not arise from the breaking down of the organic acids to the same extent as in the normal cases. Some knowledge of the rôle of the carbohydrates under anaerobic conditions seemed, therefore, highly desirable.

Joints of Opuntia phoacantha were selected in the manner previously described. One set of joints was analyzed immediately, another set was placed under a large bell-jar provided with tubes for circulation of air in a dark room kept at $20^{\circ}$, and a third set was placed in the same dark room under a bell-jar in an atmosphere free of oxygen.

Anaerobic conditions were produced by the employment of the methods of Ruzieka. ${ }^{3}$ The bell-jar (15 liters capacity) was placed in a shallow pan containing 500 c. c. of a 1 per cent aqueous phenol solution, 70 c. c. 20 per cent aqueous $\mathrm{Na}_{2} \mathrm{CO}_{3}$ solution and 50 grams dextrose to which was added about 500 c. c. of paraffin oil. This mixture served as a seal. In this pan stood a large glass triangle on which was placed a shallow glass dish containing a quantitiy of pyrogallol and a stick of $\mathrm{KOH}$. In this dish stood another glass triangle which supported a container made of wire screen in which had been placed the cactus joints. In the pyrogallol dish there was also placed a small beaker containing an indicator solution made of $50 \mathrm{c}$. c. 1 per cent phenol solution, 5 c. c. 20 per cent $\mathrm{Na}_{2} \mathrm{CO}_{3}$ and 1 g. c. p. dextrose, to which was added 0.5 c. c. prepared sulphuric acid indigo solution. The oxygen was removed from the bell-jar by burning a small jet of

${ }^{3}$ RichaRDS, H. M. L. c., pp. 57, 84.

2 Abderhalden, E. Handbuch der Biochem. Arbeitsmethoden. Vol. III (2), 1239, 1910. 
hydrogen therein. The hydrogen was prepared from c. p. zine and sulphuric acid and was washed through a solution of 10 per cent lead nitrate and one of 10 per cent silver nitrate. The oxygen in the bell-jar was consumed slowly, and when the flame went out the hydrogen was immediately turned off. By means of a bent glass tube and a burette, oxygen-free water was added then to the dish containing pyrogallol and $\mathrm{KOH}$. Thus the last traces of oxygen were removed from the atmosphere in the bell-jar. In all probability the cactus joints contained some oxygen, but from all indications this was soon used up.

The plants were allowed to remain thus for 7 days, when they were analyzed in the usual manner. The results are given in table 30.

TABLE 30.-Carbohydrate-content of Opuntia phaacantha in original condition and after having been kept in air and in an atmosphere free of oxygen for 7 days. Values in percentages of the dry material.

\begin{tabular}{|c|c|c|c|c|c|c|c|}
\hline & 施 & 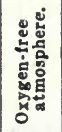 & $\dot{\xi}$ & & 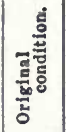 & 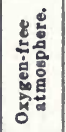 & $\dot{\check{4}}$ \\
\hline 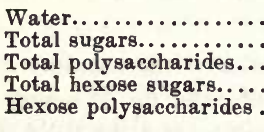 & $\begin{array}{r}80.00 \\
26.15 \\
19.20 \\
13.95 \\
7.70\end{array}$ & $\begin{array}{l}80.15 \\
21.60 \\
16.15 \\
10.25 \\
5.44\end{array}$ & $\begin{array}{l}79.80 \\
22.80 \\
17.38 \\
11.96 \\
7.33\end{array}$ & $\begin{array}{l}\text { Disaccharides............ } \\
\text { Hexoses................ } \\
\text { Total pentoses........... } \\
\text { Pentosans ................ } \\
\text { Pentoses................. }\end{array}$ & \begin{tabular}{|l|}
0.95 \\
5.92 \\
11.55 \\
10.87 \\
0.68
\end{tabular} & \begin{tabular}{|r|}
0.66 \\
4.66 \\
10.73 \\
10.11 \\
0.62
\end{tabular} & $\begin{array}{r}0.25 \\
4.88 \\
10.25 \\
9.41 \\
0.76\end{array}$ \\
\hline
\end{tabular}

It is evident that under anaerobic as well as aerobic conditions, considerable amounts of carbohydrates are consumed. This fact was established long ago by Lechartier and Bellamy ${ }^{1}$ for fruits. It is, however, noteworthy that the plants under anaerobic conditions consumed as much or even slightly more carbohydrate material than those kept in air. The conclusion, therefore, seems justified that the $\mathrm{CO}_{2}$ emission, under anaerobic conditions, previously referred to, was the result of carbohydrate respiration.

A similar experiment was carried out, using Opuntia versicolor. The same method and procedure were followed as in the preceding experiment. The plants remained under the experimental conditions for five days. The results are given in table 31.

TABLE 31.-Carbohydrate-content of Opuntia versicolor in original conditions and after having been kept in air and in an atmosphere free of oxygen for 5 days. Values in percentages of the dry material.

\begin{tabular}{|c|c|c|c|c|c|c|c|}
\hline - & 递 & 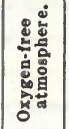 & $\dot{\xi}$ & & 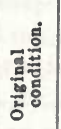 & 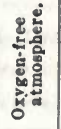 & 亡․ \\
\hline 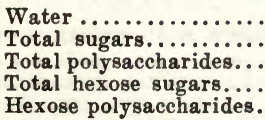 & $\begin{array}{l}70.00 \\
18.90 \\
16.22 \\
12.85 \\
10.67\end{array}$ & $\begin{array}{l}70.80 \\
12.41 \\
11.65 \\
10.92 \\
10.42\end{array}$ & $\begin{array}{r}67.15 \\
15.15 \\
13.90 \\
10.03 \\
9.12\end{array}$ & 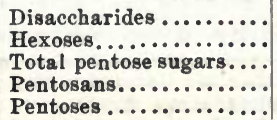 & $\begin{array}{l}0.61 \\
1.76 \\
5.72 \\
5.24 \\
0.49\end{array}$ & $\begin{array}{l}0.10 \\
0.55 \\
1.41 \\
1.16 \\
0.25\end{array}$ & $\begin{array}{l}0.28 \\
0.72 \\
4.83 \\
4.53 \\
0.30\end{array}$ \\
\hline
\end{tabular}

${ }^{2}$ Lechartier, G., and F. Benuamy. De la fermentation des fruits. Compt. rend., 69, $466,1809$. 
Opuntia versicolor shows the same behavior as Opuntia phocacantha in that for at least 5 days these plants can live with no apparent untoward effects in an atmosphere containing no oxygen. The rate of carbohydrate consumption is higher under anaerobic conditions than during aerobic respiration. This is probably due to the higher energy release and hence greater efficiency of the aerobic process, as was pointed out in the introductory discussion. The water loss under the experimental conditions was naturally low ; the plants which had consumed the larger amounts of carbohydrate showed a higher percentage of water-content.

In the foregoing experiment with Opuntia versicolor acidity determinations were also made. In each case 100 grams of the plant material which had been ground were thoroughly expressed in a meat-press. The juice thus obtained was made up to a definite volume and aliquot portions titrated with 0.1 normal potassium hydrate, using phenolphthalein as an indicator. The plants representing the original condition were collected at 4 p. m., at a time when the acidity was almost at its minimum. The results thus obtained are as follows:

Original condition ............. 0.20 c. c. 0.1 normal $\mathrm{KOH}$ per gram fresh material Kept in air................... 0.78 c. c. "

In oxygen-free atmosphere...... 0.50 c. c.

From this it is evident that acid formation is benefited by the presence of oxygen. This is quite in accord with the results obtained by Warburg. ${ }^{2}$ The principles underlying the phenomena of acidification and deacidification have been discussed by this worker and more recently by Richards and by the author." It is evident also that there is a decided acidification even in the absence of oxygen. Whether this acidity also represents malic acid, as under normal conditions, or some other acid, the product of real intramolecular respiration is an open question. The answer hereto would throw considerable light on the mode of this form of energy release.

The respiration of succulent plants represents somewhat of a modification of the process taking place in most mesophytes. The characteristic formation of acids is intimately associated with the restricted oxygen supply consequent on the structure of the succulent type. However, when these plants are deprived of all oxygen, it is evident that the final course which the respiratory process follows is further altered, and the products formed are radically different. In consideration simply of the chemical reactions of sugars in aqueous solution in the presence of oxidizing agents under various conditions, as outlined in the introductory discussion, variations in the reaction products with altered external conditions of the organism are to be expected. It was indicated in this discussion in what manifold channels the course of sugar disintegration may proceed, and what slight differences in the nature of solution may affect the main course of the reaction. Precursory to oxidation of the sugars, there must take place a dissociation or

${ }^{2}$ WARBURG, O. Ueber die Bedeutung der Organischen Saeuren fuer den Lebensprozess der Pflanzen. Specieli der Sog. Fettpflanzen. Unters. aus dem Bot. Inst. zu Tuebingen, 2, 53-150, 1886.

${ }^{2}$ SPOEHr, H. A. Biochem. Zeitschr., 57, 95, 1913. 
splitting of the sugar molecule. Such an assumption finds physiological substantiation in the fact established by Bertrand, ${ }^{1}$ that oxidases are not capable of directly oxidizing carbohydrates. The extensive researches of Godlewski and of the Russian school of Palladin and Kostytschew have made notable experimental contributions to a clearer understanding of this subject.

It is still a matter of dispute as to what are the agencies which effect this disruption of the sugar molecule. By some it has been maintained that all respiration has as its beginning zymase fermentation, and that the products of this action are then oxidized to form the familiar products of aerobic respiration. However, the results of Kostytschew ${ }^{2}$ and others make it appear highly improbable that the higher plants oxidize alcohol formed either as an intermediate product or when given the plant as nutrient. Kostytschew and Palladin ${ }^{2}$ also showed that some plants exhibit a mixed type of anaerobiosis in which the nature of sugar disintegration is different from the regular zymase fermentation. In potatoes the amount of alcohol formed was exceedingly small; while from the results with various leaves they conclude that about one-half of the $\mathrm{CO}_{2}$ production is the result of zymase action, the rest of the $\mathrm{CO}_{2}$ resulting from a different form of glycolysis. It is to be concluded, then, that in the plant sugar disintegration may follow several courses concomitantly, and that the nature of the main metabolic product depends upon which of these courses is favored. This is, of course, just what would be expected from a consideration of the behavior of sugar solutions under the influence of various catalytic agents as revealed by the extensive investigations of Nef, which have been already discussed.

It seemed, therefore, not without interest to determine how the cacti, which under normal conditions exhibit a rather modified course of respiration, behaved under anaerobic conditions. The procedure consisted essentially of expressing the juice from 200 grams of the ground cactus and determining the alcohol in this juice." A small portion of the juice was used for the determination of acidity; the remainder was used for the alcohol determinations. By addition of calcium carbonate, the juice was made neutral. To this neutralized juice there was added ammonium sulphate, 75 grams of the salt to each 100 c. c. of juice. This was carried out in a wide-mouth bottle and, after the addition of the ammonium sulphate and a

${ }^{2}$ Bertrand, G. Sur les rapports qui existent enter la constitution chemique des composes organiques et leur oxidabilite sous l'influence de la laccase. Comp. rend., 122, 1132, 1896.

Mathews, A. P. The spontaneous oxidation of sugars. Jour. Biol. Chem., 6, 1-20, 1909.

"Kostrtschew, S. Ueber den Zusammenhang der Sauerstoffatmung der Samenpflanzen mit der Alkoholgaerung. Ber. d. deut. bot. Ges., 26, 565-573, 1908.

"Pallanin, W., and S. Kostytschew. Ueber die anaerobe Atmung der Samenpflanzen ohne alkohol bildung. Ber. d. deut. bot. Ges., 25, 51-56, 1907.

KostrTschEW, S. Ueber das Wesen der anaeroben Atmung verschiedener Samenpflanzen. Ber. d. deut. bot. Ges., 31, 125-129, 1913.

- Dox, ARThur W., and A. R. LAMb. An accurate aeration method for the determination of alcohol in fermentation mixtures. Jour. Amer. Chem. Soc., 38, 2561$2568,1916$. 
few drops of toluene, the bottle was immediately attached to the aeration train. The alcohol was removed from the juice by forcing a stream of air through the solution and absorbing the alcohol which is thus distilled over in concentrated sulphuric acid.

The arrangement was as follows: The air passed first through a solution of sulphuric acid and potassium bichromate, then through a safety bottle, whereupon it was forced through the plant juice, another small safety bottle, and then through two small absorbing cylinders containing concentrated sulphuric acid. The air was passed through this train for 24 hours. The sulphuric acid was then transferred to a distilling flask connected with a condenser and receiving vessel. By means of a dropping-funnel a 2 per cent solution of potassium bichromate was added to the sulphuric acid. The warm mixture in the distilling flask was allowed to stand for 15 to 20 minutes in order to complete the oxidation of the alcohol to acetic acid, and then distilled until no more acid came over. A thermometer was kept in the solution and the temperature was not allowed to rise over $112^{\circ}$. It was found that at higher temperature there is danger of sulphuric acid being carried over. The solution can be distilled until the distillate is neutral to litmus by adding $25 \mathrm{c}$. c. of boiled water from time to time to prevent the solution from becoming too concentrated. The distillate was made up to a definite volume and titrated with 0.1 normal potassium hydroxide.

As has been stated, the nocturnal respiration of the cacti is characterized by the formation of acids. This acidification is the result of restricted oxygen supply. The question arises, then, whether under these conditions there is also formation of alcohol-that is, whether the course of respiration is so affected as to radically change the mode of the process. For this purpose Opuntia versicolor joints were collected in the morning and in the evening, and acidity and alcohol determinations made in the usual manner. The results are given in table 32 .

TABLE 32.-Diurnal variations in the acidity and alcohol content of Opuntia versicolor, May 7-8.

\begin{tabular}{|c|c|c|}
\hline & $\begin{array}{l}\text { Collected at } \\
4^{\wedge} 30^{m} \text { p. m. }\end{array}$ & $\begin{array}{l}\text { Collected at } \\
8^{n} 15^{m} \text { a. m. m. }\end{array}$ \\
\hline 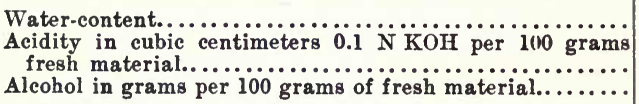 & $\begin{array}{l}75.67 \\
20.30 \\
0.0066\end{array}$ & $\begin{array}{l}75.80 \\
37.65 \\
0.0032\end{array}$ \\
\hline
\end{tabular}

There is evidently no accumulation of alcohol in these plants during the night time coincident with the nocturnal acidification. It seems highly improbable that this form of respiration can be regarded as being of intramolecular nature. It was observed, however, that there was a distinct increase in the alcohol-content of these plants after they had been exposed to sunlight for some time. This fact serves to substantiate the theory of 
acid disintegration which was advanced by the writer in an earlier paper. ${ }^{2}$ The acidity of these cacti in the morning is due essentially to the presence of malic acid. The photolysis of malic acids yields through the loss of two molecules of carbon dioxid from the carboxyl groups one molecule of ethyl alcohol.<smiles>CCC(=O)C(=O)C(O)C(=O)O</smiles>

As the photolytic distintegration of the malic acid proceeds there is thus an accumulation of ethyl alcohol.

Under anaerobic conditions there is a very active production of alcohol in the cacti. In table 33 are given the results of analyses of plants of

TABLE 33.-Acidity and alcohol content of Opuntia versicolor after being kept in air and oxygen-free atmosphere.

\begin{tabular}{|c|c|c|c|c|}
\hline Atmosphere. & $\begin{array}{l}\text { Time in } \\
\text { hours. }\end{array}$ & $\begin{array}{l}\text { Water- } \\
\text { content. }\end{array}$ & $\begin{array}{c}\text { Acidityin c.c. } \\
0.1 \mathrm{~N} \mathrm{KOH} \text { per } \\
100 \mathrm{grams} \text { fresh } \\
\text { material. }\end{array}$ & $\begin{array}{l}\text { Alcohol in } \\
\text { grams per } 100 \\
\text { grami fresh } \\
\text { material. }\end{array}$ \\
\hline 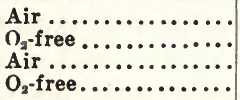 & $\begin{array}{l}168 \\
192 \\
168 \\
144\end{array}$ & $\begin{array}{l}74.30 \\
78.40 \\
73.40 \\
77.05\end{array}$ & $\begin{array}{l}83.57 \\
47.40 \\
86.80 \\
67.80\end{array}$ & $\begin{array}{l}0.0041 \\
0.3800 \\
0.0040 \\
0.0189\end{array}$ \\
\hline
\end{tabular}

Opuntia versicolor which were kept in an atmosphere freed of oxygen in the manner previously described.

The normal amount of alcohol is very small in Opuntia versicolor. In the course of normal respiration in the dark this quantity does not increase, although the acidity rises very much. When kept in an atmosphere freed of oxygen large quantities of alcohol are formed; there is also some acid formation, but this is not nearly so great as in air. It is very noticeable that due to the higher rate of sugar consumption under anaerobic conditions, the water-content of plants kept under such conditions is finally much higher than in those kept in air.

${ }^{2}$ Spozhr, H. A. Blochem. Zeitsch., 57, 106, 1913. 


\section{CONSUMPTION OF CARBOHYDRATES DURING STARVATION.}

A very striking property of many of the cacti is their ability to survive long periods of drought and starvation. A notable record of this has been made by MacDougal et al. ${ }^{2}$ on the desiccation of Echinocactus. This plant, left in the diffuse light of a room without being given any water, after six years had the same proportion of water as at the beginning, although it had lost almost 30 per cent of its original weight. It has since been found that similar conditions obtain in many other cacti. Here are given the records of the water-loss and rate of carbohydrate depletion of two sets of Opuntia phceacantha. For each series a large number of joints of the same age were taken from one plant and placed in a dark room, the temperature of which was maintained throughout the experiment at $28^{\circ} \mathrm{C}$. The joints were placed upon racks permitting free circulation of air. For over a year they remained in apparently perfectly healthy condition. At the end of this time a number of the joints were planted in soil and watered, within a week they put out roots, and shortly thereafter developed vegetative buds.

If a rather definite water-content is to be maintained during long periods while a plant is actually losing large quantities of water there must, of course, be a simultaneous loss of dry material through respiration. As has been shown, this dry material is essentially of carbohydrate nature. A considerable portion thereof is in the form of cellulose, however, and from the investigations by MacDougal et al. it is evident that this cellulose may be utilized as food material by the plant under circumstances of stress. Added to the tendency of the plant to maintain its water-balance by a concomitant loss of dry material is the factor that the burning of sugar also results in the formation of water. For each gram of sugar, calculated as $\mathrm{C}_{6} \mathrm{H}_{12} \mathrm{O}_{6}$, there is formed 0.6 gram of water. When the water-content

TABLE 34.

\begin{tabular}{|c|c|}
\hline $\begin{array}{c}\text { At water } \\
\text { content of- }\end{array}$ & Water loss. \\
\cline { 1 - 2 } p. ct. & grams. \\
60 & 2.1 \\
75 & 3.5 \\
80 & 4.5 \\
90 & 9.6 \\
\hline
\end{tabular}
of the plant is already high this factor is, of course, quite insignificant, but when the water-content is low the water added thereto by the burning of sugar may be of some significance in the economy of the plant. Naturally, the maintenance of the waterbalance is entirely a relative matter, the rates at which respiration and transpiration may proceed and the plant still maintain its water-balance depend upon the original condition. Thus, in order to maintain its original water-balance and retaining a constant rate of respiration, the plant may lose the following quantities of water at the water-content indicated in the accompanying table. For each gram of dry material, calculated as sugar, lost by respiration the water-loss equaled as shown in table 34 .

${ }^{2}$ MacDougat, D. T., E. R. Long, and J. G. Brown. End resuits of desiccation and respiration in succulent plants. Physiological Researches, 1, 289-325, 1915. 
In order that the water-balance be maintained, the lower the watercontent the less can be the rate of water-loss at a constant rate of respiration; and, conversely, the lower the water-content the higher can be the respiration at a constant rate of transpiration. The examples given in tables 35 and 36 will illustrate the point.

TABLE 35.-Loss in weight and rate of $\mathrm{CO}_{2}$ emission of Opuntia phocacantha kept in dark at $28^{\circ} \mathrm{C}$.

\begin{tabular}{|c|c|c|c|c|c|}
\hline Daye. & $\begin{array}{l}\text { Original } \\
\text { weight. }\end{array}$ & $\begin{array}{c}\text { Loss, } \\
\text { grams. }\end{array}$ & $\begin{array}{l}\text { Lose, } \\
\text { per cent. }\end{array}$ & $\begin{array}{c}\text { Mg. } \mathrm{CO}_{2} \text { per } \\
\text { hour per } \\
\text { gram dry } \\
\text { weight. }\end{array}$ & $\begin{array}{l}\text { Water- } \\
\text { content. }\end{array}$ \\
\hline $\begin{array}{r}33 \\
55 \\
91 \\
118 \\
150 \\
174 \\
189\end{array}$ & $\begin{array}{l}\dddot{426} \\
474 \\
546 \\
443 \\
465 \\
565 \\
480\end{array}$ & $\begin{array}{r}\ddot{83.0} \\
100.0 \\
167.5 \\
271.5 \\
280.0 \\
240.0 \\
253.0\end{array}$ & $\begin{array}{r}19.40 \\
21.09 \\
30.60 \\
61.20 \\
60.20 \\
42.50 \\
52.50\end{array}$ & $\begin{array}{l}0.724 \\
0.247 \\
0.249 \\
0.185 \\
0.090 \\
0.095 \\
0.128 \\
0.081\end{array}$ & $\begin{array}{l}84.75 \\
83.75 \\
84.50 \\
81.76 \\
72.68 \\
75.32 \\
80.00 \\
75.48\end{array}$ \\
\hline
\end{tabular}

The plants in table 35 had a relatively high initial water-content; they were kept at $28^{\circ}$ with a constant movement of air and, although the losses were not uniform, they lost over 60 per cent of their total weight; the watercontent was reduced by but 12 per cent. The plants in table 35 started with a much lower water-content, which is reduced by only 9 per cent, with decidedly lower total loss of weight and, relative to the total loss, a higher rate of respiration.

TABLE 36.-LOss in weight and rate of $\mathrm{CO}_{2}$ emission of Opuntia phœacantha kept in dark at $28^{\circ} \mathrm{C}$.

\begin{tabular}{|c|c|c|c|c|c|}
\hline Days. & $\begin{array}{l}\text { Original } \\
\text { weight. }\end{array}$ & $\begin{array}{c}\text { Loss, } \\
\text { grams. }\end{array}$ & $\begin{array}{c}\text { Loss, } \\
\text { per cent. }\end{array}$ & $\begin{array}{c}\mathrm{Mg} . \mathrm{CO}_{2} \text { per } \\
\text { hour per } \\
\text { gram dry } \\
\text { weight. }\end{array}$ & $\begin{array}{l}\text { Water- } \\
\text { content. }\end{array}$ \\
\hline & 169.5 & .. & & 0.250 & 68.50 \\
\hline 54 & 203.0 & 48 & 23.6 & 0.130 & 63.20 \\
\hline 72 & 186.0 & 39 & 21.0 & 0.094 & 63.80 \\
\hline 92 & 183.0 & 55 & 27.3 & 0.147 & 59.87 \\
\hline 121 & 201.0 & 66 & 32.9 & 0.074 & 59.50 \\
\hline 143 & 209.0 & 67 & 32.1 & 0.052 & 62.40 \\
\hline
\end{tabular}

One example will suffice to illustrate the manner in which the two factors of respiration and transpiration work together to maintain the waterbalance. In table 36 the first and second sets may be taken. In the initial condition the plants emitted $0.25 \mathrm{mg} . \mathrm{CO}_{2}$ per hour per gram dry material, $i$. e., they were consuming at the rate of 0.00017 gram of sugar $\left(\mathrm{C}_{6} \mathrm{H}_{12} \mathrm{O}_{6}\right)$ per hour per gram of dry material, or, calculated for the second set of plants, 0.0108 gram of sugar per hour. After 54 days there was produced $\mathrm{CO}_{2}$ at the rate of $0.13 \mathrm{mg}$. per hour per gram of dry material, equal to 0.000089 gram of sugar per hour per gram dry material, or 0.0051 gram sugar per hour for the entire set of plants. This would average 0.0079 gram of sugar 
used per hour by the plants or 10.24 grams of sugar for the 54 days. The original 63.90 grams of dry material of the plant was then reduced by 10.24 grams, leaving 53.66 grams. The burning of 10.24 grams of sugar yields 6.14 grams of water, or results in a net loss of 4.10 grams. The plants showed a total loss of 48.0 grams, hence this quantity less 4.10 grams represents the amount of water lost, i. e., 43.90 grams. There were present originally 139 grams of water in the plants; less 43.90 grams would leave 95.10 grams; to this must be added the amount of water produced by the oxidation of the carbohydrates, which brings the water-content to 101.24 grams. From the values thus calculated (53.66 grams of dry material and 101.24 grams of water) there results a theoretical water-content of 65.35 per cent. The value actually found was 63.20 per cent.

There are, of course, several factors which modify the calculated results. Most important of these is the rate of carbon-dioxid emission. This is

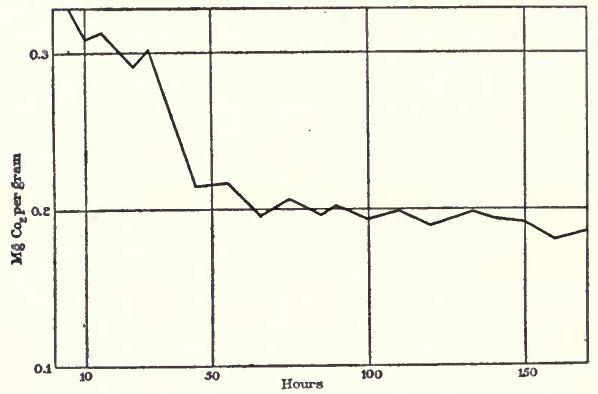

FIG. 2.

probably too high and would result in bringing the calculated water-content to too high a value. As can be seen from figure 2, the curve of the rate of carbon-dioxid emission does not decrease in a straight line, but rather abruptly, so that the total amount of sugar consumed is probably calculated too high. The abrupt drop in the curve of carbon-dioxid emission is not a traumatic effect; the cause has, however, as yet not been discovered.

It is evident that these plants do not go into a condition of rest or dormancy when the water-supply is greatly diminished, but continue their respiratory activity at about the same rate as when supplied with abundant water. This fact has already been pointed out by Richards. It would seem that this is made possible by virtue of their ability to use as food material not only the simpler monosaccharides which under these conditions are present in reduced quantities, but also the polysaccharides. How this results in the formation of pentosans in the plant will be discussed in a later section. 
The course of the depletion of the stored earbohydrates can be seen in table 37. The proportion of the various sugars maintains a surprising regularity as the depletion proceeds. This is an important fact in view of the opinion which has been frequently expressed regarding the physiological rôle of the pentoses. These sugars have been considered by some plant physiologists as end or waste products of the normal metabolism, which accumulate as the plant becomes older. Were this the case it would be expected that, in plants subjected to conditions such as these, there would be an increase in pentoses, at least relative to the other sugars. But this is found not to be the case; the pentoses apparently are drawn into the course of earbohydrate metabolism to a marked degree. The starch, which is present in very numerous minute grains, disappears slowly. After 72 days there are visible but a few seattered grains; and after 92 days practically all of the starch has disappeared.

TABLE 37.-Carbohydrate-content of Opuntia phaacantha during starvation. Values in percentages of the dry material.

\begin{tabular}{|c|c|c|c|c|c|c|}
\hline & \multicolumn{6}{|c|}{ Days. } \\
\hline & 0 & B4 & 72 & 92 & 121 & 143 \\
\hline Water. & 63.50 & 63.20 & 63.80 & 59.87 & 59.50 & 62.40 \\
\hline Total sugars... & 22.86 & 16.62 & 13.71 & 15.25 & 14.54 & 13.52 \\
\hline Total polysaccharides............... & 20.38 & 14.22 & 12.30 & 14.10 & 13.52 & 12.46 \\
\hline Total hexose sugars........ & 19.74 & 14.85 & 12.25 & 13.27 & 12.24 & 11.70 \\
\hline Hexose polysaccharides....... & 17.64 & 13.72 & 11.15 & 12.41 & 11.48 & 10.87 \\
\hline Hexoses plus disaccharides......... & 2.25 & 1.21 & 1.18 & 0.91 & 0.81 & 0.89 \\
\hline 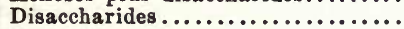 & 1.63 & 0.72 & 0.73 & 0.70 & 0.55 & 0.59 \\
\hline 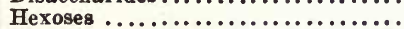 & 0.62 & 0.49 & 0.45 & 0.21 & 0.26 & 0.30 \\
\hline Total pentose sugars.............. & 2.93 & 1.68 & 1.38 & 1.84 & 2.17 & 1.72 \\
\hline 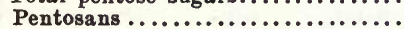 & 2.67 & 1.33 & 1.08 & 1.25 & 2.02 & 1.50 \\
\hline 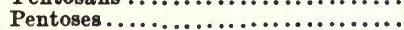 & 0.36 & 0.34 & 0.30 & 0.25 & 0.15 & 0.22 \\
\hline 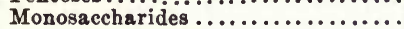 & 0.98 & 0.83 & 0.75 & 0.46 & 0.31 & 0.52 \\
\hline
\end{tabular}

Another experiment was undertaken to determine the effect of starvation on the subsequent photosynthetic activity as well as of feeding with canesugar and dextrose. A number of joints of Opuntia phoeacantha were left in the dark at $28^{\circ}$, as previously described, for 189 days. One set of joints (A) was then analyzed to determine the status of the carbohydrates. The remaining joints were placed in battery jars containing water, in such a manner that the cut end was just below the surface of the water. Within 10 days all the joints had produced roots 2 to $5 \mathrm{~cm}$. in length. The plants were then divided into 3 lots of 7 joints each and treated in various ways. $\mathrm{B}$ was placed with the roots in a sterile 1 per cent cane-sugar solution; $\mathrm{C}$ with roots in a sterile 1 per cent dextrose solution, both in the dark at $28^{\circ}$; and $\mathrm{D}$ with the roots in a nutrient solution, in the sunlight. The plants remained thus for 60 days; the solutions were changed frequently. At the end of this time the plants were all in a very healthy condition and were analyzed in the usual manner; the results are given in table 38. 
The gain in water-content of the plants which had been placed with their roots in solutions is very apparent. The effect on the carbon-dioxid production is very striking in the case of the cane-sugar and dextrose; both show a very decided increase. The plants which were in the sunlight show but a very slight gain. In none of the cases is the gain in carbohydratecontent very great. This was somewhat surprising, as the plants before the starvation contained 20.60 per cent total sugars, 4.50 per cent hexoses, and 8.28 per cent total pentoses. The plants in a solution of cane-sugar

TABLE 38.-Carbohydrate-content in percentages of the dry material of opuntia phoacantha.

\begin{tabular}{|c|c|c|c|c|}
\hline & $\mathbf{A}$ & $\mathbf{B}$ & $\mathbf{C}$ & D \\
\hline $\mathrm{Mg} . \mathrm{CO}_{2}$ per hour per gram dry weight...... & 0.080 & 0.777 & 0.865 & 0.116 \\
\hline 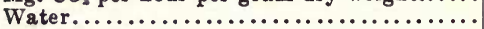 & 75.48 & 84.55 & 85.45 & 88.90 \\
\hline 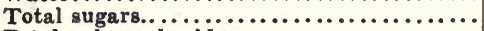 & $1] .50$ & 13.00 & 10.70 & 12.00 \\
\hline 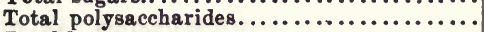 & 11.05 & 12.15 & 10.06 & 11.78 \\
\hline 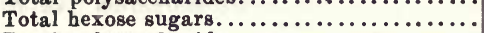 & 8.88 & 11.02 & 9.27 & 10.62 \\
\hline 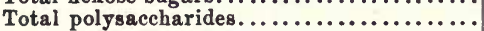 & 8.58 & 10.44 & 8.84 & 10.34 \\
\hline 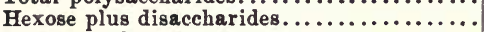 & 0.33 & 0.63 & 0.47 & 0.30 \\
\hline 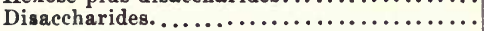 & 0.21 & 0.48 & 0.28 & 0.24 \\
\hline 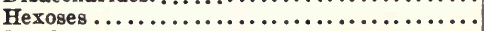 & 0.12 & 0.15 & 0.19 & 0.06 \\
\hline 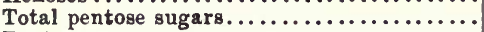 & 2.49 & 1.87 & 1.40 & 1.31 \\
\hline 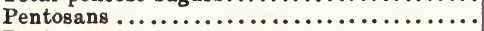 & 2.35 & 1.62 & 1.24 & 1.09 \\
\hline 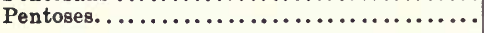 & 0.14 & 0.25 & 0.21 & 0.22 \\
\hline
\end{tabular}

A starved 189 days, $B$ subsequently for 60 days in 1 per cent cane-sugar, $C$ in 1 per cent dextrose, $D$ in sunlight.

show a greater gain in disaccharides, while the plants in dextrose show a greater gain in hexoses. The joints which had been in the sunlight exhibited but very slight gains, the hexoses being even less than in the original starved condition. This is probably of considerable importance for an understanding of the nature of the photosynthetic process. It has been found that a similar condition exists in thin leaves, the rate of photosynthesis varying with the rate of respiration, suggesting an intimate association between photosynthesis and the respiratory activity. Investigation on this subject is now in progress. In all three cases the pentosans show the usual diminution with increased water-content. 


\section{THE ORIGIN AND RÔLE OF PENTOSE SUGARS.}

The pentose sugars in plants have been most familiar as pentosans, as components of the cell walls and vessels of the plants, and as found in various gums in the form of xylan and araban. While widespread in the vegetable kingdom, the pentose sugars have but recently been regarded in their important bearing, and, in fact, were for a long time not recognized as belonging to a separate group. In fact, the presence of monosaccharide pentoses has been but very recently established. That the pentoses are of great physiological importance to the plant becomes evident in the light of recent investigations on the chemistry of the cell-nucleus. Among the chief components hereof are the so-called nucleic acids. These are highly complex substances consisting roughly of a combination of phosphoric acid, purines, pyrimidines, and several carbohydrate groups. The plant nucleic acids so far studied have been found to contain the pentose group. ${ }^{2}$ The function and fundamental importance of the nucleus in the metabolism of the plant need no further discussion here; however, a more intimate knowledge of the chemical composition and action will undoubtedly lead to a clearer understanding of the intricate reactions of this most important organ.

It is evident, then, that the $\mathbf{5}$ carbon atom group of sugars is a common component of plants and is of great importance in some of the most vital metabolic activities of the organism. Nevertheless, the origin and mode of formation of the pentose sugars is still quite obscure. This problem is of special interest because any light thereon would be of great value in gaining a clearer understanding of the process of the photosynthetic appropriation of carbon dioxid by the chlorophyllous leaf. The question resolves itself into whether the pentoses are direct products of photosynthesis or are derived from other sugars through subsequent metabolic activity. If, for instance, the formation of sugar in the green leaf actually takes place by means of a progressive addition of six molecules of formaldehyde, the presence of pentoses is to be expected.

$$
\begin{aligned}
& 2 \mathrm{CH}_{2} \mathrm{O} \rightarrow \mathrm{C}_{2} \mathrm{H}_{4} \mathrm{O}_{2} ; \mathrm{C}_{2} \mathrm{H}_{4} \mathrm{O}_{2}+\mathrm{CH}_{2} \mathrm{O} \rightarrow \mathrm{C}_{8} \mathrm{H}_{6} \mathrm{O}_{8} ; \\
& \mathrm{C}_{8} \mathrm{H}_{6} \mathrm{O}_{3}+\mathrm{CH}_{2} \mathrm{O} \rightarrow \mathrm{C}_{4} \mathrm{H}_{8} \mathrm{O}_{4} ; \mathrm{C}_{4} \mathrm{H}_{2} \mathrm{O}_{4}+\mathrm{CH}_{2} \mathrm{O} \rightarrow \mathrm{C}_{6} \mathrm{H}_{10} \mathrm{O}_{6} ; \\
& \mathrm{C}_{6} \mathrm{H}_{10} \mathrm{O}_{5}+\mathrm{CH}_{2} \mathrm{O} \rightarrow \mathrm{C}_{6} \mathrm{H}_{12} \mathrm{O}_{6} .
\end{aligned}
$$

If, again, the sugars are formed by the union of two molecules of glycerine aldehyde, hexoses or their condensation products would be the only substances formed:

$$
2 \mathrm{CH}_{2} \mathrm{OH} \cdot \mathrm{CHOH} \cdot \mathrm{CH}: \mathrm{O}, \mathrm{CH}_{2} \mathrm{OH}(\mathrm{CHOH})_{4} \cdot \mathrm{CH}: \mathrm{O} .
$$

This, however, is purely chemical speculation and so far has aided little in the solution of the problem of photosynthesis, the real course of which is probably far more complicated than has been generally assumed. Not

${ }^{2}$ Letene, J., and W. Jacoss. Ueber die Pankreas-Pentose. Ber. d. deut. chem. Ges., $43,3147-3150,1910$.

Ueber die Triticon Nucleinsaeure. Ibid., 43, 3164-3167, 1910. 
enough work has been done with the chlorophyllous leaf to draw valid conclusions, and this in turn has been due to the fact that the methods of separation and determination have not been sufficiently delicate and accurate to permit their application to such sensitive material.

Chalmont, Tollens," and Windish and Hasse ${ }^{2}$ come to the conclusion that pentoses are formed from hexoses as first products of oxidation, that they are relatively inert, and probably are of the nature of waste products. This is based essentially upon their observations that the total pentosan-content of seedlings, germinated and grown in the dark, increases with age. The writer made determinations of the total pentoses in seedlings; the results are quite the reverse, however. Wheat seeds were allowed to germinate on glass wool in the dark; at intervals a number of seedlings were removed, dried, ground, hydrolyzed with 1 per cent $\mathrm{HCl}$, and after determining and fermenting away the hexose sugars the pentose sugars were determined (see table 39):

TABLE 39.-Total hexose and pentose content of wheat seedlings.

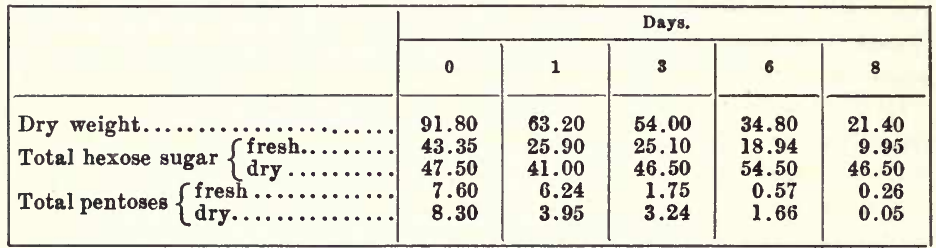

Unquestionably many organisms utilize the pentose sugars as sources of energy. In their physiological effects the differences between the pentoses and hexoses are in many cases less than exist between closely related members of either one of the groups. Many bacteria and molds are capable of utilizing pentoses as the only source of carbon, while, on the other hand, other organisms are quite incapable of doing so. The difference in food value of the various hexoses are well known.

Czapek" gives the following values for Aspergillus niger in weight of yields:

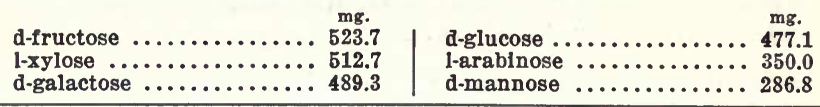

${ }^{2}$ Chalmont, G. DE. Pentosans in plants, 1. (II) Amer. Chem. Jour., 16, 218-229, 589-611, 1894. Die Bildung der Pentosane in den Pflanzen. Ber. d. deut. chem. Ges., 27,
2722-2725, 1895 .

- Toldens, B. Ueber die Kohlehydrate des Malzes und der Gerste mit besond. Beruecksichtigung der Pentosane. Chem. Zentr., 69, II, 967-968, 1898.

- Windish, W., and R. HAsse. Ueber den Pentosangehalt der Gerste und des Malzes, inbesondere ueber das Verhalten der Pentosane bel der Keimung. Chem. Zentr., 72, II, 1098-1099, 1901.

- Spoenr, H. A. The pentose sugars in plant metabolism. The Plant World, 20, 365-379, 1917.

- Czapex, F. Blochemie der Pflanzen: I. Page 311, 1913. Jena. 
The high nutritive value of $l$-xylose is quite evident, while on the other hand it is well known that the yeasts are quite incapable of utilizing any of the pentose sugars. At the same time it must be remembered that no one of the sugars is universally good nutrient material. Little is known of the rôle of the pentoses in the metabolism of the higher plants. The pentosans in the walls and vessels have been very extensively investigated, but very little is known of the origin and physiological rôle of these substances in the plant.

In the mammalian body the pentoses have been found to be about isodynamic in food value with the fats, but are not protein sparers as the hexoses are. ${ }^{2}$ In carnivorous animals as high as 50 to 60 per cent of the amount fed has been observed excreted in the urine; in omnivorous animals the percentage is less, while the herbivorous are capable of utilizing relatively large quantities.

That the pentose sugars are consumed at a very appreciable rate in the course of catabolism of the cacti was shown in the starvation experiments previously discussed. It was also demonstrated that when the cacti are deprived of water there takes place, along with increase in the amount of polysaccharides, a very decided increase in pentose sugars. As yet we have very little definite knowledge of a coordination between results obtained on the rate of respiration and the carbohydrate economy as influenced by conditions such as water-balance and temperature. No simple or constant relation seems to exist between the rate of carbon-dioxid emission and the supply of carbohydrates. It is most probable that in the protein-earbohydrate complex the clavis to this relationship must be sought. Furthermore, the rate of respiration can not be constantly or definitely associated with any one group of sugars. It has been shown that the hexose monosaccharides, which have been commonly assumed to be most directly involved in the respiratory process, are at times present in only exceedingly small amounts. This is particularly the case under conditions of low water-content and of high temperatures. In spite of the fact that the monosaccharide-content has been so greatly reduced, the rate of respiration does not show any marked diminution. It would seem, therefore, that under stress the plant possesses the power of utilizing the polysaccharides and aplastic material. An indication of this has already been obtained by MacDougal, Long, and Brown, in the study already referred to, on cacti which had been starved for a long time.

The formation of pentosans is intimately associated with this condition. As has been stated, the simpler sugars decrease in amount as the watercontent is reduced, and vice versa, an increase in water-supply results in an increase in these sugars. Furthermore, pentosan formation is also dependent upon the water-content of the plant. With continued low water-supply the pentosans increase decidedly.

${ }^{2}$ Schirozitch, P. Beitrag zur Bedeutung der Pentosen als Energie quelle im tierischem Organisms. Blochem. Zeitschr., 55, 370-392, 1913. 
In the aldose monosaccharides the first carbon atom or the carbonyl group, $-\mathrm{CH}: \mathrm{O}$, is the most reactive and is largely responsible for the great reactivity of these sugars. In the disaccharides and polysaccharides found in these plants this active carbonyl group is so united with other groups that it no longer forms the point of attack in chemical reaction. These sugars are therefore first affected on the opposite end of the chain of carbon atoms, at the $-\mathrm{CH}_{2} \mathrm{OH}$ group. ${ }^{2}$ Such a reaction results in a primary formation of glucuronic acid, $\mathrm{CH}: \mathrm{O}(\mathrm{CHOH})_{4} \cdot \mathrm{COOH}$.

This substance has been found as a product of glucose metabolism in mammals. When substances such as chloral or camphor, which unite with the earbonyl group of glucose, are fed, glucuronic acid, conjugated with these substances, is found in the urine. It has been established now that glucuronic acid is also present in the cacti. The discovery of this substance in plants is especially significant, because it permits the formulation of a rational theory of the formation of pentoses in plants.

A very general property of acids of this character is the splitting-off of $\mathrm{CO}_{2}$ from the carboxyl group when solutions thereof are exposed to the sunlight. An example of this action has already been furnished in the case of malic acid, which loses two molecules of carbon dioxid to form ethyl alcohol."

In this manner glucuronic acid would form l-xylose:

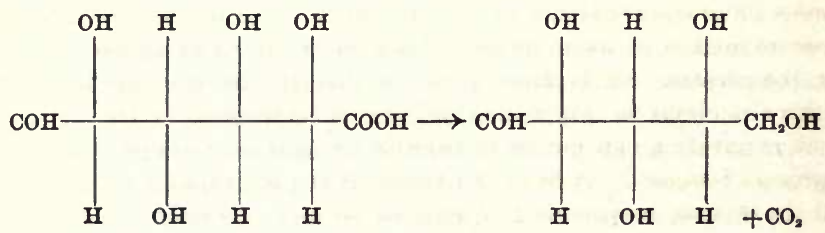

Solkowski and Neuberg" have reported the breaking-down of glucuronic acid into l-xylose and carbon dioxid by means of bacteria.

Further support of this interpretation of the formation of pentoses is obtained from a consideration of the structural relations of the various sugars concerned. If the pentoses were derived from a direct oxidation of the hexoses, $d$-glucose would yield d-arabinose and d-galactose give d-lyxose.

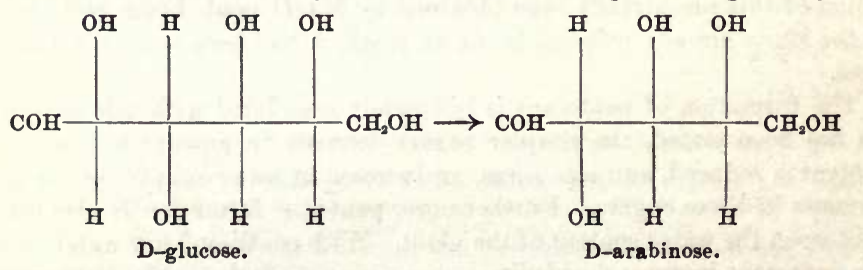

\footnotetext{
${ }^{2}$ Fischer, E., and O. Protx. Reduction der Zuckersaeure. Ber. d. deut. chem. Ges., 24, 524, 1891,

SPOEHR, H. A. Biochem. Zeitschr., 57, 101, 1913.

-Solkowskr, E., and C. Neubere. Die Verwandiung von d-glucuronsaeure in 1-xylose. Chem. Zentr., 1902, 1, 1098.
} 
THE ORIGIN AND RÔLE OF PENTOSE SUGARS.

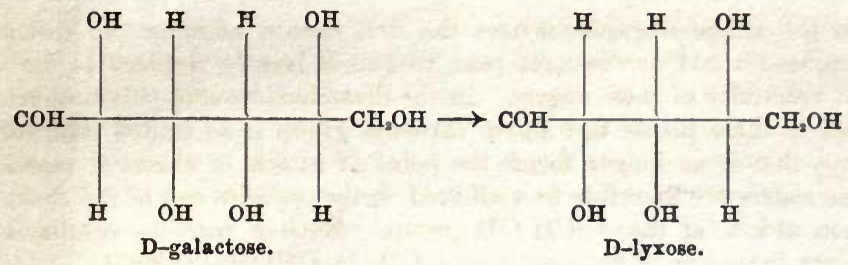

It is a striking fact, however, that in nature d-glucose has almost always been found with l-xylose, and that d-galactose is usually associated with l-arabinose. Also, it is noteworthy that the pentose sugars thus found are of the l-and not of the d-series. These facts speak strongly in favor of the theory of pentose formation here presented. A study of the photolysis of the hexonic acids which is now in progress will throw much light on these reactions.

Finally, a brief consideration may be given to the significance of such pentosan formation to the plant. A most striking property of the pentosans is their mucilaginous character. They have the power of swelling and taking up an enormous amount of water. This property is not exhibited by the hexose-polysaccharides in nearly so marked a degree. A notable increase of pentosans in the cells would have most important consequences. The enormous imbibition capacity of the pentosans would permit the absorption of large quantities of water at such times when this is available. In other words, the presence within the cell of a hydrophile colloid such as a pentosan makes possible the absorption of large quantities of water. Such, in fact, is the nature and behavior of succulent plants as the cacti. This point is of special interest in view of the fact that the hydrophile colloids in the plants are themselves products of arid conditions, and opens the way for a new conception as to the origin of the morphological character of succulent plants, based upon physiological principles. 


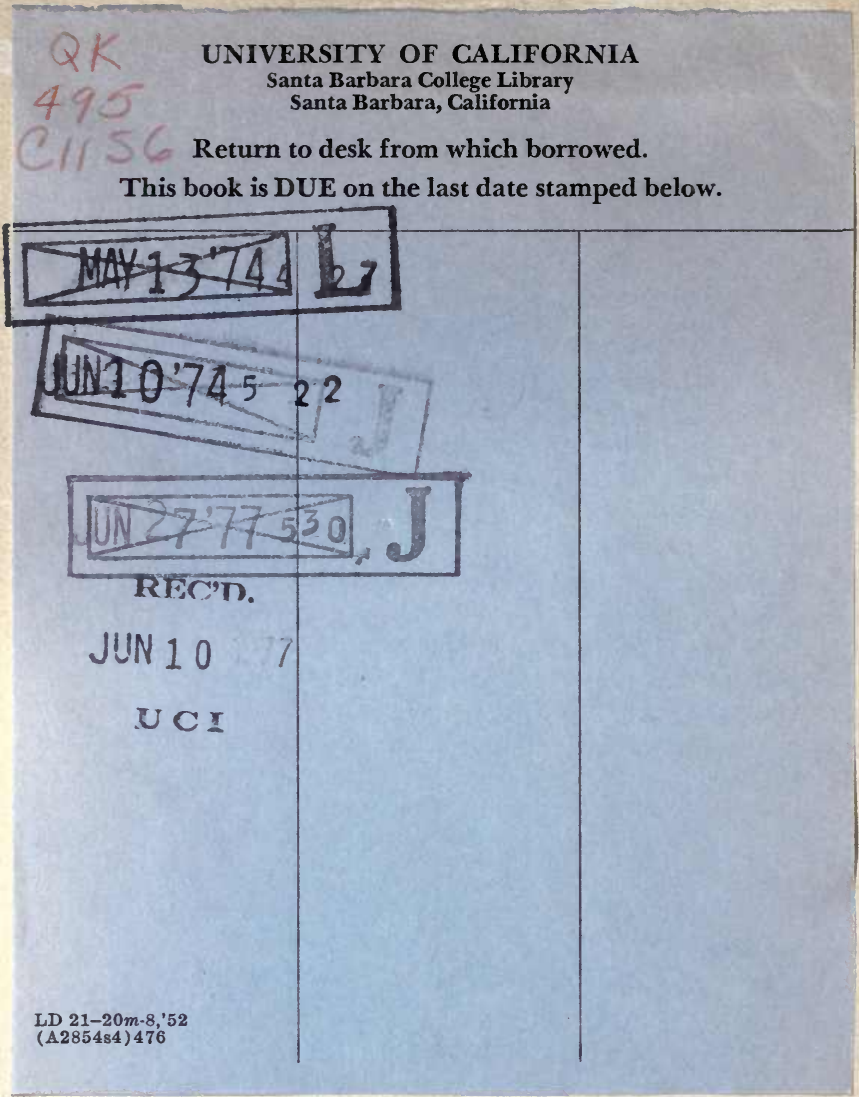





$$
\text { (2) } 150
$$

8

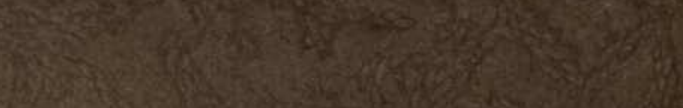

$x^{5} x^{2}=$ 